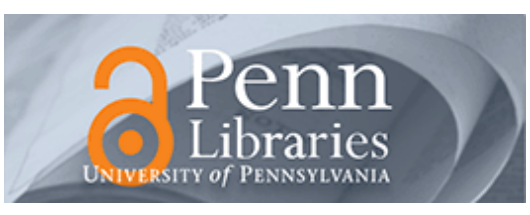

University of Pennsylvania ScholarlyCommons

Finance Papers

Wharton Faculty Research

3-16-2016

\title{
Good and Bad Variance Premia and Expected Returns
}

Mete Kilic

Ivan Shaliastovich

University of Pennsylvania

Follow this and additional works at: http://repository.upenn.edu/fnce_papers

Part of the Finance and Financial Management Commons

\section{Recommended Citation}

Kilic, M., \& Shaliastovich, I. (2016). Good and Bad Variance Premia and Expected Returns. Jacobs Levy Equity Management Centre, Retrieved from http://repository.upenn.edu/fnce_papers/47 


\title{
Good and Bad Variance Premia and Expected Returns
}

\begin{abstract}
We measure "good" and "bad" variance premia that capture risk compensations for the realized variation in positive and negative market returns, respectively. The two variance premium components jointly predict excess returns over the next 1 and 2 years with statistically significant negative (positive) coefficients on the good (bad) component. The $\mathrm{R}^{2}$ s reach about $10 \%$ for aggregate equity and portfolio returns and $20 \%$ for corporate bond returns. To explain the new empirical evidence, we develop an economic model which underscores the difference in investors' risk attitudes towards upside and downside uncertainty risks
\end{abstract}

\section{Disciplines}

Finance and Financial Management 


\title{
Good and Bad Variance Premia and Expected Returns*
}

\author{
Mete Kilic Ivan Shaliastovich
}

December 20, 2015

\begin{abstract}
We measure "good" and "bad" variance premia that capture risk compensations for the realized variation in positive and negative market returns, respectively. The two variance premium components jointly predict excess returns over the next 1 and 2 years with statistically significant negative (positive) coefficients on the good (bad) component. The $R^{2} \mathrm{~s}$ reach about $10 \%$ for aggregate equity and portfolio returns and about $20 \%$ for corporate bond returns. We show that an asset pricing model that features distinct time variation in positive and negative shocks to fundamentals can explain the good and bad variance premium evidence in the data.
\end{abstract}

${ }^{*}$ First draft: February 2015. Mete Kilic (mkilic@wharton.upenn.edu) and Ivan Shaliastovich (corresponding author, ishal@wharton.upenn.edu) are at Wharton School, University of Pennsylvania, 3620 Locust Walk, Philadelphia, PA 19104, Phone: (215) 746-0005. We are grateful to Torben Andersen, Bjorn Eraker, Nicola Fusari, Jessica Wachter, Amir Yaron, and Hao Zhou and seminar participants at Emory University, Temple University, University of Maryland, University of North Carolina at Chapel Hill, University of Wisconsin-Madison, the Wharton School, and the 2015 Midwest Finance Association meetings for helpful comments. We thank The Rodney L. White Center for Financial Research for financial support. 


\section{Introduction}

An important challenge in finance is to link expected asset returns in excess of the risk-free rate to measures of the financial market risk. Using statistical estimates of return variance to measure risk, the early asset pricing literature has generally produced inconclusive evidence for the risk and return relationship. ${ }^{1}$ A more recent strand of this literature relies on the information in option prices to gauge and quantify time-varying risk compensations in the data. In particular, the variance premium, defined as the difference between the model-free implied and realized return variation, has been shown to be a robust predictor of asset returns at maturities of 3 to 6 months. Because of its significant predictive power for short-term asset returns, the variance premium is often viewed as a measure of transient risk in financial markets.

In this paper, we show that the variance premium is driven by two distinct factors that can jointly predict future returns at long horizons of up to two years. Specifically, we decompose the variance premium into "good" and "bad" components that capture the risk premium for the realized variation in positive and negative market returns, respectively. Our proxies for the good and bad variance premia correspond to the differences between the good and bad implied and realized variance of returns. Good (bad) implied variance measures the conditional risk-neutral expectation of the 1-month squared positive (negative) log equity return, computed from option prices as in Bakshi and Madan (2000) and Bakshi, Kapadia, and Madan (2003). We also compute the good and bad realized variance measures using the high-frequency return data, following Barndorff-Nielsen, Kinnebrock, and Shephard (2010). The good variance premium is negative, on average, while the bad variance premium is positive most of the time. The two variance premium components have a lower correlation compared to the good and bad variance measures, and both significantly contribute to the variation in the total variance premium.

Our variance premium measures are straightforward to compute and have significant implications for expected asset returns. The good and bad variance premia jointly predict excess equity market returns with statistically significant coefficients at the 1- and 2-year horizons with $R^{2}$ val-

\footnotetext{
${ }^{1}$ See French, Schwert, and Stambaugh (1987), Campbell and Hentschel (1992), Glosten, Jagannathan, and Runkle (1993), and Whitelaw (1994).
} 
ues of $7 \%$ and $9 \%$, respectively. In contrast, the predictive power of the total variance premium at horizons longer than 6 months is essentially zero. Notably, both the good and bad components of the variance premium need to be incorporated to obtain high return predictability: using the individual components of the variance premium leads to results similar to those for the total variance premium alone. In particular, this suggests that both upward and downward risks play an important role in capturing time variation in the asset risk premium. ${ }^{2}$ The predictive coefficient on the good variance premium is negative, while it is positive for the bad variance premium. Because the good and bad variance premia drive the total variance premium in the same direction but predicted returns in the opposite direction, the variance premium decomposition helps uncover long-horizon return predictability, absent when the total variance premium itself is used as a predictor. This pattern holds across various markets, including aggregate equity, corporate bonds, and the cross-section of equity portfolios.

To provide an explanation for our empirical findings, we start with an affine no-arbitrage framework with exogenously specified equity price and state-price density processes. ${ }^{3}$ The equity price and state-price densities are driven by upward ("good") and downward ("bad") jumps whose time-varying intensities capture the variation in good and bad variances. We show that if all good (bad) shocks to equity carry a positive (negative) market price of risk, the equity premium is increasing in both good and bad jump intensities. At the same time, the good variance premium is decreasing in good jump intensity, while the bad variance premium is increasing in bad jump intensity. Therefore, in the return predictability regressions, the predictive coefficient for the good variance premium is negative, while it is positive for the bad variance premium.

To quantify the model, we consider a general equilibrium framework that maps directly into the no-arbitrage model specification. The economic model features upward and downward jumps to consumption, and the recursive utility of the representative agent. In this equilibrium model, equity exposures and market prices of risk are pinned down by the model and preference parameters. In particular, good (bad) consumption jumps increase (decrease) the equity prices and the

\footnotetext{
${ }^{2}$ See Ang, Chen, and Xing (2006) and Lettau, Maggiori, and Weber (2014), who emphasize the importance of the downside market risk for the cross-section of asset returns.

${ }^{3}$ See Singleton (2009) for a textbook review of the no-arbitrage asset-pricing models.
} 
state-price density, consistent with the assumptions of the no-arbitrage model. Using numerical calibrations, we show that the model can capture novel evidence of return predictability by the variance premium measures, alongside standard aggregate asset pricing and macroeconomic moments.

Our paper is related to the literature that links the variance premium to uncertainty about economic fundamentals. Bollerslev, Tauchen, and Zhou (2009) show a strong short-horizon predictive power of the variance premium for aggregate equity returns. ${ }^{4}$ In their model, the variance premium is related to the time-varying volatility of conditional consumption variance. ${ }^{5}$ Drechsler and Yaron (2011) extend the long-run risk model of Bansal and Yaron (2004) by allowing for multiple volatility factors and incorporating jumps in the expected growth and variance of consumption. The variance premium in this model becomes a proxy for the variance factor with the lowest persistence. Eraker (2008) studies the implications of volatility jumps for the variance premium. The empirical evidence in our paper suggests that the variance premium is driven by at least two factors that are related to long-horizon expected returns. Our economic model accounts for this two-factor structure by linking the components of the variance premium to the good and bad intensities of consumption jumps.

Our paper is also related to the recent literature that highlights the variation in positive and negative shocks to fundamentals. Segal, Shaliastovich, and Yaron (2015) study the implications of time variation in good and bad uncertainty, measured from macroeconomic data, for real growth and asset valuations. Bekaert and Engstrom (2009) consider a habit formation model with distinct variation in the volatilities of positive and negative Gamma shocks to fundamentals to address several stylized asset pricing puzzles, including the predictability of returns by the total variance premium. Tsai and Wachter (2014) construct a model with distinct time variation in the probabilities of rare booms and disasters to explain the value premium. Our model integrates the economic channels used in this literature in a parsimonious way, focusing on the novel empirical

\footnotetext{
${ }^{4}$ For long-horizon predictors of equity and corporate bond returns, see Keim and Stambaugh (1986), Campbell and Shiller (1988), Fama and French (1989), Cochrane (2008), among others.

${ }^{5}$ Short-horizon stock return predictability results using the variance premium have been extended since then. See Zhou (2009), Han and Zhou (2012), Bollerslev, Marrone, Xu, and Zhou (2014), and Bali and Zhou (2014), among others.
} 
evidence for a link between the good and bad variance premia and expected returns.

Our paper also contributes to a voluminous literature that shows that asset returns are predictable by volatility and jump risk factors. ${ }^{6}$ Bollerslev, Todorov, and Xu (Forthcoming) statistically disentangle the diffusive and jump components of the variance premium and show that this decomposition leads to stronger return predictability than previously shown, driven by the variation in the left jump tail. Guo, Wang, and Zhou (2014) find that realized positive and negative jump volatilities jointly predict short-horizon excess stock returns and economic fundamentals, while total jump variation has no significant predictive power. Feunou, Jahan-Parvar, and Okou (2014) study the empirical implications of decomposing the VIX index into the components computed using call and put options and find that most of the variance premium is related to downside risk. In our paper, we consider an alternative decomposition of the variance premium into the components associated with "good" and "bad" events and provide an economic model to explain our empirical findings.

Finally, our paper is related to the recent literature that highlights the importance of separating upside and downside market volatilities. Feunou, Jahan-Parvar, and Tédongap (2013), Patton and Sheppard (2013), and Bekaert, Engstrom, and Ermolov (2015) identify fluctuations in these volatility components using historical return data and consider their implications for the dynamics of equity returns. In our paper, we utilize option data and construct variance premium measures, which we show can help to better isolate separate variations in the negative and positive components of the return distribution, related to the expected excess returns.

The paper is organized as follows. Section 2 describes the empirical analysis, along with several robustness tests for predictability regressions. Section 3 discusses the model and its quantitative implications. Section 4 concludes.

\footnotetext{
${ }^{6}$ The literature that highlights jumps in prices includes Bakshi, Cao, and Chen (1997), Duffie, Pan, and Singleton (2000), Pan (2002), Andersen, Benzoni, and Lund (2002), Eraker, Johannes, and Polson (2003), Eraker (2004), Broadie, Chernov, and Johannes (2007), Santa-Clara and Yan (2010).
} 


\section{Empirical analysis}

In this section, we develop measures of the good and bad variance premia and provide empirical evidence for their relation to expected returns. Below, we describe the construction of the benchmark variance measures and provide a discussion of our findings, followed by various robustness checks.

\subsection{Good and bad implied variances}

Our goal is to construct intuitive measures that separately characterize the variation in the positive and negative components of the conditional aggregate equity return distribution. For this purpose, we utilize the method developed by Bakshi and Madan (2000) and Bakshi, Kapadia, and Madan (2003) to infer the moments of the risk-neutral return distribution from the cross-section of option prices in a model-free way.

We consider the price of a volatility contract that pays off the squared log return at time $t+1$. Let $s_{t}$ denote the natural logarithm of the price, $S_{t}$, of the underlying market index at time $t$. The payoff of the contract is $r_{t+1}^{2} \equiv\left(s_{t+1}-s_{t}\right)^{2}$. We define total implied variance, $i v_{t}$, as the price of the contract:

$$
i v_{t} \equiv e^{-r_{t}^{f}} \mathbb{E}_{t}^{Q}\left[r_{t+1}^{2}\right]
$$

where $\mathbb{E}_{t}^{Q}$ denotes the expectation under the risk-neutral measure conditional on time- $t$ information, and $r_{t}^{f}$ is the risk-free rate. Bakshi, Kapadia, and Madan (2003) show that $i v_{t}$ can be calculated using prices of OTM call and put options:

$$
i v_{t}=\int_{S_{t}}^{\infty} \frac{2\left(1-\log \left(K / S_{t}\right)\right)}{K^{2}} C(t, t+1, K) d K+\int_{0}^{S_{t}} \frac{2\left(1+\log \left(S_{t} / K\right)\right)}{K^{2}} P(t, t+1, K) d K,
$$

where $C(t, t+1, K)$ and $P(t, t+1, K)$ denote the time- $t$ prices of call and put contracts with a time-to-maturity of one period and a strike price of $K$.

We can write the payoff of the volatility contract as a sum of the two components associated 
with the positive and negative returns, respectively, ${ }^{7}$

$$
r_{t+1}^{2}=r_{t+1}^{2} \mathbb{I}\left(r_{t+1}>0\right)+r_{t+1}^{2} \mathbb{I}\left(r_{t+1} \leq 0\right)
$$

Following this decomposition, we define the good and bad implied variances, $i v_{t}^{g}$ and $i v_{t}^{b}$, as the prices of the positive and negative payoff components, respectively,

$$
\begin{aligned}
& i v_{t}^{g} \equiv e^{-r_{t}^{f}} \mathbb{E}_{t}^{Q}\left[r_{t+1}^{2} \mathbb{I}\left(r_{t+1}>0\right)\right], \\
& i v_{t}^{b} \equiv e^{-r_{t}^{f}} \mathbb{E}_{t}^{Q}\left[r_{t+1}^{2} \mathbb{I}\left(r_{t+1} \leq 0\right)\right] .
\end{aligned}
$$

Because the good and bad components of the payoff add to the total payoff of the volatility contract, we have $i v_{t}=i v_{t}^{g}+i v_{t}^{b}$ by no-arbitrage.

Similar to the total volatility contract, the prices of its good and bad components can also be computed in a model-free way from the cross-section of option prices. Indeed, Appendix A.1 shows that $i v_{t}^{g}$ and $i v_{t}^{b}$ correspond to the first and second integrals in (2), respectively,

$$
\begin{aligned}
& i v_{t}^{g}=\int_{S_{t}}^{\infty} \frac{2\left(1-\log \left(K / S_{t}\right)\right)}{K^{2}} C(t, t+1, K) d K, \\
& i v_{t}^{b}=\int_{0}^{S_{t}} \frac{2\left(1+\log \left(S_{t} / K\right)\right)}{K^{2}} P(t, t+1, K) d K .
\end{aligned}
$$

This result is intuitive. Total implied variance $i v_{t}$ is the weighted sum of the option prices, and the variance components are identified by claims that have payoffs contingent on the sign and magnitude of the realized return. Good implied variance is identified by call options that pay off only in case the return realization is positive, and bad implied variance is characterized by put options that pay off only if a negative return is realized.

We compute the implied variance measures at a monthly frequency using the S\&P 500 index options data from OptionMetrics from January 1996 to August 2014. We use the averages of the bid and ask quotes for each option contract and eliminate the options with a mid quote lower

\footnotetext{
${ }^{7}$ One can consider thresholds different than zero for the decomposition. We opt for an intuitive measure of good and bad events in the stock market and characterize them by positive and negative returns.
} 
than $\$ 3 / 8$. Options with zero trading volume, with a time-to-maturity lower than 7 days, and those that violate standard no-arbitrage conditions are also filtered out. For each option contract, we compute moneyness as the strike price divided by the current value of the S\&P 500 index, $K / S_{t}$. As (5) indicates, we use only OTM options, namely, calls with $K / S_{t}>1$ and puts with $K / S_{t}<1$. The range of available moneyness in the data highly varies over time. We use options in the moneyness range from 0.85 to 1.15 in our benchmark analysis. This ensures that our implied variance measures capture similar economic content throughout the time series and are not driven by deep OTM options at moneyness levels that are not available most of the time. The integrals in (5) are calculated using a cubic spline across implied volatilities because a continuum of strike prices is not available. If the lowest (highest) available moneyness is higher than 0.85 (lower than 1.15), we use the implied volatility of the lowest (highest) moneyness level for implied volatilities outside the available range in the data. We then compute the option prices from the implied volatilities on the grid of spline. We linearly interpolate across available maturities to compute one-month implied variances. We report the robustness of our results to various alternative choices of the moneyness range in Section 2.5.

Figure 1 plots the time series of total, good, and bad implied variances. ${ }^{8}$ The implied variance measures are volatile and spike in bad economic times, such as the Russian financial crisis in 1998, leading to the failure of LTCM, the burst of the dot-com bubble in 2002, and the Great Recession period in 2008 and 2009. Total implied variance behaves very similarly to the traditional measure of return volatility, namely, $V I X$. Indeed, the correlation between $i v_{t}$ and $V I X^{2}$ is $99.24 \%$ in levels, and $97.33 \%$ in first differences. Table 1 provides summary statistics for the variance measures, and Table 2 provides a correlation matrix. Both tables report statistics for the sample from January 1996 to August 2014, and a subsample excluding the Great Recession from December 2007 to June 2009. $i v_{t}^{b}$ is higher than $i v_{t}^{g}$, both on average and throughout the sample. Good and bad implied variances are highly correlated with a correlation coefficient of 0.97 and are both fairly persistent with $\operatorname{AR}(1)$ coefficients of 0.81 .

\footnotetext{
${ }^{8}$ Following Bollerslev, Tauchen, and Zhou (2009), Drechsler and Yaron (2011), and Zhou (2009), we report variances in units of volatility in percent, squared, and divided by 12 for comparability with the existing literature. As a result, all variance measures have the same units as $V I X^{2} / 12$.
} 


\subsection{Good and bad realized variances}

In addition to the risk-neutral variance measures, we construct measures of the realized variances using high-frequency data. Following Barndorff-Nielsen and Shephard (2004), realized variance, $r v_{t}$, is defined as the sum of squared high-frequency returns, $r_{t, i}$, within each period:

$$
r v_{t}=\sum_{i=1}^{H_{t}} r_{t, i}^{2}
$$

where $H_{t}$ is the number of high-frequency intervals in period $t$.

Following Barndorff-Nielsen, Kinnebrock, and Shephard (2010), we decompose the realized variance, $r v_{t}$, into good and bad realized variances, $r v_{t}^{g}$ and $r v_{t}^{b}$, as

$$
r v_{t}^{g}=\sum_{i=1}^{H_{t}} r_{t, i}^{2} \mathbb{I}\left(r_{t, i}>0\right), \quad r v_{t}^{b}=\sum_{i=1}^{H_{t}} r_{t, i}^{2} \mathbb{I}\left(r_{t, i} \leq 0\right)
$$

Intuitively, the good and bad realized variance measures capture information about time variation in the positive and negative components of the physical distributions of returns. Indeed, BarndorffNielsen, Kinnebrock, and Shephard (2010) show that, as $H_{t} \rightarrow \infty, r v_{t}^{g}$ and $r v_{t}^{b}$ converge to half of the Gaussian diffusion in the returns and positive and negative quadratic jump variation, respectively.

We use 5-minute S\&P 500 futures returns from TICKDATA to construct the realized variance measures at a monthly frequency. ${ }^{9}$ As shown in Table 1 , the total, good, and bad realized variance measures have similar statistical properties and are more volatile and less persistent than their implied counterparts. Figure 2 plots the time series of total, good, and bad realized variances. All of the realized variances move closely with each other, consistent with the correlation evidence in Table 2. The realized variances spike in bad economic times, especially in October 2008, following the Lehman crash. This corresponds to the month with the lowest aggregate equity return in our sample. In terms of the difference between good and bad realized variances, bad variance tends

\footnotetext{
${ }^{9}$ Liu, Patton, and Sheppard (2012) show that 5-minute sampling frequency achieves the optimal trade-off between the precision of the estimators and the impact of the microstructure noise. We treat returns from the close of a trading day to the open of the next trading day as a 5-minute interval.
} 
to rise above good variance in several periods of variance spikes, such as the Great Recession. Another large deviation of $r v_{t}^{b}$ from $r v_{t}^{g}$ occurs in September 2001. This is due to one data point: stock exchanges were closed from September 10, 2001 to September 17, 2001. At the opening of the market on September 17, the S\&P 500 futures price fell by 5.5\%, leading to a large increase in bad, relative to good, realized variance.

\subsection{The good and bad variance premia}

The variance premium is defined as the difference between the risk-neutral and physical expectation of quadratic return variation. Using the measures of implied and realized variance above, we define our proxy for the variance premium $v p_{t}$ as the difference between $i v_{t}$ and $r v_{t}:{ }^{10}$

$$
v p_{t}=i v_{t}-r v_{t}
$$

and the good and bad variance premia, $v p_{t}^{g}$ and $v p_{t}^{b}$, as the difference between corresponding implied and realized variances

$$
v p_{t}^{g}=i v_{t}^{g}-r v_{t}^{g}, \quad v p_{t}^{b}=i v_{t}^{b}-r v_{t}^{b}
$$

Figure 3 plots the time series of the total, good, and bad variance premia, and Table 1 reports summary statistics. Total implied variance is higher than realized variance most of the time, so that $v p_{t}$ is positive on average. Similarly, the bad variance premium is also positive throughout most of the sample. Notably, $v p_{t}^{b}$ is larger than $v p_{t}$ on average. On the other hand, good implied variance tends to be lower than good realized variance, so that that our estimate of the average good variance premium is negative.

\footnotetext{
${ }^{10}$ The empirical measures for the variance premium are only proxies for the actual variance risk premia, as they rely on the statistical estimates of the conditional variance. Our definition of the variance premium corresponds to the one in Bollerslev, Tauchen, and Zhou (2009), who assume $r v_{t} \approx \mathbb{E}_{t}\left[r v_{t+1}\right]$. For robustness, we also entertain a forward-looking measure of expected quadratic variation as discussed in Section 2.5. Alternatively, Bakshi and Kapadia (2003) identify the variance premium from delta-hedged option gains, and Carr and Wu (2009) develop a model-free empirical strategy for identification of the variance premium as the price minus the payoff of a contract that pays off realized variance.
} 
Table 2 shows that in the benchmark sample, the correlation between the good and bad variance premia is $87 \%$. A significant portion of this correlation, however, is driven by a sharp drop in October 2008, caused by a large jump in all the realized variances in this month. Removing this data point, the correlation drops to 59\%. Notably, the correlation between the good and bad variance premium measures is significantly smaller than those between the good and bad variances themselves. Indeed, the correlations between the good and bad realized or implied variances exceed $97 \%$ in the full sample and are above $93 \%$, excluding the Great Recession. Thus, using the variance premium rather than variance measures helps isolate separate variations in the negative and positive components of the distribution.

The signs and magnitudes of the good and bad variance premia suggest that investors are willing to pay a positive premium for an asset that pays off when bad variance is high. The magnitude of this premium is quantitatively large and higher than the premium for an asset that pays off when total variance is high. On other hand, the average risk compensation to hedge good variance risk is negative. The distinct properties of $v p_{t}^{g}$ and $v p_{t}^{b}$ suggest that they can potentially contain more information and help identify separate risk factors compared to $v p_{t}$ alone.

\subsection{Predicting returns with good and bad variance premia}

In this section, we analyze the predictability of future returns by the variance premium measures. As shown in the literature (see Bollerslev, Tauchen, and Zhou (2009)), the total variance premium has a significant predictive power for aggregate equity market returns at short horizons of 3 to 6 months. We show that good and bad components of the variance premium, $v p_{t}^{g}$ and $v p_{t}^{b}$, jointly predict excess returns with statistically significant coefficients at horizons longer than 6 months, up to 24 months with increasing $R^{2}$ values in horizon. In multivariate predictability regressions, the coefficient on $v p_{t}^{g}$ is negative, while it is positive and larger than that of $v p_{t}$ for $v p_{t}^{b}$. This evidence also holds in corporate bond markets and a cross-section of equity portfolios and is robust to alternative specifications of the benchmark predictability regressions. 
All predictability regressions presented in this section have the following form:

$$
\frac{12}{h} \sum_{i=1}^{h}\left(r_{t+i}-r_{t+i-1}^{f}\right)=\beta_{0, h}+\beta_{h}^{\prime} X_{t}+\epsilon_{t+h},
$$

where $h$ is the horizon of the regression, $r_{t+1}$ denotes a monthly log return, and $r_{t}^{f}$ is the monthly log risk-free rate. The vector $X_{t}$ contains the predictor variables.

To evaluate the statistical significance of our predictors, we report two types of standard errors and the associated $p$-values. The first are the Newey-West standard errors computed using three more lags than the predictability horizon. However, Newey-West standard errors are known to be biased downward in finite samples with overlapping returns (Hodrick (1992)). Another concern is that both the returns and variance premia deviate substantially from the average values during periods of high economic stress, such as during the Great Recession. Because both dependent and independent variables take extreme values, in small samples, this can make standard asymptotic inference unreliable. To alleviate these concerns, we adopt a bootstrap approach that relies on the empirical distribution of returns to compute standard errors. The series are simulated under the null hypothesis of no predictability, preserving the heteroskedasticity of the original return sample in the data, and the same relation between extreme values of predictors and volatility of future returns. This allows us to characterize the small-sample distribution of predictive coefficients and compute corresponding standard errors. Appendix A.2 provides details about the bootstrap approach. Because the small sample distributions are not Normal, we directly report the $p$-values, rather than $t$-statistics, for the hypothesis tests.

Our economic model implies that the good variance premium should predict aggregate equity returns with a negative sign, while the coefficient on the bad variance premium is positive. To assess the plausibility of these economic restrictions in the data, we report the $p$-values for the onesided tests. Specifically, the $p$-value for the good (bad) variance premium coefficient is computed under the null hypothesis of no return predictability against an alternative hypothesis that the slope coefficient is negative (positive). For consistency, we also rely on the one-sided $p$-values to test return predictability by the total variance premium. For equity returns, we test whether the 
coefficient on $v p_{t}$ is positive, consistent with the literature and our economic model. For other assets, such as corporate bonds, the signs of the coefficients do not follow directly from the theory. In this case, we follow a rule that if a predictive coefficient is positive (negative) at the 12-month horizon in our benchmark analysis in Table 3, the $p$-value corresponds to the probability of a higher (lower) value for the coefficient under the null of no predictability.

\section{Predictability evidence}

Panel A of Table 3 reports the results of predictive regressions for excess aggregate equity returns by $v p_{t}$, as well as $v p_{t}^{g}$ and $v p_{t}^{b}$, jointly. We find that our proxy for the total variance premium, $v p_{t}$, predicts returns with a positive sign, and the predictive coefficient is statistically significant at 1 - and 3 -month horizons. ${ }^{11}$ The goodness of fit peaks at a 3 -month horizon with an $R^{2}$ of $6 \% .{ }^{12}$ The predictive coefficient is not statistically different from zero for the horizons of 6 months and above under the bootstrap standard errors and for 12 months and above using the Newey-West standard errors. At these horizons, the $R^{2}$ values are essentially zero. ${ }^{13}$

Next, we turn to the multivariate predictability regressions using $v p_{t}^{g}$ and $v p_{t}^{b}$. At short horizons, the predictive power of the two variance premia is comparable to that of $v p_{t}$ alone. However, at longer horizons, the evidence suggests that the two variance premia contain additional, economically and statistically significant information about the expected returns. First, the coefficient on $v p_{t}^{g}$ is negative at all horizons, starting from 3 months. It is statistically significant under the Newey-West standard errors from 6 months, and under the bootstrap standard errors from 12 months. The coefficient on the bad variance premium is always positive, and is significant for the horizons of 3 months and above. Notably, the coefficient on the bad variance premium in the multivariate setting is significantly larger than that on the total variance premium in univariate regressions: it is about twice as large, even at a 1-month horizon. Finally, the multivariate

\footnotetext{
${ }^{11}$ We refer to coefficients with bootstrap $p$-values smaller than or equal to $5 \%$ as statistically significant unless stated otherwise.

${ }^{12}$ All reported $R^{2}$ values are adjusted.

${ }^{13}$ Our findings are comparable to those in the literature that rely on $V I X$, rather than implied variance, to compute variance premium (see Bollerslev, Tauchen, and Zhou (2009)). In this case, the coefficient on total variance premium is significant up to 12 months, and the adjusted $R^{2}$ values at 1-, 3-, 6-, 12-, 18-, and 24-month horizons are $5 \%, 8 \%, 4 \%, 1 \%, 0 \%$, and $0 \%$, respectively.
} 
regression delivers a significantly higher goodness of fit, with $R^{2}$ values of $7 \%$ at the 12 -month and $9 \%$ at the 24-month horizons, while there is no evidence of significant predictive power by $v p_{t}$ alone at these horizons. Notably, we find that it is important to include both of the variance premium measures to predict future returns. Indeed, when only one of these variables is used in the regressions, the $R^{2}$ s drop to values similar to those for the total variance premium alone. This highlights the importance of the upside and downside variations in capturing the fluctuations in expected returns.

Panels B and C of Table 3 show predictability evidence for high-yield and investment-grade bond returns from Barclay's bond indexes. Corporate bonds are risky securities that are claims on firms' assets, so we use them as alternative test portfolios to expand the predictability evidence. At horizons of 1 and 2 years, the total variance premium can predict future excess returns with an $R^{2}$ of $4 \%$ for high-yield portfolios and $6 \%$ for investment-grade portfolios. Interestingly, the signs of the coefficients on $v p_{t}$ are negative at these horizons and statistically significant. Similar to aggregate equity results, decomposing the total variance premium into its good and bad components substantially magnifies bond return predictability. At the horizons of 1 and 2 years, the $R^{2}$ s in multivariate regressions range from $18 \%$ to $24 \%$ for high-yield and investment-grade bond returns. The coefficients on the good variance premium are all negative, and those on the bad variance premium are positive. Nearly all of the coefficients are significant under both the Newey-West and bootstrap standard errors. Notably, compared with equity returns, the coefficients on the good variance premium are often larger, in absolute value, than those on the bad variance premium, which can help explain the negative coefficient on the total variance premium in univariate regressions.

Figure 4 plots the predicted 12-month excess equity returns, implied by our regressions. The predicted excess equity returns implied by the multivariate regression stay at low levels in moderate periods, such as from 2003 to 2007, and spike in periods of distress, such as during the Great Recession period in 2008 and 2009. For comparison, we also show the predicted 12-month excess returns from the univariate regression based on the total variance premium. The implied risk premium is much less volatile and does not capture pronounced increases in risk in periods of high 
economic stress. The correlation between the implied equity premium extracted from univariate and multivariate projections is quite low, and is equal to $15 \%$. We also verify that the results are similar for bond returns. The predicted bond returns implied by the univariate regression are less volatile than those based on the multivariate specification, and the correlations between the two are quite low.

Finally, we expand the set of the test assets to include the cross-section of equity portfolio returns. This allows us not only to assess the predictability evidence at the level of individual portfolios but also to run a joint test that predictability coefficients across all of the portfolios on the good (bad) variance premium are negative (positive). ${ }^{14}$ Table 4 summarizes the results for ten size, book-to-market, and industry portfolios. The cross-sectional results support and strengthen our evidence for the aggregate returns. At a 3-month horizon, the total variance premium is a significant predictor in the cross-section of book-to-market portfolios, with a joint $p$-value of $1 \%$, and is marginally significant for size and industry portfolios with $p$-values of $8 \%$. The median $R^{2} \mathrm{~s}$ vary from $3 \%$ for industry to $6 \%$ for book-to-market portfolios. There is, however, no significant evidence of predictability at long horizons: the $p$-values are above $40 \%$ at the 1-year horizon and $60 \%$ at the 2-year horizon, and all the $R^{2}$ are below $1 \%$. On the other hand, the coefficients on the good and bad variance premia are statistically significant, in joint tests, at these horizons, with $p$-values of $4 \%$ and below. The median $R^{2}$ increases from $8 \%$ at a 1 -year to $19 \%$ at a 2 -year horizon for size portfolios, from $3 \%$ to $9 \%$ for book-to-market, and from $5 \%$ to $8 \%$ for industry portfolios.

Our evidence suggests that the variance premium is driven by at least two factors that have opposite association with long-horizon excess returns. This can account for a weaker predictive power of $v p_{t}$ alone compared to $v p_{t}^{g}$ and $v p_{t}^{b}$, jointly. Once the two factors of the variance premium are uncovered, predictability becomes stronger at longer horizons, suggesting that the variance premium contains information about persistent risk factors in financial markets.

\footnotetext{
${ }^{14}$ Appendix A.2 describes the computation of $p$-values for this exercise.
} 


\subsection{Robustness tests}

In this section we show that our empirical evidence is robust to different sample periods, alternative specifications for the predictive regressions, construction of the variance premium measures, and including higher-order moments of returns in predictability regressions.

\section{Different sample periods}

The Great Recession (December 2007 - June 2009) was a period of high equity market volatility, as shown in Figures 1 and 2, which translates into the extreme values for the variance premium measures (see Figure 3). We perform several robustness checks to assess whether these observations play a significant role in our results.

First, we exclude the Great Recession period from our analysis. The predictability results for the sample excluding December 2007 - June 2009 are reported in Table 5. For aggregate equity returns, the results are similar to those based on the entire sample, both in terms of the magnitude and sign of coefficients and an increase in predictive power in multivariate regressions. In this restricted sample, $v p_{t}$ predicts returns with a positive coefficient, which is statistically significant at all horizons as opposed to the full sample, where the predictive coefficients are not significant at long horizons. However, the goodness of fit tends to be quite low, and the $R^{2} \mathrm{~s}$ do not exceed $2 \%$. In multivariate regressions, the signs on the good (bad) variance premium are all negative (positive), in line with the full sample evidence. While the coefficient on $v p_{t}^{b}$ is significant at all horizons above 3 months, the significance of the coefficient on $v p_{t}^{g}$ is weaker compared to the full sample regressions. The bootstrap $p$-values are $8 \%$ and $5 \%$ at 12 - and 24 -month horizons, respectively, whereas the Newey-West $p$-values are below 4\%. For corporate bonds, we find no evidence of return predictability by $v p_{t}$ at any horizon, and the $R^{2}$ values are essentially zero. At the same time, the joint predictive power of $v p_{t}^{g}$ and $v p_{t}^{b}$ increases with horizon, and signs are in line with the full sample. At 1- and 2-year horizons, the $R^{2}$ s are $6 \%$ and $7 \%$ for high-yield bonds, and $2 \%$ and $5 \%$ for investment-grade bonds, respectively. The coefficients are significant for high-yield bonds at most horizons, while they are significant for investment-grade bonds at a 
3-month horizon, and marginally significant at a 2-year horizon.

We also test the robustness of the predictability results for the cross-section of equity portfolios to the exclusion of the Great Recession period and find similar results. For all three groups of portfolios considered in Section 2.4, the predictive coefficient on the total variance premium is significant at 3-, 12-, and 24-month horizons, however, with moderate $R^{2}$ values that do not exceed $3 \%$ at any of the horizons considered for any of the portfolios. In multivariate regressions, the coefficients on the good (bad) variance premium are significantly negative (positive) with $p$-values below $2 \%$ at $3-, 12-$, and 24 -month horizons. The predictive power in multivariate regressions is stronger, in line with the full sample evidence.

Finally, we also verify the robustness of our results to outliers by running a robust predictability regression. In this approach, we exclude any observation with a Cook's distance greater than one and use Huber (1964) weights to determine the coefficients. The results are consistent with the benchmark findings and are omitted for brevity.

Our benchmark sample covers the period from January 1996 to August 2014, given the availability of options data from OptionMetrics. To provide further robustness checks to our main results, we extend the sample using options data from CBOE from January 1988 to December 1995. ${ }^{15}$ The options in this data set are not as liquid as those in the OptionMetrics sample from January 1996, and the range of available moneyness is significantly narrower. Because of these data issues, we choose to use these data in the robustness checks and focus on a more standard data set from OptionMetrics in the benchmark analysis.

As shown in Table 6, the empirical results based on the extended sample are quite similar to the benchmark sample. In univariate regressions, the total variance premium is a significant and positive predictor of future equity returns at all horizons from 3 months, while we do not find any evidence for predictability of future bond returns. The $R^{2} \mathrm{~s}$ do not exceed $3 \%$ in equity return regressions and are zero for bond returns. In multivariate regressions, a high good (bad) variance premium predicts lower (higher) future asset returns across all of the maturities. The significance

\footnotetext{
${ }^{15}$ This data set is also used in Ait-Sahalia, Wang, and Yared (2001) and Eraker (2004), among others. We thank Bjorn Eraker for providing this data set to us. We follow the OptionMetrics procedure to compute dividend yields and the zero-coupon yield curve for this data set.
} 
of the coefficients is comparable to that in the full sample. The $R^{2}$ s are $11 \%, 14 \%$ and $6 \%$ for stock, high-yield and investment-grade bond returns, respectively, at the 1-year horizon, all of which are substantially above those for the total variance premium alone.

Notably, our main findings are not driven solely by the benchmark sample, which starts in 1996, and they hold even in the restricted sample from 1988 to 1995. Indeed, in this subsample, the 1-year predictive coefficients on the good and bad variance premia are -0.25 and 0.42 , respectively, so that the good (bad) variance premium predicts future equity returns with a negative (positive) sign. Results are similar for the bond returns.

\section{Constrained predictability regressions}

Our benchmark estimate of the implied equity premium, obtained from a linear regression of future 12-month returns on the two variance premia, occasionally takes negative values, as can be seen from Figure 4. Our economic model, however, suggests that the conditional equity premium should always be positive. To assess the role of the negative estimates for the implied equity premium for the predictability evidence, we follow Pettenuzzo, Timmermann, and Valkanov (2014) and consider a constrained regression approach in which the linear regression coefficients are estimated subject to the constraint that the fitted values are positive at each point in the sample.

Notably, the largest observed negative equity premium corresponds to September 2001. As discussed in Section 2.2, this is due to the stock market interruption for a week following September 11, and a mechanically inflated value for the realized bad variance, which treats the realized weekly return as a 5-minute return. Although this measurement outlier does not affect our benchmark results, it impacts constrained regressions, which are sensitive to extreme observations. Because this observation is primarily caused by statistical issues in measurements of the realized variance, rather than economic considerations, we exclude it from the constrained regression specification. ${ }^{16}$

Table 7 reports the predictability results for the constrained specification, and Figure 4 plots the

\footnotetext{
${ }^{16}$ Specifically, bad realized variance is 74.37 in September 2001. Almost half of this value, 32.02, is attributable to the week when markets were closed. If we assume that the weekly price drop occurred in 5 , 10 , or 400 intervals (there are around 4005 -minute observations during the week), the contribution to bad realized variance would be $6.40,3.20$, or 0.08 instead of 32.02 . All of these values lead to a positive fitted value for the excess return.
} 
predicted series from multivariate regressions. In univariate regressions, the constrained approach tries to address the negativity of the implied equity premium in October 2008 by increasing the constant of the regression and lowering the coefficient on $v p_{t}$ to virtually zero. As a result, in the constrained estimation there is no significant evidence of stock return predictability by total variance risk premium at all horizons. The predicted excess return is also negative in the multivariate setting in this period. However, because the coefficients on $v p_{t}^{g}$ and $v p_{t}^{b}$ are of the opposite sign, and both variance premium measures drop sharply in this period, the required adjustment on the coefficients is much smaller. Overall, the predicted values from constrained and unconstrained regressions closely track each other as shown in Figure 4. The statistical predictability evidence also remains very similar to the benchmark setting, as shown in Table 7 .

\section{Relation to higher-order moments}

Intuitively, measures of good and bad variance and variance premia are related to the higher-order conditional moments of the return distribution. For example, the price of the cubic contract in Bakshi, Kapadia, and Madan (2003) is positively related to the call option prices used to calculate $i v_{t}^{g}$ and negatively related to the put option prices used to calculate $i v_{t}^{b}$. We therefore assess whether the information in the good and bad variance premia can be fully subsumed by the measures of the higher-order conditional moments of returns.

We construct the implied skewness measure skew following Bakshi, Kapadia, and Madan (2003) and also compute realized skewness using the high-frequency return data as in Amaya, Christoffersen, Jacobs, and Vasquez (2013). We refer to the difference between skew and realized skewness as the skewness risk premium, srp. ${ }^{17}$ Tables C.6 and C.7 show that adding either skew or srp to the good and bad variance premium measures does not affect our benchmark evidence for the relation between the variance premium and the future returns. In fact, the significance of the coefficients on the variance premia tends to improve when we control for measures of skewness.

\footnotetext{
${ }^{17}$ Chang, Christoffersen, and Jacobs (2013) show evidence of a skewness risk premium in the cross-section of returns, and Conrad, Dittmar, and Ghysels (2013) find that inidividual stocks' skewness is strongly related to future returns. Kozhan, Neuberger, and Schneider (2013) find that a skewness premium can explain most of the implied volatility skew for index options.
} 
The coefficients on skewness tend to be negative for equity and positive for bonds, but are quite imprecisely estimated.

We also consider regression specifications that incorporate the estimates of the implied kurtosis. Similar to skewness regressions, the inclusion of measures of kurtosis does not materially affect our results for the signs and magnitudes of the variance risk premium coefficients. These results are not reported for brevity. In all, the evidence suggests that higher moments of the return distribution do not fully subsume the predictive content in the good and bad variance premia.

\section{Alternative implied and realized variance measures}

Finally, we check the robustness of our results against a number of alternative measurements of the implied and realized variance measures and report our findings in Appendix C. For implied variances, we consider extending the range of the cubic spline to 0 - 3 (Table C.1), using options in the moneyness range 0.8 - 1.2 (Table C.2) and 0.9 - 1.1 (Table C.3). We also compute realized variances using 5-minute returns of S\&P 500 E-Mini futures (Table C.4) and use expected, rather than realized, variances to construct the variance premium measures (Table C.5). Overall, our key results remain robust to all these alternative specifications.

\section{Model}

Motivated by our empirical evidence, we develop a no-arbitrage asset pricing model that takes an exogenous specification for the equity price process, $S_{t}$, and the state-price density, $\pi_{t}$. We use this model to analytically derive a relation between the equity premium and the good and bad components of the variance premium, and discuss the conditions under which the model can help explain the empirical findings in the data. In Section 3.2, we consider a general equilibrium environment that maps directly into the no-arbitrage model specification and provides economic justification for the reduced-form assumptions. 


\subsection{No-arbitrage framework}

\subsubsection{Model dynamics}

We assume that the aggregate equity price follows the process

$$
\frac{d S_{t}}{S_{t^{-}}}=\mu_{S, t} d t+\sum_{i=g, b} \beta_{i, \sigma} \sigma_{i, \lambda} \sqrt{\lambda_{i, t}} d B_{i, t}+\sum_{i=g, b}\left(e^{\beta_{i, c} Z_{i, c, t}}-1\right) d N_{i, t}+\sum_{i=g, b}\left(e^{\beta_{i, \lambda} Z_{i, \lambda, t}}-1\right) d N_{i, t}^{\lambda}
$$

where $\mu_{S, t}$ is the drift, $B_{i, t}$ is a standard Brownian motion, and $N_{i, t}$ and $N_{i, t}^{\lambda}$ are Poisson processes. We consider "good" and "bad" shocks to the equity price, and therefore $i=g$ and $i=b$ for each type of shock. The intensity of $N_{i, t}$ is time varying and follows the jump-diffusion process:

$$
d \lambda_{i, t}=\kappa_{i}\left(\bar{\lambda}_{i}-\lambda_{i, t}\right)+\sigma_{i, \lambda} \sqrt{\lambda_{i, t}} d B_{i, t}+Z_{i, \lambda, t} d N_{i, t}^{\lambda}
$$

where $i=g, b$. For parsimony, the intensity of $N_{i, t}^{\lambda}$ is equal to $\lambda_{i, t}$. Instantaneous shocks $d B_{i, t}$, $d N_{i, t}$, and $d N_{i, t}^{\lambda}$ are independent, conditional on $\lambda_{i, t}$. Finally, we assume that jump sizes $Z_{i, c, t}$ and $Z_{i, \lambda, t}$ take nonnegative values and have time-invariant distributions that are independent of $B_{i, t}$, $N_{i, t}$, and $N_{i, t}^{\lambda}$.

In our framework, the aggregate equity price is driven by good and bad Brownian motion shocks $d B_{i, t}$, fundamental jumps $d N_{i, t}$, and intensity jumps $d N_{i, t}^{\lambda}$. The exposures of the equity price to these shocks are given by $\beta_{i, \sigma}, \beta_{i, c}$, and $\beta_{i, \lambda}$, respectively. If a fundamental jump occurs, the $\log$ stock price moves by $\beta_{i, c} Z_{i, c, t}{ }^{18}$ Because $Z_{i, c, t}$ takes only nonnegative values, the sign of $\beta_{i, c}$ determines whether a fundamental jump moves the equity price upward or downward. To bring economic content to the notion of good and bad jumps, we assume that $\beta_{g, c}$ is positive, and $\beta_{b, c}$ is negative.

\footnotetext{
${ }^{18}$ Ito's lemma implies

$$
d \log S_{t}=\mu_{S, t}^{\log } d t+\sum_{i=g, b} \beta_{i, \sigma} \sigma_{i, \lambda} \sqrt{\lambda_{i, t}} d B_{i, t}+\sum_{i=g, b} \beta_{i, c} Z_{i, c, t} d N_{i, t}+\sum_{i=g, b} \beta_{i, \lambda} Z_{i, \lambda, t} d N_{i, t}^{\lambda}
$$
}

where

$$
\mu_{S, t}^{\log }=\mu_{S, t}-\frac{1}{2} \sum_{i=g, b} \beta_{i, \sigma}^{2} \sigma_{i, \lambda}^{2} \lambda_{i, t}
$$


The specification of the price dynamics in (11) and (12) allows for a correlation between price and intensity processes through common Brownian motion shocks $d B_{i, t}$ and intensity jumps $d N_{i, t}^{\lambda}$. Hence, stock prices move not only due to the fundamental jump realizations but also due to the perceived changes in the probability of jumps. Under the assumption that a higher probability of a price increase (decrease) has a direct positive (negative) impact on prices, we have $\beta_{g, \sigma}, \beta_{g, \lambda} \geq 0$, and $\beta_{b, \sigma}, \beta_{b, \lambda} \leq 0$.

Finally, we assume that the state-price density follows the process

$$
\begin{aligned}
\frac{d \pi_{t}}{\pi_{t^{-}}} & =\mu_{\pi, t} d t-\sum_{i=g, b} \Lambda_{i, \sigma} \sigma_{i, \lambda} \sqrt{\lambda_{i, t}} d B_{i, t} \\
& +\sum_{i=g, b}\left(e^{-\Lambda_{i, c} Z_{i, c, t}}-1\right) d N_{i, t}+\sum_{i=g, b}\left(e^{-\Lambda_{i, \lambda} Z_{i, \lambda, t}}-1\right) d N_{i, t}^{\lambda}
\end{aligned}
$$

which implies that it is affected by all shocks that also impact the equity price $S_{t}$. The exposures $\Lambda_{i, \sigma}, \Lambda_{i, c}$, and $\Lambda_{i, \lambda}$, are the market prices of each risk. The state-price density proxies for the marginal utility of agents and high marginal utility states correspond to "bad" times under concave utility functions (Breeden and Litzenberger (1978)). In our no-arbitrage setup, we assume that states with high (low) equity price correspond to low (high) marginal utility, so that $\Lambda_{g, c}>0$ and $\Lambda_{b, c}<0$ for fundamental shocks, and $\Lambda_{g, \sigma}, \Lambda_{g, \lambda} \geq 0, \Lambda_{b, \sigma}, \Lambda_{b, \lambda} \leq 0$ for intensity shocks.

\subsubsection{The equity premium}

The comovement of the price process with the state-price density gives rise to the equity premium. In our specification, the instantaneous equity premium captures compensation for good and bad diffusive, fundamental jump, and intensity jump risks. As shown in Appendix B.1.1, the 
instantaneous equity premium can be written as

$$
\begin{aligned}
r_{t}^{e}-r_{t}^{f} & =\underbrace{\sum_{i=g, b} \beta_{\sigma, i} \Lambda_{\sigma, i} \sigma_{i, \lambda}^{2}}_{\text {diffusion }} \lambda_{i, t} \\
& +\underbrace{\sum_{i=g, b} \mathbb{E}\left[\left(e^{-\Lambda_{i, c} Z_{i, c, t}}-1\right)\left(1-e^{\beta_{i, c} Z_{i, c, t}}\right)\right]}_{\text {fundamental jump }} \lambda_{i, t} \\
& +\underbrace{\sum_{i=g, b} \mathbb{E}\left[\left(e^{-\Lambda_{i, \lambda} Z_{i, \lambda, t}}-1\right)\left(1-e^{\beta_{i, \lambda} Z_{i, \lambda, t}}\right)\right]}_{\text {intensity jump }} \lambda_{i, t},
\end{aligned}
$$

where $r_{t}^{e}$ is the instantaneous expected equity return, $r_{t}^{e}=\frac{1}{d t} E_{t^{-}}\left(\frac{d S_{t}}{S_{t^{-}}}+\frac{D_{t}}{S_{t}}\right), \frac{D_{t}}{S_{t}}$ is the dividend yield, and $r_{t}^{f}$ is the instantaneous risk-free rate.

In Section 3.1.1, we assumed that the equity exposures and the market prices of good shocks are all positive, and they are all negative for bad shocks. Indeed, a positive good diffusive shock increases the price of equity $\left(\beta_{\sigma, g}>0\right)$ and decreases marginal utility $\left(\Lambda_{\sigma, i}>0\right)$. Similarly, good jumps decrease marginal utility, $\left(e^{-\Lambda_{g} Z_{g}}-1\right)<0$ and increase the equity price $\left(e^{\beta_{g} Z_{g}}-1\right)>0$. The opposite is true for bad shocks. Because equity prices are low in adverse economic states associated with high marginal utility, the equity premium is positive. Further, the conditional equity premium increases in both good and bad jump intensities. When jump intensities rise, the quantity of risk that investors face increases, and the required risk compensations increase.

\subsubsection{Dynamics under the risk-neutral measure}

Given the specification of the state-price density and the price process under the physical measure, we can write the corresponding price dynamics under the risk-neutral measure, $Q$, as follows:

$$
\frac{d S_{t}}{S_{t^{-}}}=\mu_{S, t}^{Q} d t+\sum_{i=g, b} \beta_{i, \sigma} \sigma_{i, \lambda} \sqrt{\lambda_{i, t}} d B_{i, t}^{Q}+\sum_{i=g, b}\left(e^{\beta_{i, c} Z_{i, c, t}^{Q}}-1\right) d N_{i, t}^{Q}+\sum_{i=g, b}\left(e^{\beta_{i, \lambda} Z_{i, \lambda, t}^{Q}}-1\right) d N_{i, t}^{\lambda, Q}
$$

where $B_{i, t}^{Q}$ is again a standard Brownian motion, $N_{i, t}^{Q}$ is a Poisson process with intensity $\lambda_{i, t}^{c, Q}$, and $N_{i, t}^{\lambda, Q}$ is a Poisson process with intensity $\lambda_{i, t}^{\lambda, Q}$. The risk-neutral measure is absolutely continuous 
with respect to the physical measure which implies $Z_{i, c, t}^{Q} \geq 0$ and $Z_{i, \lambda, t}^{Q} \geq 0$.

The risk-neutral drift of the price process is given by the risk-free rate minus the dividend yield. The adjustment for the diffusive risk is also standard and takes into account the risk compensation for the Brownian motion, given by the product of the market price and quantity of the diffusive risk:

$$
d B_{i, t}^{Q}=d B_{i, t}+\Lambda_{i, \sigma} \sigma_{i, \lambda} \sqrt{\lambda_{i, t}}
$$

Jump sizes and jump intensities also change under the risk-neutral measure, and the direction of the change depends on the sign of the market price of the jump risk. Indeed, the risk-neutral jump intensities and jump distributions satisfy ${ }^{19}$

$$
\begin{array}{rr}
\lambda_{i, t}^{c, Q}=\lambda_{i, t} \mathbb{E}\left[e^{-\Lambda_{i, c} Z_{i, c, t}}\right], & \lambda_{i, t}^{\lambda, Q}=\lambda_{i, t} \mathbb{E}\left[e^{-\Lambda_{i, \lambda} Z_{i, \lambda, t}}\right], \\
\mathbb{E}^{Q}\left[e^{\beta_{i, c} Z_{i, c, t}}\right]=\frac{\mathbb{E}\left[e^{\left(\beta_{i, c}-\Lambda_{i, c}\right) Z_{i, c, t}}\right]}{\mathbb{E}\left[e^{-\Lambda_{i, c} Z_{i, c, t}}\right]}, \quad \mathbb{E}^{Q}\left[e^{\beta_{i, \lambda} Z_{i, \lambda, t}}\right]=\frac{\mathbb{E}\left[e^{\left(\beta_{i, \lambda}-\Lambda_{i, \lambda}\right) Z_{i, \lambda, t}}\right]}{\mathbb{E}\left[e^{-\Lambda_{i, \lambda} Z_{i, \lambda, t}}\right]} .
\end{array}
$$

Overall, the risk-neutral measure is more "pessimistic" regarding all shocks: it amplifies bad events and downweights good events relative to the physical measure. Specifically, the intensities of good jumps are lower under the risk-neutral measure, namely, $\lambda_{g, t}^{c, Q}<\lambda_{g, t}$ and $\lambda_{g, t}^{\lambda, Q} \leq \lambda_{g, t}$, because these shocks have a positive market price of risk. Furthermore, the distributions of good jumps are twisted by factors $\frac{e^{-\Lambda_{g} Z_{g, t}}}{\mathbb{E}\left[e^{-\Lambda_{g} Z_{g, t}}\right]}$, leading to higher probabilities for lower values of $Z_{g, t}$ under the risk-neutral measure. As a result, the means of good jump size distributions are lower under the risk-neutral measure. Analogously, because they have negative market prices of risk, bad jumps have a higher intensity under the risk-neutral measure and their distributions are tilted toward larger values. ${ }^{20}$

\footnotetext{
${ }^{19} \mathbb{E}^{Q}$ denotes expectation under the risk-neutral measure, while $\mathbb{E}$ without a superscript is expectation under the physical measure.

${ }^{20}$ Another way to see the adjustment of mean jump sizes is the definition of the risk-neutral measure:

$$
\mathbb{E}^{Q}[Z]=\mathbb{E}\left[Z \frac{e^{-\Lambda Z}}{\mathbb{E}\left[e^{-\Lambda Z}\right]}\right]=\mathbb{E}[Z]+\operatorname{cov}\left(Z, \frac{e^{-\Lambda Z}}{\mathbb{E}\left[e^{-\Lambda Z}\right]}\right)
$$
}




\subsubsection{Quadratic variation and the variance premium}

The instantaneous quadratic variation in log equity price can be defined $\mathrm{as}^{21}$

$$
V_{t, t+d t} \equiv d[\log S, \log S]_{t}=\sum_{i=g, b} \beta_{i, \sigma}^{2} \sigma_{i, \lambda}^{2} \lambda_{i, t} d t+\sum_{i=g, b} \beta_{i, c}^{2} Z_{i, c, t}^{2} d N_{i, t}+\sum_{i=g, b} \beta_{i, \lambda}^{2} Z_{i, \lambda, t}^{2} d N_{i, t}^{\lambda}
$$

Therefore, the expected instantaneous quadratic variation under the physical and the risk-neutral measure is given by ${ }^{22}$

$$
\begin{aligned}
& \frac{1}{d t} \mathbb{E}_{t^{-}}\left[V_{t, t+d t}\right]=\sum_{i=g, b} \beta_{i, \sigma}^{2} \sigma_{i, \lambda}^{2} \lambda_{i, t}+\sum_{i=g, b} \beta_{i, c}^{2} \mathbb{E}\left[Z_{i, c, t}^{2}\right] \lambda_{i, t}+\sum_{i=g, b} \beta_{i, \lambda}^{2} \mathbb{E}\left[Z_{i, \lambda, t}^{2}\right] \lambda_{i, t}, \\
& \frac{1}{d t} \mathbb{E}_{t^{-}}^{Q}\left[V_{t, t+d t}\right]=\sum_{i=g, b} \beta_{i, \sigma}^{2} \sigma_{i, \lambda}^{2} \lambda_{i, t}+\sum_{i=g, b} \beta_{i, c}^{2} \mathbb{E}^{Q}\left[Z_{i, c, t}^{2}\right] \lambda_{i, t}^{c, Q}+\sum_{i=g, b} \beta_{i, \lambda}^{2} \mathbb{E}^{Q}\left[Z_{i, \lambda, t}^{2}\right] \lambda_{i, t}^{\lambda, Q} .
\end{aligned}
$$

The instantaneous quadratic variation has three components. The first component comes from the diffusive dynamics of the equity price process and is equal under both measures. The next two components capture the variation from fundamental jumps and intensity jumps, respectively, which are the sources of non-Normality in the distribution of returns.

We define the instantaneous variance premium as the difference between expected quadratic variation under the risk-neutral and physical measures. Using the transformation of jump intensities in (17), the variance premium can be written as

$$
\begin{aligned}
V P_{t, t+d t} & =\frac{1}{d t}\left(\mathbb{E}_{t^{-}}^{Q}\left[V_{t, t+d t}\right]-\mathbb{E}_{t^{-}}\left[V_{t, t+d t}\right]\right) \\
& =\sum_{i=g, b} \beta_{i, c}^{2}\left(\mathbb{E}^{Q}\left[Z_{i, c, t}^{2}\right] \mathbb{E}\left[e^{-\Lambda_{i, c} Z_{i, c, t}}\right]-\mathbb{E}\left[Z_{i, c, t}^{2}\right]\right) \lambda_{i, t} \\
& +\sum_{i=g, b} \beta_{i, \lambda}^{2}\left(\mathbb{E}^{Q}\left[Z_{i, \lambda, t}^{2}\right] \mathbb{E}\left[e^{-\Lambda_{i, \lambda} Z_{i, \lambda, t}}\right]-\mathbb{E}\left[Z_{i, \lambda, t}^{2}\right]\right) \lambda_{i, t} .
\end{aligned}
$$

where the covariance term is negative (positive) for good (bad) jumps.

${ }^{21}$ To simplify the exposition, we focus on instantaneous return variation. Appendix B.1.2 discusses quadratic variation computed over a discrete time interval from $t$ to $t+\tau$ and shows that for $\tau=1$ it is approximately equal to the instantaneous one. In the quantitative assessment of the model in Section 3.3, we find that the approximation is extremely accurate.

${ }^{22}$ The expected instantaneous quadratic variation is equivalent to the instantaneous variance. 
The compensation for jump risk in equity price gives rise to the variance premium in the model. Indeed, because good jumps have positive market prices of risk, the risk-neutral distributions of good jumps are tilted toward lower values, as discussed in Section 3.1.3, which implies $\mathbb{E}^{Q}\left[Z_{g, c, t}^{2}\right]<$ $\mathbb{E}\left[Z_{g, c, t}^{2}\right]$ and $\mathbb{E}^{Q}\left[Z_{g, \lambda, t}^{2}\right] \leq \mathbb{E}\left[Z_{g, \lambda, t}^{2}\right]$. Further, good jumps are also less frequent under the riskneutral measure $\left(\mathbb{E}\left[e^{-\Lambda_{g, c} Z_{g, c, t}}\right]<1\right.$ and $\left.\mathbb{E}\left[e^{-\Lambda_{g, \lambda} Z_{g, \lambda, t}}\right] \leq 1\right)$. Hence, while an increase in good jump intensity, $\lambda_{g, t}$, raises the expected quadratic variations, the increase is smaller under the risk-neutral measure, so that the variance premium is decreasing in good jump intensity, $\lambda_{g, t}$. To the contrary, the effect of an increase in bad jump intensity is magnified under the risk-neutral measure, which causes the variance premium to be increasing in bad jump intensity, $\lambda_{b, t}$.

We can summarize model implications for the equity premium and the variance premium as follows:

$$
\begin{aligned}
r_{t}^{e}-r_{t}^{f} & =\beta_{g}^{e p} \lambda_{g, t}+\beta_{b}^{e p} \lambda_{b, t}, \\
V P_{t, t+d t} & =\beta_{g}^{v p} \lambda_{g, t}+\beta_{b}^{v p} \lambda_{b, t} .
\end{aligned}
$$

The equity premium is increasing in both good and bad jump intensities implying $\beta_{g}^{e p}, \beta_{b}^{e p}>0$, as shown in Section 3.1.2. This section shows that the variance premium is decreasing in good jump intensity and increasing in bad jump intensity, leading to $\beta_{g}^{v p}<0, \beta_{b}^{v p}>0$. In the univariate regressions of instantaneous excess returns on the variance premium, the regression coefficient is given by

$$
\beta=\frac{\operatorname{cov}\left(r_{t}^{e}-r_{t}^{f}, V P_{t, t+d t}\right)}{\operatorname{var}\left(V P_{t, t+d t}\right)}=\frac{\beta_{g}^{e p} \beta_{g}^{v p} \operatorname{var}\left(\lambda_{g, t}\right)+\beta_{b}^{e p} \beta_{b}^{v p} \operatorname{var}\left(\lambda_{b, t}\right)}{\left(\beta_{g}^{v p}\right)^{2} \operatorname{var}\left(\lambda_{g, t}\right)+\left(\beta_{b}^{v p}\right)^{2} \operatorname{var}\left(\lambda_{b, t}\right)}
$$

Empirical evidence in the literature starting from Bollerslev, Tauchen, and Zhou (2009) finds that $\beta$ is positive, in line with our findings for aggregate equity returns in Section 2. This suggests that the contribution of the bad jumps $\left(\beta_{b}^{e p} \beta_{b}^{v p} \operatorname{var}\left(\lambda_{b, t}\right)\right)$ to the regression coefficient is larger than that of the good ones $\left(\left|\beta_{g}^{e p} \beta_{g}^{v p} \operatorname{var}\left(\lambda_{g, t}\right)\right|\right)$. However, in our model, the total variance premium does not fully capture fluctuations in the equity premium. Indeed, the two factors that drive the variance premium actually have an opposite effect on the equity premium. This motivates our decom- 
position of the variance premium into good and bad components, thereby helping to separately identify movements in good and bad jump intensity and their link to the equity premium.

\subsubsection{Good and bad variance premia}

Barndorff-Nielsen, Kinnebrock, and Shephard (2010) show that if the log price follows a right continuous jump-diffusion process with left limits, then the sum of squared positive (negative) returns converge to the sum of half of the diffusive variation and the sum of squared positive (negative) jumps as the sampling frequency increases. Therefore, following Barndorff-Nielsen, Kinnebrock, and Shephard (2010), we define good and bad instantaneous quadratic variation as

$$
V_{t, t+d t}^{i} \equiv \frac{1}{2}\left(\sum_{i=g, b} \beta_{i, \sigma}^{2} \sigma_{i, \lambda}^{2} \lambda_{i, t} d t\right)+\beta_{i, c}^{2} Z_{i, c, t}^{2} d N_{i, t}+\beta_{i, \lambda}^{2} Z_{i, \lambda, t}^{2} d N_{i, t}^{\lambda}
$$

where $i=g, b$. Expected good and bad quadratic variations under the physical and risk-neutral variance are then given by

$$
\begin{aligned}
& \frac{1}{d t} \mathbb{E}_{t^{-}}\left[V_{t, t+d t}^{i}\right]=\frac{1}{2}\left(\sum_{i=g, b} \beta_{i, \sigma}^{2} \sigma_{i, \lambda}^{2} \lambda_{i, t}\right)+\beta_{i, c}^{2} \mathbb{E}\left[Z_{i, c, t}^{2}\right] \lambda_{i, t}+\beta_{i, \lambda}^{2} \mathbb{E}\left[Z_{i, \lambda, t}^{2}\right] \lambda_{i, t}, \\
& \frac{1}{d t} \mathbb{E}_{t^{-}}^{Q}\left[V_{t, t+d t}^{i}\right]=\frac{1}{2}\left(\sum_{i=g, b} \beta_{i, \sigma}^{2} \sigma_{i, \lambda}^{2} \lambda_{i, t}\right)+\beta_{i, c}^{2} \mathbb{E}^{Q}\left[Z_{i, c, t}^{2}\right] \lambda_{i, t}^{c, Q}+\beta_{i, \lambda}^{2} \mathbb{E}^{Q}\left[Z_{i, \lambda, t}^{2}\right] \lambda_{i, t}^{\lambda, Q} .
\end{aligned}
$$

Good and bad variances share a common component driven by the diffusive volatility of the equity price. On the other hand, the jump component of the good (bad) variance depends on only the good (bad) jump intensity.

We define the good and bad variance premia as the difference between the corresponding 
expected quadratic variations under the risk-neutral and the physical measure:

$$
\begin{aligned}
V P_{t, t+d t}^{i} & =\frac{1}{d t}\left(\mathbb{E}_{t^{-}}^{Q}\left[V_{t, t+d t}^{i}\right]-\mathbb{E}_{t^{-}}\left[V_{t, t+d t}^{i}\right]\right) \\
& =\beta_{i, c}^{2}\left(\mathbb{E}^{Q}\left[Z_{i, c, t}^{2}\right] \mathbb{E}\left[e^{-\Lambda_{i, c} Z_{i, c, t}}\right]-\mathbb{E}\left[Z_{i, c, t}^{2}\right]\right) \lambda_{i, t} \\
& +\beta_{i, \lambda}^{2}\left(\mathbb{E}^{Q}\left[Z_{i, \lambda, t}^{2}\right] \mathbb{E}\left[e^{-\Lambda_{i, \lambda} Z_{i, \lambda, t}}\right]-\mathbb{E}\left[Z_{i, \lambda, t}^{2}\right]\right) \lambda_{i, t}
\end{aligned}
$$

which implies $V P_{t}=V P_{t}^{g}+V P_{t}^{b}$. Similar to the total variance premium, the good and bad variance premia arise due to the compensation for the jump risk in equity prices. Indeed, they exactly correspond to the components of the total variance premium associated with $\lambda_{g, t}$ and $\lambda_{b, t}$ :

$$
V P_{t, t+d t}^{g}=\beta_{g}^{v p} \lambda_{g, t}, \quad V P_{t, t+d t}^{b}=\beta_{b}^{v p} \lambda_{b, t}
$$

In our benchmark model, the two jump intensities are uncorrelated, so that the good and bad variance premia represent two independent factors that drive the total variance premium. Recall that the good and bad variances share a common diffusive component and thus are correlated. This motivates our choice for the variance premia as cleaner measures of the equity jump risk compensation and is consistent with the empirical finding that measures of good and bad variances have a much higher correlation than the good and bad variance premia, as shown in Section 2 .

Following our discussion in Section 3.1.4, the good variance premium is decreasing in good jump intensity $\left(\beta_{g}^{v p}<0\right)$, while the bad variance premium increases in bad jump intensity $\left(\beta_{b}^{v p}>0\right)$. This implies that the covariance of the equity premium with good variance premium is negative, and it is positive with the bad variance premium. Hence, in multivariate regressions of future excess returns on the good and bad variance premia, the coefficient on the good variance premium $\left(\beta_{g}^{e p} / \beta_{g}^{v p}\right)$ is negative, while the coefficient on the bad variance premium $\left(\beta_{b}^{e p} / \beta_{b}^{v p}\right)$ is positive. In particular, the coefficient on the bad variance premium in multivariate regressions is larger than the one on the total variance premium in the univariate setting. These model implications are qualitatively in line with the empirical evidence in Section 2. In the next section, we consider 
quantitative implications of the model and show that they are also consistent with the data.

\subsection{General equilibrium}

In this section, we consider a parsimonious general equilibrium model that can give rise to the reduced-form, no-arbitrage framework in Section 3.1. The economic model links equity exposures and market prices of risk to investor's preferences and dynamics of the fundamentals and provides a discipline on the signs and magnitudes of the model parameters. We show that the general equilibrium model can quantitatively explain the empirical patterns of the variance premia presented in Section 2, while accounting for the key features of the macroeconomic and equity market data.

\subsubsection{Consumption dynamics}

We consider a Lucas tree endowment economy. Aggregate consumption, which is equal to aggregate endowment, is given by

$$
\frac{d C_{t}}{C_{t^{-}}}=\mu d t+\left(e^{Z_{g, c, t}}-1\right) d N_{g, t}+\left(e^{-Z_{b, c, t}}-1\right) d N_{b, t}
$$

where $N_{g, t}$ and $N_{b, t}$ are Poisson processes with jump intensities $\lambda_{g, t}$ and $\lambda_{b, t}$, respectively. Each intensity follows a jump-diffusion process

$$
d \lambda_{i, t}=\kappa_{i}\left(\bar{\lambda}_{i}-\lambda_{i, t}\right)+\sigma_{i, \lambda} \sqrt{\lambda_{i, t}} d B_{i, t}+Z_{i, \lambda, t} d N_{i, t}^{\lambda}
$$

where $i=g, b$. As in Section 3.1, the intensity of $N_{i, t}^{\lambda}$ is also given by $\lambda_{i, t}$. Instantaneous shocks $d B_{i, t}, d N_{i, t}$, and $d N_{i, t}^{\lambda}$ are assumed to be independent, conditional on $\lambda_{i, t}$. All jump sizes $Z$ take nonnegative values and have time-invariant distributions. Specifically, in the calibration analysis,

we assume that the jump size distribution is Gamma, $Z_{i, j, t} \sim \Gamma\left(k_{i, j}, \frac{\mu_{i, j}}{k_{i, j}}\right)$ for $i=g, b$ and $j=c, \lambda$, where $k$ is the shape parameter, and $\mu$ corresponds to the mean of the distribution.

In our economic model, we use upward and downward jumps as a convenient way to model positive and negative movements to economic fundamentals. We view these jumps as capturing 
regular dynamics of aggregate endowment in normal times, implying that jumps are small and frequent. The probabilities of good and bad jumps vary over time and are driven by distinct processes. Our specification of consumption dynamics is related to Segal, Shaliastovich, and Yaron (2015) and Tsai and Wachter (2014), who also use Poisson jumps with separate intensities to isolate the variation in upward and downward moves in the fundamentals. It is also closely related to the good and bad environments specification of Bekaert and Engstrom (2009). In their setup, positive and negative Gamma-distributed shocks drive movements in realized and expected consumption, consumption volatility, and the habit level.

Notably, because jumps are not compensated, jump intensities directly affect the conditional means of the processes. Expected consumption growth increases at times of good jump intensity and decreases when bad intensity is high. Segal, Shaliastovich, and Yaron (2015) provide direct empirical evidence for the feedback from macroeconomic volatilities on future real growth, consistent with this model assumption.

\subsubsection{State-price density}

We adopt the continuous-time analog of the recursive utility function defined by Epstein and Zin (1989) and Weil (1990) with an elasticity of intertemporal substitution (EIS) equal to one. Duffie

and Epstein (1992) show that, in this case, the continuation utility of the representative agent is given by

$$
V_{t}=\mathbb{E}_{t} \int_{t}^{\infty} f\left(C_{s}, V_{s}\right) d s
$$

where

$$
f(C, V)=\beta(1-\gamma) V\left(\log C-\frac{1}{1-\gamma} \log ((1-\gamma) V)\right)
$$

The parameter $\beta$ is the rate of time preference and $\gamma$ is a coefficient of the relative risk aversion. As $\gamma$ approaches one, the utility function converges to logarithmic utility. Recursive preferences 
allow for a preference for the timing of the resolution of uncertainty. Specifically, the agent prefers early resolution of uncertainty if relative risk aversion is greater than the inverse of the EIS, which corresponds to $\gamma>1$ in this model. The analysis in this section focuses on this case.

Given the dynamics of the consumption process, we can characterize the equilibrium solution for the value function (see Appendix B.2.1 for the details):

$$
V_{t}=\frac{C_{t}^{1-\gamma}}{1-\gamma} e^{a+b_{g} \lambda_{g, t}+b_{b} \lambda_{b, t}}
$$

where $a, b_{g}$, and $b_{b}$ are constants that depend on the model and preference parameters. Perceived jump probabilities directly impact the utility of the agent. Specifically, when $\gamma>1$, an increase in good jump intensity increases the utility of the representative agent, and an increase in bad jump intensity lowers the utility: $b_{g}<0$ and $b_{b}>0$, as shown in Appendix B.2.1.

The state-price density represents the marginal utility of the representative agent. As shown in Duffie and Skiadas (1994), the state-price density takes on the following form:

$$
\pi_{t}=\exp \left\{\int_{0}^{t} \frac{\partial}{\partial V} f\left(C_{s}, V_{s}\right) d s\right\} \frac{\partial}{\partial C} f\left(C_{t}, V_{t}\right)
$$

It follows from the Ito's lemma that in our equilibrium model, the state-price density satisfies the following stochastic differential equation:

$$
\begin{aligned}
\frac{d \pi_{t}}{\pi_{t^{-}}} & =\mu_{\pi, t} d t+b_{g} \sigma_{g, \lambda} \sqrt{\lambda_{g, t}} d B_{g, t}+b_{b} \sigma_{b, \lambda} \sqrt{\lambda_{b, t}} d B_{b, t} \\
& +\left(e^{-\gamma Z_{g, c, t}}-1\right) d N_{g, t}+\left(e^{\gamma Z_{b, c, t}}-1\right) d N_{b, t} \\
& +\left(e^{b_{g} Z_{g, \lambda, t}}-1\right) d N_{g, t}^{\lambda}+\left(e^{b_{b} Z_{b, \lambda, t}}-1\right) d N_{b, t}^{\lambda}
\end{aligned}
$$

The state-price process in the general equilibrium model can be directly mapped into the noarbitrage specification Section 3.1. Indeed, the market prices of risk in the two models are related as follows:

$$
\Lambda_{g, c}=\gamma, \Lambda_{b, c}=-\gamma, \Lambda_{g, \sigma}=\Lambda_{g, \lambda}=-b_{g}, \Lambda_{b, \sigma}=\Lambda_{b, \lambda}=-b_{b}
$$


The size of the impact of fundamental consumption shocks on marginal utility is equal to the risk aversion parameter $\gamma>0$. It immediately follows that good (bad) jumps in consumption lead to a decrease (increase) in marginal utility: $\Lambda_{g, c}>0, \Lambda_{b, c}<0$. Furthermore, if risk aversion is greater than one, positive shocks to good (bad) jump intensity result in a decrease (increase) in marginal utility $\left(b_{g}<0\right.$ and $\left.b_{b}>0\right)$. Hence, the market prices of good intensity risks are positive, while they are negative for bad intensity risks : $\Lambda_{g, \sigma}=\Lambda_{g, \lambda}>0, \Lambda_{b, \sigma}=\Lambda_{b, \lambda}<0$. The general equilibrium model implications for the signs of the market prices of risks are in line with our reduced-form assumptions in Section 3.1.

\subsubsection{Pricing of aggregate equity}

In the data, consumption is different from dividends: equity dividends are much smaller than aggregate consumption and are more volatile. To introduce dividends in a parsimonious way, we follow Abel (1999) and specify the aggregate dividend as a levered consumption process: ${ }^{23}$

$$
\frac{d D_{t}}{D_{t^{-}}}=\mu_{d} d t+\left(e^{\phi Z_{g, c}}-1\right) d N_{g, t}+\left(e^{-\phi Z_{b, c}}-1\right) d N_{b, t}
$$

Notably, dividends are exposed to the underlying consumption jumps and the dividend exposure is governed by the dividend leverage parameter $\phi>1$. For simplicity, we assume that the dividend exposure is the same for good and bad jump risks and there is no other idiosyncratic dividend risk.

Equity represents a claim on future dividends. Appendix B.2.2 shows that, in equilibrium, the price of aggregate equity satisfies:

$$
\begin{aligned}
\frac{d S_{t}}{S_{t^{-}}} & =\mu_{S, t} d t+b_{d g}^{*} \sigma_{g, \lambda} \sqrt{\lambda_{g, t}} d B_{g, t}+b_{d b}^{*} \sigma_{b, \lambda} \sqrt{\lambda_{b, t}} d B_{b, t} \\
& +\left(e^{\phi Z_{g, c, t}}-1\right) d N_{g, t}+\left(e^{-\phi Z_{b, c, t}}-1\right) d N_{b, t} \\
& +\left(e^{b_{d g}^{*} Z_{g, c, t}}-1\right) d N_{g, t}^{\lambda}+\left(e^{b_{d b}^{*} Z_{g, b, t}}-1\right) d N_{b, t}^{\lambda}
\end{aligned}
$$

\footnotetext{
${ }^{23}$ This is in line with the empirical evidence in Longstaff and Piazzesi (2004) and the modeling approaches in Campbell and Cochrane (1999) and Bansal and Yaron (2004).
} 
where $b_{d g}^{*}$ and $b_{d b}^{*}$ are the loadings of the log price-dividend ratio on $\lambda_{g, t}$ and $\lambda_{b, t}$.

The equity price process in the general equilibrium model can be directly mapped into the no-arbitrage specification Section 3.1. Indeed, the equity exposures in the two models are related as follows:

$$
\beta_{g, c}=\phi, \beta_{b, c}=-\phi, \beta_{g, \sigma}=\beta_{g, \lambda}=b_{d g}^{*}, \beta_{b, \sigma}=\beta_{b, \lambda}=b_{d b}^{*}
$$

Equity prices are exposed to fundamental consumption and jump intensity risks. The equity exposures to good and bad consumption jumps are equal to the leverage parameter $\phi$. It thus follows that equity prices increase with good consumption jumps and decrease with bad consumption jumps: $\beta_{g, c}>0, \beta_{b, c}<0$. Similar to our discussion of the value function, for $\gamma>1$ and $\phi>1$, an increase in good (bad) jump intensity is good (bad) news for equity prices, $b_{d g}^{*}>0$ and $b_{d b}^{*}<0$. Therefore, the equity exposure to the good jump intensity is positive and that to bad jump intensity is negative: $\beta_{g, \sigma}=\beta_{g, \lambda} \geq 0, \beta_{b, \sigma}=\beta_{b, \lambda} \leq 0$. These model implications are in line with the reduced-form assumptions in Section 3.1.

\subsection{Quantitative model implications}

\subsubsection{Model calibration}

We calibrate the model at a monthly frequency. The model parameter values are summarized in Table 8 .

For parsimony, we use the same parameter values for the good and bad consumption jump distributions and jump intensities. In this case, the unconditional consumption growth distribution is symmetric, and all the asymmetry in returns arises endogenously in the model. Specifically, the jump sizes follow Gamma distribution, $Z_{i, j, t} \sim \Gamma\left(k_{i, j}, \frac{\mu_{i, j}}{k_{i, j}}\right)$ for $i=g, b$ and $j=c, \lambda$, where $k$ is the shape parameter, and $\mu$ corresponds to the mean of the distribution. The average jump in consumption, $\mu_{i, c}$, is 0.0015. Notably, consumption jumps are much smaller than the typical calibrations entertained in the disaster literature (see Barro (2006)). The scale parameter $k_{i, c}$ 
is 0.05 , which implies that the jump distribution is quite volatile. This helps generate sizable risk premia for the instantaneous consumption jump risk, while maintaining reasonable levels of consumption growth volatility.

The intensities of good and bad jumps vary over time. The average frequency of good or bad consumption jumps is about once every 2 months, helping the model generate reasonable values for the mean and volatility of consumption and dividend growth. We calibrate the mean reversion parameter $\kappa_{i}$ to match the $\mathrm{AR}(1)$ coefficient of 0.81 of the implied variances in the data. The implied variances, arguably, are less prone to measurement errors relative to other variance measures. We calibrate the intensity jump distribution parameters $\mu_{c}, k_{i, \lambda}$ and the diffusive volatility $\sigma_{i, \lambda}$ to match the level and the volatility of the implied and physical return volatility and the variance premium.

We set the risk aversion coefficient, $\gamma$, to 10 , which is similar to the traditional values in the literature. The time-rate of preference, $\beta$, is set to 0.00001 to keep the risk-free rate at a low level. Finally, we set the mean consumption and dividend growth rates to $1.93 \%$, annualized, and the dividend leverage parameter $\phi$ to 5 to target the volatility of dividends in the data.

Table 9 shows that our model delivers a good fit to the standard moments of consumption and dividend growth in the data. In the table we show the population values from the model, computed from a long simulation of 50,000 years, as well as small-sample statistics based on 10,000 samples with a length of 18 years each. The monthly model output is time-aggregated to an annual horizon. The volatilities of consumption and dividend growth rates are $2.38 \%$ and $11.97 \%$ in the model, which are quite close to $1.58 \%$ and $9.83 \%$, respectively, in the data. ${ }^{24}$ The means of consumption and dividend growth are about $2 \%$ in the model. It is $1.74 \%$ for consumption growth and is slightly higher in our sample for the dividends. All of the data values are well within the small-sample $90 \%$ confidence interval of the model. Recall that our consumption calibration does not feature large consumption disasters. Indeed, the probability of an annual consumption drop by more than $15 \%$ is $0.12 \%$ in simulated data.

\footnotetext{
${ }^{24}$ All model moments in the text refer to the median from small sample distributions unless stated otherwise.
} 


\subsubsection{Asset pricing implications}

Table 9 shows model implications for equity returns and the risk-free rate. In the model, the average excess equity return is $5.33 \%$ and the return volatility is $16.06 \%$, both of which are in line with the evidence in the data. The equity premium represents risk compensation for the "fundamental jump" risk in realized consumption growth, and the diffusive and jump risk in jump intensities (see equation (14)). Both channels contribute about equally to the total risk compensation. The average model risk-free rate is $1.35 \%$ and is quite smooth, as in the data.

Table 10 reports model output for the implied and realized variances and variance premia. ${ }^{25}$ The model matches the average levels of the variance variables quite well. For example, average good implied variance is 13.60 in the data, relative to 12.11 in the model. Bad implied variances are 25.82 and 23.01, on average, in the data and in the model. The model nearly exactly captures the negative good variance premium of -2.60 , and matches the level of the bad variance premium of 9.43 in the data quite well. Notably, the good variance premium is lower, in absolute value, than the bad variance premium. Due to the concavity of the utility function, investors are more sensitive to bad events than to good events, so that the market prices and the equity exposures to good jump risks are smaller, in absolute values, than to bad jumps.

The model implications for the volatilities of variance measures are broadly in line with the data. For instance, bad variances, implied and realized, are more volatile than good variances in the data. The model can account for this empirical finding due to the endogenous differences in equity exposures and market prices of risk as discussed above. Quantitatively, while many of the data statistics are within the confidence interval of the model, there are some noticeable discrepancies between the data and the model. The model tends to overshoot volatilities of the implied variances and underestimate the variation in the variance premium. Recall that the model volatilities are driven by just two components, good and bad jump intensities, which share the same parameter values. Extending the framework to incorporate the additional volatility factors as suggested in

\footnotetext{
${ }^{25}$ In the model, the implied variance of 1-month squared log returns is very similar to the expected quadratic variation of high-frequency returns over the month. The two have comparable average values, and their correlation is above $99 \%$.
} 
Bates (2000) and Andersen, Fusari, and Todorov (Forthcoming) or to allow for asymmetry in good and bad jump calibration can help the model to better account for the dynamics of the volatility measures.

Next, we assess quantitative model implications for return predictability by the variance premium. Specifically, we regress future excess equity returns on total variance premium and on good and bad variance premia, and report the results in Table 11. Similar to Drechsler and Yaron (2011), total variance premium predicts excess returns with a positive coefficient with magnitudes declining with horizon. However, small-sample regression coefficients and $R^{2}$ values have wide confidence bands. The median $R^{2}$ s are below $4 \%$ in small samples, and they are virtually zero in the population. Once we decompose the variance premium into good and bad components, the predictive coefficient on the good (bad) variance premium is negative (positive), while the confidence bands for the bad variance premium are narrower. Furthermore, the goodness of fit improves significantly in multivariate regressions, and the $R^{2}$ values more than double: they are equal to $9 \%$ at the 12 -month horizon and $8 \%$ at the 24 -month horizon. The predictive power and signs of coefficients are in line with the empirical evidence in Section 2.

To further assess the empirical plausibility of the model structure, we use the calibrated model to infer the conditional equity premium and relate it to the constrained equity premium estimates in the data. Specifically, we infer the implied values of $\lambda_{g, t}$ and $\lambda_{b, t}$, period by period, from the empirical time series of the good and bad variance premia using the economic restrictions of the model in equation (25). Then we compute the model-implied conditional equity premium following equation (14). We plot the model equity premium along with the predicted 12-month excess returns from the constrained regression approach in Figure 5. Quite remarkably, the model tracks the observed estimate of the equity premium in the data very well. Indeed, the correlation between the model-implied equity premium and the predicted 12 -month excess returns is $92 \%$ in levels, and $85 \%$ in first differences. The model-implied equity premium predicts 12-month (24month) excess returns with an $\bar{R}^{2}$ of $5.3 \%$ (9.4\%). Notably, while both the model and the data rely on the good and bad variance premia as predictors of future returns, the good fit of the model is by no means mechanical, and is supportive of the primitive model channels, which allow mapping 
of the components of the variance premium into the equity premium.

\subsubsection{The importance of model ingredients}

Our benchmark model features separate fluctuations in good and bad jump intensities, and recursive utility of the representative agent. Below, we discuss the importance of these model ingredients for the quantitative results in the model.

Our model incorporates the good and bad jumps, whose intensities are time varying and driven by separate processes. These model ingredients are important to explain the predictability of future excess returns by the components of the variance premia in the data. If we only entertain downward jumps in the fundamentals, then the good variance premium is zero. Alternatively, if we have the same underlying intensity process for the good and bad jumps, then the good and bad variance premia become perfectly correlated. In both cases, the total variance premium contains the same information as the bad variance premium, so decomposing total variance premium into the good and bad components should not make any difference for return predictability. This is contrary to our findings in the data that the good variance premium contains risk premium information above and beyond the bad variance premium.

To highlight the role of recursive utility, we also consider the case of a standard time-separable power utility specification. The state-price density, implied by these preferences, is given by

$$
\pi_{t}=e^{-\beta t} C_{t}^{-\gamma}
$$

In this case, only the fundamental consumption risks are priced, $\Lambda_{g, c}=\gamma, \Lambda_{b, c}=-\gamma$, and investors are not concerned with the good and bad jump intensity risks: $\Lambda_{g, \sigma}=\Lambda_{g, \lambda}=0, \Lambda_{b, \sigma}=\Lambda_{b, \lambda}=0$. The equity returns remain risky with respect to the good and bad fundamental jumps $\left(\beta_{g, c}=\phi\right.$, $\left.\beta_{b, c}=-\phi\right)$. However, compared with the benchmark model, for $\phi<\gamma$, equity prices fall at times of high good jump intensity and increase when bad jump intensity is high. This is a direct consequence of a low EIS, which, in the power utility model, is equal to the reciprocal of the risk aversion coefficient $\gamma$. With this restriction, good return jumps are now caused by good 
fundamental jumps in consumption and jumps in bad intensity, making an economic interpretation of a good return jump less clear.

Power utility restriction has a significant effect on quantitative model results. The power utility model implies a low equity premium of $1.9 \%$, which reflects the compensation only for the realized consumption jump risk. The risk-free rate increases to an unrealistically high level of $15.5 \%$, which is typical for power utility models. We further check whether the power utility model can still account for the levels and movements of the in-sample risk premium. Similar to the exercise in the benchmark model, we extract the implied equity premium using the observed time series of the good and bad variance premia in the data under the restrictions of the power utility model. We find that the model-implied in-sample equity premium is too low, and it co-moves much less with the estimate in the data: the correlation of the model-implied equity premium with the predicted 12-month excess equity return in the data drops to $44 \%$ in levels and $-3 \%$ in the first difference. The power utility model fails to account for the conditional movements in the equity premium even at larger levels of risk aversion, which are required to match the average risk premium in the data.

In a related environment with good and bad Gamma-distributed consumption shocks, Bekaert

and Engstrom (2009) extend the power utility model to allow for movements in expected growth rates and the external habits. In their model, total variance premium also has a two-factor structure, and under the estimated parameter values, it decreases (increases) at times of good (bad) consumption volatility. They show that the model can account for the standard moments of the consumption and asset-market dynamics and capture predictability of returns by the total variance premium, but they do not consider the decomposition of the variance premium into the two components. We leave the analysis of this model along these dimensions for future research.

\section{Conclusion}

In this paper, we show that the variance premium is driven by "good" and "bad" components, which separately capture the time-varying risk compensations for the realized variation in positive 
and negative market returns. The good and bad variance premia contain distinct information about future excess returns on equity and corporate bonds, especially at long horizons of 1 and 2 years. Indeed, in multivariate predictability regressions, the predictive coefficients on the good variance premium are negative, while they are all positive for the bad variance premium, and the $R^{2}$ s reach about $10 \%$ for equity and $20 \%$ for corporate bond returns. In contrast, the predictive coefficients on the variance premium itself are insignificant at these horizons, and its predictive power is essentially zero.

To rationalize the empirical evidence in the data, we consider a model that features upward (good) and downward (bad) equity jumps with time-varying intensities. We show that when good (bad) jump shocks carry a positive (negative) market price of risk, the equity premium is increasing in good and bad jump intensities, while the variance premium is decreasing in good and increasing in bad jump intensity. Therefore, the good variance premium predicts future returns with a negative sign, while the bad variance premium predicts them with a positive sign, consistent with the data. We quantify the magnitudes of these effects by imposing the restrictions of a general equilibrium model. Using numerical calibrations, we show that the model can capture the novel evidence of return predictability by the variance premium measures, alongside standard aggregate asset pricing and macroeconomic moments.

There are several extensions of our paper that would be interesting to address in future work. On the empirical side, we consider the predictability of the U.S. equity and corporate bond returns. It would be useful to extend our analysis for international asset returns, as in Bollerslev, Marrone, Xu, and Zhou (2014), and for other asset classes, such as government bonds, currencies, and commodities. Further, while our variance premium measures capture volatility risks in aggregate equity markets, one can use similar methods to compute the good and bad variance premia in other asset markets. ${ }^{26}$ On the model side, our specification can be extended to allow for separate sources of risk in the expected growth or consumption volatility, as in Bansal and Yaron (2004), including Poisson jump risk as in Drechsler and Yaron (2011), or time-varying skew-normal risk as

\footnotetext{
${ }^{26}$ See Londono and Zhou (2014) and Prokopczuk and Wese Simen (2014), who compute the total variance premium for currency and commodity markets, respectively.
} 
in Colacito, Ghysels, and Meng (2013). One can also enrich the model by separating volatility and jump risk factors, consistent with the findings in Santa-Clara and Yan (2010), and incorporating additional volatility-related factors, such as the long-run volatility (see Duffie, Pan, and Singleton (2000)), or volatility of volatility (see Bollerslev, Tauchen, and Zhou (2009)). Further, for simplicity, the two jump intensities are assumed to be uncorrelated in our framework. In the data, the good and bad volatility of returns have a more complex dynamic dependency, as discussed in Patton and Sheppard (2013), and the model can be extended to take this into account. Finally, we entertain the endowment economy, in which intensities of the good and bad jumps are specified exogenously. It would be interesting to provide a deeper foundation for jump and volatility risks using more primitive economic models with production and investment. 


\section{Appendix}

\section{A Empirical analysis}

\section{A.1 Good and bad implied variances}

Let $S$ be the price of the underlying security at time $t+1$ and $H(S)$ a twice differentiable payoff function. Bakshi, Kapadia, and Madan (2003) show that $H(S)$ can be spanned as

$$
H(S)=H(\bar{S})+(P-\bar{S}) H_{P}(\bar{S})+\int_{\bar{S}}^{\infty} H_{S S}(K)(S-K)^{+} d K+\int_{0}^{\bar{S}} H_{S S}(K)(K-S)^{+} d K
$$

where subscripts represent derivatives and $\bar{S}$ is a constant. The payoff of the volatility contract is given by $H(S)=\left(\log \left(\frac{S}{S_{t}}\right)\right)^{2}$. The definition of the volatility contract payoff along with (A.1) implies

$$
H(S)=\int_{S_{t}}^{\infty} \frac{2\left(1-\log \left(K / S_{t}\right)\right)}{K^{2}}(S-K)^{+} d K+\int_{0}^{\bar{S}} \frac{2\left(1+\log \left(S_{t} / K\right)\right)}{K^{2}}(K-S)^{+} d K .
$$

Note that the price of the volatility contract is $i v_{t}=e^{-r_{t}^{f}} \mathbb{E}_{t}^{Q}[H(S)]$, while the price of a call option is $C(t, t+1, K)=e^{-r_{t}^{f}} \mathbb{E}_{t}^{Q}\left[(S-K)^{+}\right]$and the put price is $P(t, t+1, K)=e^{-r_{t}^{f}} \mathbb{E}_{t}^{Q}\left[(K-S)^{+}\right]$. Equation (A.2) along with these definitions implies (2).

Now consider the "good" volatility contract with price $i v_{t}^{g}=e^{-r_{t}^{f}} \mathbb{E}_{t}^{Q}\left[r_{t+1}^{2} \mathbb{I}\left(r_{t+1}>0\right)\right]$. The payoff can be written as $H^{g}(S)=\left(\log \left(\frac{S}{S_{t}}\right)\right)^{2} \mathbb{I}\left(S>S_{t}\right)$. Although $H_{S S}$ is not continuous at $S=S_{t}$, we can write

$$
\begin{aligned}
H^{g}(S) & =\lim _{T \downarrow S_{t}} \int_{T}^{\infty} H_{S S}(K)(S-K)^{+} d K+\lim _{T \uparrow S_{t}} \int_{0}^{T} H_{S S}(K)(K-S)^{+} d K, \\
& =\int_{S_{t}}^{\infty} \frac{2}{S^{2}}\left(1-\log \left(\frac{S}{S_{t}}\right)\right)(S-K)^{+} d K .
\end{aligned}
$$

The computation of good implied variance in (5) follows from (A.3) and the definition of a call option. The computation is analogous for implied bad variance.

\section{A.2 Bootstrap approach}

To bootstrap standard errors, we first standardize excess returns, $r_{t+1}-r_{t}^{f}$, by subtracting the unconditional mean and dividing by $i v_{t}$. We draw a random sample with replacement from this distribution with the same length as the return series in the data. Simulated returns then correspond to standardized 
returns scaled up by the observations of $i v_{t}$. We run the return predictability regressions in the simulated samples on the variance premium measures in the data. We repeat this procedure 10,000 times to construct a small-sample distribution of regression coefficients, which we use to compute standard errors and $p$-values. In this approach, the time series of predictor variables, as well as heteroskedasticity of returns, remain the same as in the data, while there is no predictability of returns under the null.

We further consider the joint evidence for return predictability across multiple equity portfolios, namely, ten portfolios formed on size and book-to-market and ten industry portfolios from Kenneth French's website. Following MacKinnon (2009), we compute $p$-values that summarize the statistical significance of portfolio return predictability within each of the three groups. We standardize all excess portfolio returns by their unconditional mean and $i v_{t}$ as described above. From the standardized sample, we draw a random sample of ten returns with replacement with the same length as in the data, and we compute simulated returns using the unconditional average portfolio return and the time series of $i v_{t}$. This preserves the dependence of portfolio returns in the cross-section and the heteroskedasticity in the time series. For a predictor variable that predicts aggregate equity market returns with a positive (negative) sign, we choose the maximum (minimum) of the ten predictive coefficients as the critical value. Following this approach, we construct 10,000 cross-sections of returns that have the same size as the original data and create a small-sample distribution of minimum (maximum) coefficient values. The $p$-value is the probability that the minimum (maximum) predictive coefficient is smaller (larger) than its empirical counterpart in simulated samples.

\section{B Model}

\section{B.1 No-arbitrage framework}

\section{B.1.1 Equity premium}

The no-arbitrage assumption implies

$$
S_{t}=\mathbb{E}_{t^{-}}\left[\int_{t}^{\infty} \frac{\pi_{s}}{\pi_{t}} D_{s} d s\right]
$$


where $D_{t}$ denotes the dividend. Multiplying both sides of (B.1) by $\pi_{t}$, we have

$$
\pi_{t} S_{t}=\mathbb{E}_{t^{-}}\left[\int_{t}^{\infty} \pi_{s} D_{s} d s\right]
$$

which implies

$$
\pi_{t} S_{t}=\mathbb{E}_{t^{-}}\left[\pi_{s} S_{s}+\int_{t}^{s} \pi_{u} D_{u} d u\right]
$$

for $s>t$. Adding $\int_{0}^{t} \pi_{u} D_{u} d u$ to both sides of (B.3), we have

$$
\pi_{t} S_{t}+\int_{0}^{t} \pi_{u} D_{u} d u=\mathbb{E}_{t^{-}}\left[\pi_{s} S_{s}+\int_{0}^{s} \pi_{u} D_{u} d u\right]
$$

which implies that $\pi_{t} S_{t}+\int_{0}^{t} \pi_{u} D_{u} d u$ is a martingale. Therefore, the sum of the drift and instantaneous mean of the jump term in $\frac{d\left(\pi_{t} S_{t}\right)}{\pi_{t} S_{t}}+\frac{D_{t}}{S_{t}} d t$ is zero.

Applying Ito's lemma using the stochastic differential equations (11) and (13), the mean of $\frac{d\left(\pi_{t} S_{t}\right)}{\pi_{t} S_{t}}+$ $\frac{D_{t}}{S_{t}} d t$ becomes

$$
\begin{aligned}
0 & =\mu_{S, t}+\mu_{\pi, t}-\sum_{i=g, b} \beta_{\sigma, i} \Lambda_{\sigma, i} \sigma_{i, \lambda}^{2} \lambda_{i, t}+\frac{D_{t}}{S_{t}} \\
& +\sum_{i=g, b} \mathbb{E}\left[e^{\left(\beta_{i, c}-\Lambda_{i, c}\right) Z_{i, c, t}}-1\right] \lambda_{i, t}+\sum_{i=g, b} \mathbb{E}\left[e^{\left(\beta_{i, \lambda}-\Lambda_{i, \lambda}\right) Z_{i, \lambda, t}}-1\right] \lambda_{i, t} .
\end{aligned}
$$

We can define the instantaneous expected return as

$$
r_{t}^{e}=\mu_{S, t}+\frac{D_{t}}{S_{t}}+\sum_{i=g, b} \mathbb{E}_{t}\left[e^{\beta_{i, c} Z_{i, c, t}}-1\right] \lambda_{i, t}+\sum_{i=g, b} \mathbb{E}_{t}\left[e^{\beta_{i, \lambda} Z_{i, \lambda, t}}-1\right] \lambda_{i, t}
$$

The instantaneous risk-free rate in the economy is given by

$$
r_{t}^{f}=-\mu_{\pi, t}-\sum_{i=g, b} \mathbb{E}\left[e^{-\Lambda_{i, c} Z_{i, c, t}}+e^{-\Lambda_{i, \lambda} Z_{i, \lambda, t}}-2\right] \lambda_{i, t}
$$

Combining the solutions to the risk-free rate above and the expected return in (B.6) leads to the expression for the equity premium. 


\section{B.1.2 Quadratic variation}

Here, we examine the properties of quadratic variation from $t$ to $t+\tau$, which is defined as

$$
\begin{aligned}
V_{t, t+\tau} & =\int_{t}^{t+\tau} d[\log S, \log S]_{s} \\
& =\sum_{i=g, b} \beta_{i, \sigma}^{2} \sigma_{i, \lambda}^{2} \int_{t}^{t+\tau} \lambda_{i, s} d s+\sum_{i=g, b} \beta_{i, c}^{2} Z_{i, c, t}^{2} \int_{t}^{t+\tau} d N_{i, s}+\sum_{i=g, b} \beta_{i, \lambda}^{2} Z_{i, \lambda, t}^{2} \int_{t}^{t+\tau} d N_{i, s}^{\lambda} .
\end{aligned}
$$

The expected quadratic variation from $t$ to $t+\tau$ is then given by

$$
\mathbb{E}_{t^{-}}\left[V_{t, t+\tau}\right]=\sum_{i=g, b}\left(\beta_{i, \sigma}^{2} \sigma_{i, \lambda}^{2}+\beta_{i, c}^{2} \mathbb{E}\left[Z_{i, c, t}^{2}\right]+\beta_{i, \lambda}^{2} \mathbb{E}\left[Z_{i, \lambda, t}^{2}\right]\right) \mathbb{E}_{t^{-}}\left[\int_{t}^{t+\tau} \lambda_{i, s} d s\right]
$$

From (B.9), we can see that it is crucial to compute the quantity $\mathbb{E}_{t}\left[\int_{t}^{t+\tau} \lambda_{i, s} d s\right]$. Nowotny (2011) and Li and Zinna (2014) show that the conditional expectation $\mathbb{E}_{t}\left[\lambda_{i, s}\right]$ is given by

$$
\mathbb{E}_{t^{-}}\left[\lambda_{i, s}\right]=e^{-\left(\kappa_{i}-\mathbb{E}\left[Z_{i, \lambda, t}\right]\right)(s-t)} \lambda_{t}+\left(1-e^{-\left(\kappa_{i}-\mathbb{E}\left[Z_{i, \lambda, t}\right]\right)(s-t)}\right) \frac{\kappa_{i} \bar{\lambda}_{i}}{\kappa_{i}-\mathbb{E}\left[Z_{i, \lambda, t}\right]},
$$

where $s>t$. We can compute the integral of $\mathbb{E}_{t}\left[\lambda_{i, s}\right]$ from $t$ to $t+\tau$, and obtain

$$
\mathbb{E}_{t^{-}}\left[\int_{t}^{t+\tau} \lambda_{i, s} d s\right]=\frac{\kappa_{i} \bar{\lambda}_{i} \tau}{\kappa_{i}-\mathbb{E}\left[Z_{i, \lambda, t}\right]}-\frac{\kappa_{i} \bar{\lambda}_{i}\left(1-e^{-\left(\kappa_{i}-\mathbb{E}\left[Z_{i, \lambda, t}\right]\right) \tau}\right)}{\left(\kappa_{i}-\mathbb{E}\left[Z_{i, \lambda, t}\right]\right)^{2}}+\lambda_{i, t} \frac{1-e^{-\left(\kappa_{i}-\mathbb{E}\left[Z_{i, \lambda, t}\right]\right) \tau}}{\kappa_{i}-\mathbb{E}\left[Z_{i, \lambda, t}\right]}
$$

which is affine in $\lambda_{i, t}$. For small values of $\tau$, we can use the approximation $1-e^{-\left(\kappa_{i}-\mathbb{E}\left[Z_{i, \lambda, t}\right]\right) \tau} \approx$ $\left(\kappa_{i}-\mathbb{E}\left[Z_{i, \lambda, t}\right]\right) \tau$, which implies

$$
\mathbb{E}_{t^{-}}\left[\int_{t}^{t+\tau} \lambda_{i, s} d s\right] \approx \lambda_{i, t} \tau
$$

Using the approximation, the expected quadratic variation in (B.9) becomes

$$
\mathbb{E}_{t^{-}}\left[V_{t, t+\tau}\right] \approx \sum_{i=g, b}\left(\beta_{i, \sigma}^{2} \sigma_{i, \lambda}^{2}+\beta_{i, c}^{2} \mathbb{E}\left[Z_{i, c, t}^{2}\right]+\beta_{i, \lambda}^{2} \mathbb{E}\left[Z_{i, \lambda, t}^{2}\right]\right) \lambda_{i, t} \tau
$$

which is equal to $\mathbb{E}_{t}\left[V_{t, t+d t}\right]$ in (19) if $\tau=1$.

Note that this approximation has two dimensions. The first is the elimination of the nonlinearity in $\tau$ for small values of $\tau$. The second is the elimination of the so-called "drift difference" in the computation of the variance premium that arises from the differences in the mean reversion parameter $\kappa_{i}$ and $\mathbb{E}\left[Z_{i, \lambda, t}\right]$, leading to different levels of persistence under the risk-neutral and physical measures (Drechsler and Yaron (2011)). We compute the exact and approximate values of $\mathbb{E}_{t^{-}}\left[\int_{t}^{t+\tau} \lambda_{i, s} d s\right]$ in our monthly calibration and find that the approximation is highly accurate for $\tau=1$ (which is the relevant case for this paper), 
while the discrepancy between the exact and approximate values starts to increase for higher values of $\tau$.

\section{B.2 General equilibrium}

\section{B.2.1 The value function and the state-price density}

The conjecture in equation (31), along with the definition of the value function in (29) and (30), implies

$$
f(C, V)=-\beta V\left(a+b_{g} \lambda_{g}+b_{b} \lambda_{b}\right)
$$

Furthermore, Duffie and Epstein (1992) show that, under the optimal consumption path, $V_{t}+\int_{0}^{t} f\left(C_{s}, V_{s}\right) d s$ is a martingale, which implies $\mathbb{E}_{t}\left[d V_{t}+f\left(C_{t}, V_{t}\right)\right]=0$. From the process of the value function that can be computed applying Ito's lemma to $V_{t}=V\left(C_{t}, \lambda_{g, t}, \lambda_{b, t}\right)$, we obtain ${ }^{27}$

$$
\begin{aligned}
0 & =\underbrace{(1-\gamma) \mu+b_{g} \kappa_{g} \bar{\lambda}_{g}+b_{b} \kappa_{b} \bar{\lambda}_{b}-\beta a}_{=0} \\
& +\lambda_{g, t} \underbrace{\left[-b_{g} \kappa_{g}+\frac{1}{2} b_{g}^{2} \sigma_{g, \lambda}^{2}+\mathbb{E}\left[e^{(1-\gamma) Z_{g, c, t}}-1\right]+\mathbb{E}\left[e^{b_{g} Z_{g, \lambda, t}}-1\right]-\beta b_{g}\right]}_{=0} \\
& +\lambda_{b, t} \underbrace{\left[-b_{b} \kappa_{b}+\frac{1}{2} b_{b}^{2} \sigma_{b, \lambda}^{2}+\mathbb{E}\left[e^{-(1-\gamma) Z_{g, b, t}}-1\right]+\mathbb{E}\left[e^{b_{b} Z_{b, \lambda, t}}-1\right]-\beta b_{b}\right]}_{=0} .
\end{aligned}
$$

It follows from (B.15) that $a, b_{g}$, and $b_{b}$ solve the equations

$$
\begin{aligned}
& a=\frac{1}{\beta}\left((1-\gamma) \mu+b_{g} \kappa_{g} \bar{\lambda}_{g}+b_{b} \kappa_{b} \bar{\lambda}_{b}\right), \\
& 0=\frac{1}{2} b_{g}^{2} \sigma_{g, \lambda}^{2}-b_{g}\left(\kappa_{g}+\beta\right)+\mathbb{E}\left[e^{b_{g} Z_{g, \lambda, t}}-1\right]+\mathbb{E}\left[e^{(1-\gamma) Z_{g, c, t}}-1\right], \\
& 0=\frac{1}{2} b_{b}^{2} \sigma_{b, \lambda}^{2}-b_{b}\left(\kappa_{b}+\beta\right)+\mathbb{E}\left[e^{b_{b} Z_{b, \lambda, t}}-1\right]+\mathbb{E}\left[e^{-(1-\gamma) Z_{b, c, t}}-1\right] .
\end{aligned}
$$

The equations for $b_{g}$ and $b_{b}$ both have two solutions. We choose the solution that satisfies $b_{i}=0$ if $Z_{i, c, t}=0$ for $i=g, b$. This implies that we choose the negative solution for $b_{g}$ for $\gamma>1$. Both solutions for $b_{b}$ are positive, and the smaller one satisfies $b_{i}=0$ if $Z_{i, c, t}=0$ for $i=g, b$. Note that, for $\gamma=1$, this corresponds to $b_{g}=b_{b}=0$.

We can do a second-order approximation of the exponential function that brings the equation (B.16)

${ }^{27}$ See Seo and Wachter (2015) for further details. 
into quadratic form:

$$
e^{b_{i} Z_{i, \lambda, t}} \approx 1+b_{g} Z_{i, \lambda, t}+\frac{1}{2} b_{g}^{2} Z_{i, \lambda, t}^{2}
$$

Solving the quadratic equation results in $^{28}$

$$
\begin{aligned}
& b_{g} \approx \frac{\kappa_{g}-\mathbb{E}\left[Z_{g, \lambda, t}\right]+\beta}{\mathbb{E}\left[Z_{g, \lambda, t}^{2}\right]+\sigma_{g, \lambda}^{2}}-\sqrt{\frac{\left(\kappa_{g}-\mathbb{E}\left[Z_{g, \lambda, t}\right]+\beta\right)^{2}}{\left(\mathbb{E}\left[Z_{g, \lambda, t}^{2}\right]+\sigma_{g, \lambda}^{2}\right)^{2}}-2 \frac{\mathbb{E}\left[e^{\left.(1-\gamma) Z_{g, c, t}\right]-1}\right.}{\mathbb{E}\left[Z_{g, \lambda, t}^{2}\right]+\sigma_{g, \lambda}^{2}}}, \\
& b_{b} \approx \frac{\kappa_{b}-\mathbb{E}\left[Z_{b, \lambda, t}\right]+\beta}{\mathbb{E}\left[Z_{b, \lambda, t}^{2}\right]+\sigma_{b, \lambda}^{2}}-\sqrt{\frac{\left(\kappa_{b}-\mathbb{E}\left[Z_{b, \lambda, t}\right]+\beta\right)^{2}}{\left(\mathbb{E}\left[Z_{b, \lambda, t}^{2}\right]+\sigma_{b, \lambda}^{2}\right)^{2}}-2 \frac{\mathbb{E}\left[e^{\left.-(1-\gamma) Z_{b, c, t}\right]-1}\right.}{\mathbb{E}\left[Z_{b, \lambda, t}^{2}\right]+\sigma_{b, \lambda}^{2}}} .
\end{aligned}
$$

As economic intuition suggests, we choose the root of the quadratic equation that satisfies $b_{i}=0$ if $Z_{i, c, t}=0$ for $i=g, b$ is analogous to the exact solutions to (B.16).

Note that $\beta>0$ and $\kappa_{i}-\mathbb{E}\left[Z_{i, \lambda, t}\right]>0$ are standing assumptions. We assume that the terms inside the square roots are nonnegative so that a real solution exists. This places a joint restriction on preference parameters and the riskiness in the economy. For example, a higher value for $\gamma$ and a lower value for $\kappa_{i}$ make it harder to satisfy this constraint, restricting the risk aversion of the representative agent and the persistence of state variables.

The drift of the state-price density in (33) is given by

$$
\begin{aligned}
\mu_{\pi, t}=-\beta-\mu & -\lambda_{g, t}\left(\mathbb{E}\left[e^{(1-\gamma) Z_{g, c, t}}-1\right]+\mathbb{E}\left[e^{b_{g} Z_{g, \lambda, t}}-1\right]\right) \\
- & \lambda_{b, t}\left(\mathbb{E}\left[e^{-(1-\gamma) Z_{g, c, t}}-1\right]+\mathbb{E}\left[e^{b_{g} Z_{g, \lambda, t}}-1\right]\right)
\end{aligned}
$$

\section{B.2.2 Price of equity}

Let $H_{t, s-t}$ be the time- $t$ price of a claim on the dividend at $s$ :

$$
H_{t, s-t}=H\left(D_{t}, \lambda_{g, t}, \lambda_{b, t}, s-t\right)=\mathbb{E}_{t^{-}}\left[\frac{\pi_{s}}{\pi_{t}} D_{s}\right]
$$

so that the price of aggregate equity becomes

$$
S_{t}=\int_{0}^{\infty} H_{t, \tau} d \tau
$$

\footnotetext{
${ }^{28}$ We use the exact solutions for $a, b_{g}$, and $b_{b}$ in the numerical simulations and verify that the approximate values deviate less than $1 \%$ from the exact values.
} 
Multiplying both sides of (B.20) by $\pi_{t}$, we have $\pi_{t} H_{t, s-t}=\mathbb{E}_{t^{-}}\left[\pi_{s} D_{s}\right]$. Conjecture that

$$
H_{t, \tau}=D_{t} e^{a_{d}(\tau)+b_{d g}(\tau) \lambda_{g, t}+b_{d b}(\tau) \lambda_{b, t}}
$$

Applying Ito's lemma to $\pi_{t}$ and $H_{t, \tau}$, we derive the process $\frac{d\left(\pi_{t} H_{t, \tau}\right)}{\pi_{t} H_{t, \tau}}$. Because $\pi_{t} H_{t, \tau}$ is a martingale, the sum of the drift and expected jumps, which is affine in $\lambda_{g, t}$ and $\lambda_{b, t}$, must be equal to zero. Setting the constant and the coefficients on $\lambda_{g, t}$ and $\lambda_{b, t}$ to zero results in the following system of ordinary differential equations (ODE) that $a_{d}(\tau), b_{d g}(\tau)$, and $b_{d b}(\tau)$ solve

$$
\begin{aligned}
a_{d}^{\prime}(\tau) & =-\beta-\mu+\mu_{d}+\kappa_{g} \bar{\lambda}_{g} b_{d g}(\tau)+\kappa_{b} \bar{\lambda}_{b} b_{d b}(\tau) \\
b_{d g}^{\prime}(\tau) & =\frac{1}{2} b_{d g}^{2}(\tau) \sigma_{g, \lambda}^{2}+\left(b_{g} \sigma_{g, \lambda}^{2}-\kappa_{g}\right) b_{d g}(\tau) \\
& +\mathbb{E}\left[e^{(\phi-\gamma) Z_{g, c, t}}\right]-\mathbb{E}\left[e^{(1-\gamma) Z_{g, c, t}}\right]+\mathbb{E}\left[e^{\left(b_{g}+b_{d g}(\tau)\right) Z_{g, \lambda, t}}-e^{b_{g} Z_{g, \lambda, t}}\right], \\
b_{d b}^{\prime}(\tau) & =\frac{1}{2} b_{d b}^{2}(\tau) \sigma_{b, \lambda}^{2}+\left(b_{b} \sigma_{b, \lambda}^{2}-\kappa_{b}\right) b_{d b}(\tau) \\
& +\mathbb{E}\left[e^{-(\phi-\gamma) Z_{b, c, t}}\right]-\mathbb{E}\left[e^{-(1-\gamma) Z_{b, c, t}}\right]+\mathbb{E}\left[e^{\left(b_{b}+b_{d b}(\tau)\right) Z_{b, \lambda, t}}-e^{b_{b} Z_{b, \lambda, t}}\right] .
\end{aligned}
$$

The no-arbitrage relation, $D_{s}=H_{s, 0}$, implies the initial conditions $a_{d}(0)=0, b_{d g}(0)=0$, and $b_{d b}(0)=0$. If dividends are not levered $(\phi=1)$, then we have $b_{d g}(\tau)=b_{d b}(\tau)=0$. In this case, equity is a claim on aggregate consumption and its price only changes due to realized consumption shocks. Furthermore, we have $a_{d}(\tau)=-\beta \tau$ in the case of $\mu_{d}=\mu$ and $\phi=1$, which implies the result in Weil (1990) that the wealth-consumption ratio is constant and equal to $1 / \beta$ if the EIS is equal to one.

While we use the exact solution of this system of ODEs in (B.23) in our calibration, the following approximation (which we verify to be numerically very accurate) is helpful to obtain closed-form expressions:

$$
e^{b_{d i}(\tau) Z_{i, \lambda, t}} \approx 1+b_{d i}(\tau) Z_{i, \lambda, t}+\frac{1}{2} b_{d i}(\tau)^{2} Z_{i, \lambda, t}^{2}
$$

where $i=g, b$. Plugging in (B.24) into (B.23), the ODE's for $b_{d g}(\tau)$, and $b_{d b}(\tau)$ become Ricatti equations with the following solution:

$$
b_{d i}(\tau)=\frac{2\left(1-e^{-\eta_{i} \tau}\right) l_{0, i}}{2 \eta_{i}-\left(l_{1, i}+\eta_{i}\right)\left(1-e^{-\eta_{i} \tau}\right)}
$$

where

$$
\eta_{i}=\sqrt{l_{1, i}^{2}-4 l_{0, i} l_{2, i}}
$$


for $i=g, b .^{29}$ The terms in $b_{d i}(\tau)$ are given by

$$
\begin{array}{ll}
l_{0, g}=\mathbb{E}\left[e^{(\phi-\gamma) Z_{g, c, t}}\right]-\mathbb{E}\left[e^{(1-\gamma) Z_{g, c, t}}\right], & l_{0, b}=\mathbb{E}\left[e^{-(\phi-\gamma) Z_{b, c, t}}\right]-\mathbb{E}\left[e^{-(1-\gamma) Z_{b, c, t}}\right], \\
l_{1, g}=b_{g} \sigma_{g, \lambda}^{2}-\kappa_{g}+\mathbb{E}\left[e^{b_{g} Z_{g, \lambda, t}} Z_{g, \lambda, t}\right], & l_{1, b}=b_{b} \sigma_{b, \lambda}^{2}-\kappa_{b}+\mathbb{E}\left[e^{b_{b} Z_{b, \lambda, t}} Z_{b, \lambda, t}\right], \\
l_{2, g}=\frac{1}{2}\left(\sigma_{g, \lambda}^{2}+\mathbb{E}\left[e^{b_{g} Z_{g, \lambda, t}} Z_{g, \lambda, t}^{2}\right]\right), & l_{2, b}=\frac{1}{2}\left(\sigma_{b, \lambda}^{2}+\mathbb{E}\left[e^{b_{b} Z_{b, \lambda, t}} Z_{b, \lambda, t}^{2}\right]\right) .
\end{array}
$$

The approximation preserves the property that $b_{d g}(\tau)=b_{d b}(\tau)=0$ for $\phi=1$. Note that $1-e^{-\eta_{i} \tau} \leq 1$. If $\phi>1$, we have $l_{0, g}>0$, implying a positive numerator for $b_{d g}(\tau)$. Furthermore, $b_{g}<0$ and $\kappa_{g}-\mathbb{E}\left[Z_{g, \lambda, t}\right]>$ 0 imply $l_{1, g}<0$. Because $l_{2, g}>0$, we have $\eta_{g}<\left|l_{1, g}\right| \leq-l_{1, g}$. This implies that the denominator of $b_{d g}(\tau)$ is also positive. Hence, $b_{d g}(\tau)>0$ for $\phi>1$. An analogous argument implies $b_{d b}(\tau)<0$ for $\phi>1$.

Equation (B.25) implies that $b_{d g}(\tau)$ and $b_{d b}(\tau)$ have finite limits, while $a_{d}^{\prime}(\tau)$ converges to a negative value, resulting in finite prices.

Finally, we use a continuous-time version of the classic Campbell and Shiller (1988) approximation as is standard in the literature. Let $G\left(\lambda_{g, t}, \lambda_{b, t}\right)$ denote the price-dividend ratio of equity which is given by

$$
G\left(\lambda_{g, t}, \lambda_{b, t}\right)=\frac{S_{t}}{D_{t}}=\int_{0}^{\infty} e^{a_{d}(\tau)+b_{d g}(\tau) \lambda_{g, t}+b_{d b}(\tau) \lambda_{b, t}} d \tau
$$

Let $g_{t}=\log \left(G\left(\lambda_{g, t}, \lambda_{b, t}\right)\right)$. The Taylor approximation for $\lambda_{g}^{*}$ and $\lambda_{b}^{*}$ implies

$$
g_{t} \approx g\left(\lambda_{g}^{*}, \lambda_{b}^{*}\right)+\frac{\partial g}{\partial \lambda_{g}}\left(\lambda_{g}^{*}, \lambda_{b}^{*}\right)\left(\lambda_{g, t}-\lambda_{g}^{*}\right)+\frac{\partial g}{\partial \lambda_{b}}\left(\lambda_{g}^{*}, \lambda_{b}^{*}\right)\left(\lambda_{b, t}-\lambda_{b}^{*}\right)
$$

The partial derivatives of the log price-dividend ratio are given by

$$
b_{d i}^{*}=\frac{\partial g}{\partial \lambda_{i}}\left(\lambda_{g}^{*}, \lambda_{b}^{*}\right)=\frac{1}{G\left(\lambda_{g}^{*}, \lambda_{b}^{*}\right)} \int_{0}^{\infty} b_{d, i}(\tau) e^{a_{d}(\tau)+b_{d g}(\tau) \lambda_{g}^{*}+b_{d b}(\tau) \lambda_{b}^{*}} d \tau .
$$

This implies that the signs of $b_{d i}^{*}$ and $b_{d, i}(\tau)$ are identical for $i=g, b$. We can write the log price-dividend ratio as

$$
g\left(\lambda_{g, t}, \lambda_{b, t}\right)=a_{d}^{*}+b_{d g}^{*} \lambda_{g, t}+b_{d b}^{*} \lambda_{b, t},
$$

where

$$
a_{d}^{*}=g\left(\lambda_{g}^{*}, \lambda_{b}^{*}\right)-b_{d g}^{*} \lambda_{g}^{*}-b_{d b}^{*} \lambda_{b}^{*}
$$

Equity price can be written as

$$
S_{t}=D_{t} e^{a_{d}^{*}+b_{d g}^{*} \lambda_{g, t}+b_{d b}^{*} \lambda_{b, t}}
$$

\footnotetext{
${ }^{29}$ Note that the solution requires $l_{1, i}^{2}-4 l_{0, i} l_{2, i}>0$.
} 
Applying Ito's lemma to (B.33) implies (36), where

$$
\mu_{S, t}=\mu_{d}+b_{d g}^{*} \kappa_{g}\left(\overline{\lambda_{g}}-\lambda_{g, t}\right)+b_{d b}^{*} \kappa_{b}\left(\overline{\lambda_{b}}-\lambda_{b, t}\right)+\frac{1}{2}\left(b_{d g}^{*}\right)^{2} \sigma_{g, \lambda}^{2} \lambda_{g, t}+\frac{1}{2}\left(b_{d b}^{*}\right)^{2} \sigma_{b, \lambda}^{2} \lambda_{b, t} .
$$

We set $\lambda_{i}^{*}=\mathbb{E}\left[\lambda_{i, t}\right]$ for $i=g, b$ in the numerical model solution.

\section{B.2.3 Model with power utility}

We use the same solution methodology as in Section B.2.2 and find that $b_{d g}(\tau)$ and $b_{d b}(\tau)$ solve the following ODEs:

$$
\begin{aligned}
b_{d g}^{\prime}(\tau) & =\frac{1}{2} b_{d g}^{2}(\tau) \sigma_{g, \lambda}^{2}-b_{d g}(\tau) \kappa_{g}+\mathbb{E}\left[e^{(\phi-\gamma) Z_{g, c, t}}+e^{b_{d g}(\tau) Z_{g, \lambda, t}}-2\right] \\
b_{d b}^{\prime}(\tau) & =\frac{1}{2} b_{d b}^{2}(\tau) \sigma_{b, \lambda}^{2}-b_{d b}(\tau) \kappa_{b}+\mathbb{E}\left[e^{-(\phi-\gamma) Z_{b, c, t}}+e^{b_{d b}(\tau) Z_{b, \lambda, t}}-2\right] .
\end{aligned}
$$

Using the approximation in (B.24), $b_{d g}(\tau)$ and $b_{d b}(\tau)$ take the form (B.25) with

$$
\begin{array}{ll}
l_{0, g}=\mathbb{E}\left[e^{(\phi-\gamma) Z_{g, c, t}}\right]-1, & l_{0, b}=\mathbb{E}\left[e^{-(\phi-\gamma) Z_{b, c, t}}\right]-1, \\
l_{1, g}=-\left(\kappa_{g}-\mathbb{E}\left[Z_{g, \lambda, t}\right]\right), & l_{1, b}=-\left(\kappa_{b}-\mathbb{E}\left[Z_{b, \lambda, t}\right]\right), \\
l_{2, g}=\frac{1}{2}\left(\sigma_{g, \lambda}^{2}+\mathbb{E}\left[Z_{g, \lambda, t}^{2}\right]\right), & l_{2, b}=\frac{1}{2}\left(\sigma_{b, \lambda}^{2}+\mathbb{E}\left[Z_{b, \lambda, t}^{2}\right]\right) .
\end{array}
$$

Standing assumptions imply that $b_{d g}(\tau)>0$ and $b_{d b}(\tau)<0$ if and only if $\phi>\gamma$. Note that the denominator in (B.25) is positive because $l_{1, i}<0$ for $i=g, b$ for power utility. Therefore, the sign of $l_{0, i}$ determines the sign of $b_{d i}(\tau)$. If $\phi>\gamma$, then $l_{0, g}>0$ and $l_{0, b}<0$. If $\phi<\gamma$, then $l_{0, g}<0$ and $l_{0, b}>0$.

This is equivalent to the result in Bansal and Yaron (2004) that prices are increasing in expected growth only if the leverage parameter is greater the inverse of EIS. For power utility, EIS is equal to $1 / \gamma$.

\section{Additional tables}


Table C.1: Predicting Excess Returns with Variance Premium Using Extended Spline

\begin{tabular}{|c|c|c|c|c|c|c|c|c|c|c|c|c|c|c|c|c|c|c|c|c|c|c|c|c|}
\hline & \multicolumn{24}{|c|}{ Forecast Horizon $h$} \\
\hline & \multicolumn{4}{|c|}{1} & \multicolumn{4}{|c|}{3} & \multicolumn{4}{|c|}{6} & \multicolumn{4}{|c|}{12} & \multicolumn{4}{|c|}{18} & \multicolumn{4}{|c|}{24} \\
\hline & Coef & $\mathrm{SE}$ & $p$-val & $\bar{R}^{2}$ & Coef & $\mathrm{SE}$ & $p$-val & $\bar{R}^{2}$ & Coef & $\mathrm{SE}$ & $p$-val & $\bar{R}^{2}$ & Coef & $\mathrm{SE}$ & $p$-val & $\bar{R}^{2}$ & Coef & $\mathrm{SE}$ & $p$-val & $\bar{R}^{2}$ & Coef & $\mathrm{SE}$ & $p$-val & $\bar{R}^{2}$ \\
\hline \multicolumn{25}{|c|}{ Panel A: Equity Returns } \\
\hline \multirow[t]{2}{*}{$v p_{t}$} & 0.42 & 0.09 & 0.00 & 0.04 & 0.32 & 0.06 & 0.00 & 0.07 & 0.16 & 0.05 & 0.00 & 0.03 & 0.06 & 0.04 & 0.08 & 0.00 & 0.04 & 0.04 & 0.20 & 0.00 & 0.04 & 0.04 & 0.18 & 0.00 \\
\hline & & 0.28 & 0.08 & & & 0.16 & 0.03 & & & 0.11 & 0.07 & & & 0.06 & 0.18 & & & 0.05 & 0.22 & & & 0.04 & 0.18 & \\
\hline \multirow[t]{2}{*}{$v p_{t}^{g}$} & 0.22 & 0.28 & 0.78 & 0.04 & -0.04 & 0.24 & 0.44 & 0.09 & -0.28 & 0.13 & 0.01 & 0.08 & -0.35 & 0.11 & 0.00 & 0.09 & -0.32 & 0.09 & 0.00 & 0.09 & -0.32 & 0.10 & 0.00 & 0.11 \\
\hline & & 0.58 & 0.66 & & & 0.45 & 0.48 & & & 0.35 & 0.21 & & & 0.24 & 0.07 & & & 0.19 & 0.05 & & & 0.16 & 0.03 & \\
\hline \multirow[t]{2}{*}{$v p_{t}^{b}$} & 0.66 & 0.38 & 0.04 & & 0.76 & 0.30 & 0.01 & & 0.70 & 0.19 & 0.00 & & 0.56 & 0.15 & 0.00 & & 0.47 & 0.13 & 0.00 & & 0.46 & 0.15 & 0.00 & \\
\hline & & 0.57 & 0.12 & & & 0.40 & 0.02 & & & 0.32 & 0.01 & & & 0.25 & 0.01 & & & 0.21 & 0.01 & & & 0.19 & 0.01 & \\
\hline \multicolumn{25}{|c|}{ Panel B: High-Yield Bond Returns } \\
\hline \multirow[t]{2}{*}{$v p_{t}$} & 0.26 & 0.10 & 1.00 & 0.05 & 0.07 & 0.05 & 0.90 & 0.00 & -0.01 & 0.05 & 0.42 & 0.00 & -0.05 & 0.04 & 0.08 & 0.01 & -0.04 & 0.03 & 0.09 & 0.01 & -0.04 & 0.03 & 0.08 & 0.01 \\
\hline & & 0.14 & 0.95 & & & 0.08 & 0.81 & & & 0.06 & 0.45 & & & 0.03 & 0.06 & & & 0.03 & 0.04 & & & 0.02 & 0.03 & \\
\hline \multirow[t]{2}{*}{$v p_{t}^{g}$} & -0.05 & 0.29 & 0.44 & 0.06 & -0.47 & 0.15 & 0.00 & 0.11 & -0.57 & 0.15 & 0.00 & 0.18 & -0.48 & 0.13 & 0.00 & 0.24 & -0.39 & 0.10 & 0.00 & 0.23 & -0.35 & 0.09 & 0.00 & 0.26 \\
\hline & & 0.30 & 0.44 & & & 0.23 & 0.01 & & & 0.18 & 0.00 & & & 0.12 & 0.00 & & & 0.10 & 0.00 & & & 0.09 & 0.00 & \\
\hline \multirow[t]{2}{*}{$v p_{t}^{b}$} & 0.64 & 0.29 & 0.01 & & 0.73 & 0.24 & 0.00 & & 0.67 & 0.24 & 0.00 & & 0.48 & 0.20 & 0.01 & & 0.38 & 0.15 & 0.01 & & 0.35 & 0.14 & 0.01 & \\
\hline & & 0.29 & 0.01 & & & 0.21 & 0.00 & & & 0.16 & 0.00 & & & 0.13 & 0.00 & & & 0.11 & 0.00 & & & 0.10 & 0.00 & \\
\hline \multicolumn{25}{|c|}{ Panel C: Investment-Grade Bond Returns } \\
\hline \multirow[t]{2}{*}{$v p_{t}$} & -0.08 & 0.04 & 0.01 & 0.01 & -0.06 & 0.04 & 0.06 & 0.02 & -0.03 & 0.02 & 0.07 & 0.01 & -0.04 & 0.02 & 0.02 & 0.03 & -0.03 & 0.01 & 0.02 & 0.03 & -0.03 & 0.01 & 0.03 & 0.03 \\
\hline & & 0.11 & 0.20 & & & 0.06 & 0.16 & & & 0.04 & 0.23 & & & 0.02 & 0.05 & & & 0.02 & 0.04 & & & 0.01 & 0.03 & \\
\hline \multirow[t]{2}{*}{$v p_{t}^{g}$} & -0.37 & 0.11 & 0.00 & 0.05 & -0.36 & 0.07 & 0.00 & 0.13 & -0.26 & 0.08 & 0.00 & 0.15 & -0.23 & 0.08 & 0.00 & 0.20 & -0.18 & 0.06 & 0.00 & 0.20 & -0.17 & 0.05 & 0.00 & 0.23 \\
\hline & & 0.22 & 0.02 & & & 0.17 & 0.01 & & & 0.13 & 0.01 & & & 0.09 & 0.00 & & & 0.07 & 0.00 & & & 0.06 & 0.00 & \\
\hline \multirow[t]{2}{*}{$v p_{t}^{b}$} & 0.27 & 0.13 & 0.02 & & 0.30 & 0.10 & 0.00 & & 0.26 & 0.12 & 0.02 & & 0.19 & 0.11 & 0.04 & & 0.16 & 0.09 & 0.04 & & 0.15 & 0.07 & 0.02 & \\
\hline & & 0.21 & 0.07 & & & 0.15 & 0.01 & & & 0.12 & 0.01 & & & 0.09 & 0.01 & & & 0.08 & 0.02 & & & 0.07 & 0.02 & \\
\hline
\end{tabular}

This table presents predictability regression evidence for equity returns (Panel A), high-yield bond returns (Panel B), and investment-grade bond returns (Panel C) from January 1996 to August 2014. Implied variance measures are computed using a cubic spline as in the benchmark case. Moneyness levels are extended to 0-3 using the implied volatility of the lowest $(>0.85)$ or highest $(<1.15)$ moneyness. The dependent variable is the annualized $\log$ excess return over the next $h$ months $(h=1,3,6,12,18,24)$. For each asset, the table shows the coefficient (Coef), the standard errors (SE), and the $p$-values for a univariate predictability regression with the variance premium $v p_{t}$, and a multivariate regression with the good and bad variance premia, $v p_{t}^{g}$ and $v p_{t}^{b}$, as predictor variables. For each coefficient, the first line reports the Newey-West standard error with three more lags than the forecast horizon $h$, and the corresponding $p$-value. The second line reports the standard error and the $p$-value from the bootstrap approach. The $p$-values are calculated for one-sided tests as described in Section 2.4 . 
Table C.2: Predicting Excess Returns with Variance Premium Using Moneyness Range 0.8-1.2

\begin{tabular}{|c|c|c|c|c|c|c|c|c|c|c|c|c|c|c|c|c|c|c|c|c|c|c|c|c|}
\hline & \multicolumn{24}{|c|}{ Forecast Horizon $h$} \\
\hline & \multicolumn{4}{|c|}{1} & \multicolumn{4}{|c|}{3} & \multicolumn{4}{|c|}{6} & \multicolumn{4}{|c|}{12} & \multicolumn{4}{|c|}{18} & \multicolumn{4}{|c|}{24} \\
\hline & Coef & $\mathrm{SE}$ & $p$-val & $\bar{R}^{2}$ & Coef & $\mathrm{SE}$ & $p$-val & $\bar{R}^{2}$ & Coef & $\mathrm{SE}$ & $p$-val & $\bar{R}^{2}$ & Coef & $\mathrm{SE}$ & $p$-val & $\bar{R}^{2}$ & Coef & SE & $p$-val & $\bar{R}^{2}$ & Coef & $\mathrm{SE}$ & $p$-val & $\bar{R}^{2}$ \\
\hline \multicolumn{25}{|c|}{ Panel A: Equity Returns } \\
\hline \multirow[t]{2}{*}{$v p_{t}$} & 0.38 & 0.08 & 0.00 & 0.04 & 0.30 & 0.06 & 0.00 & 0.07 & 0.14 & 0.05 & 0.00 & 0.03 & 0.05 & 0.04 & 0.12 & 0.00 & 0.03 & 0.04 & 0.25 & 0.00 & 0.03 & 0.03 & 0.23 & 0.00 \\
\hline & & 0.25 & 0.08 & & & 0.15 & 0.03 & & & 0.10 & 0.09 & & & 0.06 & 0.22 & & & 0.05 & 0.27 & & & 0.04 & 0.24 & \\
\hline \multirow[t]{2}{*}{$v p_{t}^{g}$} & 0.16 & 0.31 & 0.70 & 0.04 & -0.13 & 0.25 & 0.29 & 0.09 & -0.34 & 0.15 & 0.01 & 0.07 & -0.38 & 0.13 & 0.00 & 0.07 & -0.34 & 0.11 & 0.00 & 0.08 & -0.34 & 0.12 & 0.00 & 0.10 \\
\hline & & 0.56 & 0.62 & & & 0.44 & 0.39 & & & 0.35 & 0.16 & & & 0.24 & 0.06 & & & 0.20 & 0.04 & & & 0.17 & 0.02 & \\
\hline \multirow[t]{2}{*}{$v p_{t}^{b}$} & 0.63 & 0.36 & 0.04 & & 0.77 & 0.28 & 0.00 & & 0.67 & 0.18 & 0.00 & & 0.52 & 0.15 & 0.00 & & 0.44 & 0.13 & 0.00 & & 0.44 & 0.15 & 0.00 & \\
\hline & & 0.55 & 0.12 & & & 0.38 & 0.02 & & & 0.30 & 0.01 & & & 0.23 & 0.01 & & & 0.21 & 0.02 & & & 0.19 & 0.01 & \\
\hline \multicolumn{25}{|c|}{ Panel B: High-Yield Bond Returns } \\
\hline \multirow[t]{2}{*}{$v p_{t}$} & 0.24 & 0.09 & 1.00 & 0.05 & 0.05 & 0.04 & 0.86 & 0.00 & -0.03 & 0.04 & 0.24 & 0.00 & -0.06 & 0.03 & 0.02 & 0.02 & -0.05 & 0.03 & 0.03 & 0.02 & -0.04 & 0.02 & 0.03 & 0.02 \\
\hline & & 0.13 & 0.96 & & & 0.08 & 0.77 & & & 0.05 & 0.33 & & & 0.03 & 0.02 & & & 0.02 & 0.02 & & & 0.02 & 0.01 & \\
\hline \multirow[t]{2}{*}{$v p_{t}^{g}$} & -0.09 & 0.32 & 0.39 & 0.06 & -0.50 & 0.19 & 0.00 & 0.09 & -0.58 & 0.19 & 0.00 & 0.15 & -0.49 & 0.17 & 0.00 & 0.21 & -0.39 & 0.13 & 0.00 & 0.20 & -0.36 & 0.12 & 0.00 & 0.23 \\
\hline & & 0.29 & 0.39 & & & 0.23 & 0.01 & & & 0.18 & 0.00 & & & 0.13 & 0.00 & & & 0.10 & 0.00 & & & 0.09 & 0.00 & \\
\hline \multirow[t]{2}{*}{$v p_{t}^{b}$} & 0.59 & 0.30 & 0.03 & & 0.66 & 0.26 & 0.01 & & 0.59 & 0.26 & 0.01 & & 0.42 & 0.21 & 0.03 & & 0.33 & 0.17 & 0.03 & & 0.31 & 0.16 & 0.03 & \\
\hline & & 0.29 & 0.01 & & & 0.20 & 0.00 & & & 0.16 & 0.00 & & & 0.12 & 0.00 & & & 0.11 & 0.00 & & & 0.10 & 0.00 & \\
\hline \multicolumn{25}{|c|}{ Panel C: Investment-Grade Bond Returns } \\
\hline \multirow[t]{2}{*}{$v p_{t}$} & -0.08 & 0.04 & 0.01 & 0.01 & -0.06 & 0.03 & 0.03 & 0.02 & -0.03 & 0.02 & 0.02 & 0.01 & -0.04 & 0.02 & 0.00 & 0.04 & -0.03 & 0.01 & 0.00 & 0.04 & -0.03 & 0.01 & 0.01 & 0.04 \\
\hline & & 0.09 & 0.17 & & & 0.06 & 0.13 & & & 0.04 & 0.17 & & & 0.02 & 0.03 & & & 0.02 & 0.02 & & & 0.01 & 0.01 & \\
\hline \multirow[t]{2}{*}{$v p_{t}^{g}$} & -0.40 & 0.11 & 0.00 & 0.05 & -0.38 & 0.08 & 0.00 & 0.13 & -0.28 & 0.10 & 0.00 & 0.14 & -0.23 & 0.10 & 0.01 & 0.18 & -0.19 & 0.08 & 0.01 & 0.18 & -0.17 & 0.07 & 0.00 & 0.21 \\
\hline & & 0.21 & 0.01 & & & 0.17 & 0.00 & & & 0.13 & 0.01 & & & 0.09 & 0.00 & & & 0.08 & 0.00 & & & 0.07 & 0.00 & \\
\hline \multirow[t]{2}{*}{$v p_{t}^{b}$} & 0.28 & 0.12 & 0.01 & & 0.29 & 0.11 & 0.00 & & 0.23 & 0.13 & 0.04 & & 0.17 & 0.12 & 0.08 & & 0.14 & 0.10 & 0.09 & & 0.13 & 0.08 & 0.05 & \\
\hline & & 0.21 & 0.07 & & & 0.15 & 0.01 & & & 0.11 & 0.01 & & & 0.09 & 0.02 & & & 0.08 & 0.03 & & & 0.07 & 0.03 & \\
\hline
\end{tabular}

This table presents predictability regression evidence for equity returns (Panel A), high-yield bond returns (Panel B), and investment-grade bond returns (Panel C) from January 1996 to August 2014. Implied variance measures are computed using options in the moneyness range from 0.8 to 1.2 . The dependent variable is the annualized log excess return over the next $h$ months $(h=1,3,6,12,18,24)$. For each asset, the table shows the coefficient (Coef), the standard errors (SE), and the $p$-values for a univariate predictability regression with the variance premium $v p_{t}$, and a multivariate regression with the good and bad variance premia, $v p_{t}^{g}$ and $v p_{t}^{b}$, as predictor variables. For each coefficient, the first line reports the Newey-West standard error with three more lags than the forecast horizon $h$, and the corresponding $p$-value. The second line reports the standard error and the $p$-value from the bootstrap approach. The $p$-values are calculated for one-sided tests as described in Section 2.4. 
Table C.3: Predicting Excess Returns with Variance Premium Using Moneyness Range 0.9-1.1

\begin{tabular}{|c|c|c|c|c|c|c|c|c|c|c|c|c|c|c|c|c|c|c|c|c|c|c|c|c|}
\hline & \multicolumn{24}{|c|}{ Forecast Horizon $h$} \\
\hline & \multicolumn{4}{|c|}{1} & \multicolumn{4}{|c|}{3} & \multicolumn{4}{|c|}{6} & \multicolumn{4}{|c|}{12} & \multicolumn{4}{|c|}{18} & \multicolumn{4}{|c|}{24} \\
\hline & Coef & SE & $p$-val & $\bar{R}^{2}$ & Coef & $\mathrm{SE}$ & $p$-val & $\bar{R}^{2}$ & Coef & $\mathrm{SE}$ & $p$-val & $\bar{R}^{2}$ & Coef & $\mathrm{SE}$ & $p$-val & $\bar{R}^{2}$ & Coef & $\mathrm{SE}$ & $p$-val & $\bar{R}^{2}$ & Coef & $\mathrm{SE}$ & $p$-val & $\bar{R}^{2}$ \\
\hline \multicolumn{25}{|c|}{ Panel A: Equity Returns } \\
\hline \multirow[t]{2}{*}{$v p_{t}$} & 0.30 & 0.06 & 0.00 & 0.03 & 0.21 & 0.04 & 0.00 & 0.04 & 0.07 & 0.03 & 0.00 & 0.01 & 0.01 & 0.03 & 0.41 & 0.00 & -0.01 & 0.02 & 0.60 & 0.00 & -0.01 & 0.02 & 0.68 & 0.00 \\
\hline & & 0.20 & 0.08 & & & 0.13 & 0.07 & & & 0.10 & 0.22 & & & 0.06 & 0.44 & & & 0.04 & 0.54 & & & 0.04 & 0.58 & \\
\hline \multirow[t]{2}{*}{$v p_{t}^{g}$} & -0.04 & 0.63 & 0.47 & 0.03 & -0.35 & 0.55 & 0.26 & 0.05 & -0.53 & 0.33 & 0.06 & 0.02 & -0.71 & 0.19 & 0.00 & 0.05 & -0.60 & 0.17 & 0.00 & 0.05 & -0.58 & 0.22 & 0.00 & 0.06 \\
\hline & & 0.78 & 0.48 & & & 0.54 & 0.26 & & & 0.44 & 0.11 & & & 0.34 & 0.02 & & & 0.30 & 0.02 & & & 0.27 & 0.02 & \\
\hline \multirow[t]{2}{*}{$v p_{t}^{b}$} & 0.65 & 0.63 & 0.15 & & 0.80 & 0.58 & 0.08 & & 0.70 & 0.36 & 0.03 & & 0.75 & 0.20 & 0.00 & & 0.62 & 0.19 & 0.00 & & 0.59 & 0.23 & 0.00 & \\
\hline & & 0.81 & 0.21 & & & 0.48 & 0.04 & & & 0.38 & 0.03 & & & 0.32 & 0.01 & & & 0.29 & 0.02 & & & 0.27 & 0.01 & \\
\hline \multicolumn{25}{|c|}{ Panel B: High-Yield Bond Returns } \\
\hline \multirow[t]{2}{*}{$v p_{t}$} & 0.18 & 0.09 & 0.97 & 0.03 & -0.01 & 0.02 & 0.27 & 0.00 & -0.08 & 0.02 & 0.00 & 0.02 & -0.09 & 0.02 & 0.00 & 0.07 & -0.07 & 0.01 & 0.00 & 0.07 & -0.06 & 0.01 & 0.00 & 0.07 \\
\hline & & 0.10 & 0.94 & & & 0.07 & 0.45 & & & 0.05 & 0.05 & & & 0.03 & 0.00 & & & 0.02 & 0.00 & & & 0.02 & 0.00 & \\
\hline \multirow[t]{2}{*}{$v p_{t}^{g}$} & -0.67 & 0.57 & 0.12 & 0.06 & -0.75 & 0.35 & 0.02 & 0.04 & -0.81 & 0.32 & 0.01 & 0.10 & -0.69 & 0.24 & 0.00 & 0.17 & -0.53 & 0.21 & 0.00 & 0.16 & -0.51 & 0.21 & 0.01 & 0.19 \\
\hline & & 0.40 & 0.04 & & & 0.28 & 0.00 & & & 0.23 & 0.00 & & & 0.18 & 0.00 & & & 0.16 & 0.00 & & & 0.14 & 0.00 & \\
\hline \multirow[t]{2}{*}{$v p_{t}^{b}$} & 1.06 & 0.52 & 0.02 & & 0.75 & 0.36 & 0.02 & & 0.69 & 0.33 & 0.02 & & 0.53 & 0.24 & 0.01 & & 0.41 & 0.21 & 0.02 & & 0.40 & 0.21 & 0.03 & \\
\hline & & 0.42 & 0.01 & & & 0.25 & 0.00 & & & 0.20 & 0.00 & & & 0.17 & 0.00 & & & 0.15 & 0.00 & & & 0.14 & 0.00 & \\
\hline \multicolumn{25}{|c|}{ Panel C: Investment-Grade Bond Returns } \\
\hline \multirow[t]{2}{*}{$v p_{t}$} & -0.1 & 0.02 & 0.00 & 0.03 & -0.08 & 0.01 & 0.00 & 0.06 & -0.05 & 0.01 & 0.00 & 0.05 & -0.06 & 0.01 & 0.00 & 0.10 & -0.04 & 0.01 & 0.00 & 0.10 & -0.04 & 0.01 & 0.00 & 0.09 \\
\hline & & 0.08 & 0.07 & & & 0.05 & 0.03 & & & 0.04 & 0.06 & & & 0.02 & 0.00 & & & 0.02 & 0.00 & & & 0.01 & 0.00 & \\
\hline \multirow[t]{2}{*}{$v p_{t}^{g}$} & -0.50 & 0.28 & 0.04 & 0.04 & -0.50 & 0.15 & 0.00 & 0.11 & -0.37 & 0.16 & 0.01 & 0.11 & -0.28 & 0.15 & 0.04 & 0.15 & -0.22 & 0.13 & 0.05 & 0.15 & -0.23 & 0.12 & 0.03 & 0.18 \\
\hline & & 0.29 & 0.03 & & & 0.20 & 0.00 & & & 0.17 & 0.01 & & & 0.13 & 0.01 & & & 0.11 & 0.02 & & & 0.10 & 0.01 & \\
\hline \multirow[t]{2}{*}{$v p_{t}^{b}$} & 0.32 & 0.28 & 0.13 & & 0.36 & 0.16 & 0.01 & & 0.28 & 0.16 & 0.04 & & 0.18 & 0.15 & 0.12 & & 0.14 & 0.13 & 0.15 & & 0.16 & 0.12 & 0.09 & \\
\hline & & 0.31 & 0.13 & & & 0.18 & 0.02 & & & 0.15 & 0.02 & & & 0.12 & 0.06 & & & 0.11 & 0.09 & & & 0.10 & 0.05 & \\
\hline
\end{tabular}

This table presents predictability regression evidence for equity returns (Panel A), high-yield bond returns (Panel B), and investment-grade bond returns (Panel C) from January 1996 to August 2014. Implied variance measures are computed using options in the moneyness range from 0.9 to 1.1 . The dependent variable is the annualized log excess return over the next $h$ months $(h=1,3,6,12,18,24)$. For each asset, the table shows the coefficient (Coef), the standard errors (SE), and the $p$-values for a univariate predictability regression with the variance premium $v p_{t}$, and a multivariate regression with the good and bad variance premia, $v p_{t}^{g}$ and $v p_{t}^{b}$, as predictor variables. For each coefficient, the first line reports the Newey-West standard error with three more lags than the forecast horizon $h$, and the corresponding $p$-value. The second line reports the standard error and the $p$-value from the bootstrap approach. The $p$-values are calculated for one-sided tests as described in Section 2.4. 
Table C.4: Predicting Excess Returns with Variance Premium Using E-Mini Futures

\begin{tabular}{|c|c|c|c|c|c|c|c|c|c|c|c|c|c|c|c|c|c|c|c|c|c|c|c|c|}
\hline & \multicolumn{24}{|c|}{ Forecast Horizon $h$} \\
\hline & \multicolumn{4}{|c|}{1} & \multicolumn{4}{|c|}{3} & \multicolumn{4}{|c|}{6} & \multicolumn{4}{|c|}{12} & \multicolumn{4}{|c|}{18} & \multicolumn{4}{|c|}{24} \\
\hline & Coef & SE & $p$-val & $\bar{R}^{2}$ & Coef & $\mathrm{SE}$ & $p$-val & $\bar{R}^{2}$ & Coef & $\mathrm{SE}$ & $p$-val & $\bar{R}^{2}$ & Coef & $\mathrm{SE}$ & $p$-val & $\bar{R}^{2}$ & Coef & $\mathrm{SE}$ & $p$-val & $\bar{R}^{2}$ & Coef & $\mathrm{SE}$ & $p$-val & $\bar{R}^{2}$ \\
\hline \multicolumn{25}{|c|}{ Panel A: Equity Returns } \\
\hline \multirow[t]{2}{*}{$v p_{t}$} & 0.37 & 0.08 & 0.00 & 0.04 & 0.27 & 0.05 & 0.00 & 0.05 & 0.12 & 0.04 & 0.00 & 0.01 & 0.03 & 0.04 & 0.20 & 0.00 & 0.01 & 0.04 & 0.37 & 0.00 & 0.01 & 0.03 & 0.36 & 0.00 \\
\hline & & 0.24 & 0.08 & & & 0.16 & 0.05 & & & 0.11 & 0.14 & & & 0.06 & 0.30 & & & 0.05 & 0.39 & & & 0.04 & 0.37 & \\
\hline \multirow[t]{2}{*}{$v p_{t}^{g}$} & -0.06 & 0.49 & 0.45 & 0.04 & -0.30 & 0.41 & 0.24 & 0.07 & -0.53 & 0.22 & 0.01 & 0.07 & -0.64 & 0.15 & 0.00 & 0.11 & -0.58 & 0.12 & 0.00 & 0.12 & -0.59 & 0.15 & 0.00 & 0.16 \\
\hline & & 0.63 & 0.48 & & & 0.49 & 0.28 & & & 0.40 & 0.09 & & & 0.29 & 0.01 & & & 0.24 & 0.01 & & & 0.21 & 0.00 & \\
\hline \multirow[t]{2}{*}{$v p_{t}^{b}$} & 0.82 & 0.51 & 0.06 & & 0.86 & 0.45 & 0.03 & & 0.81 & 0.26 & 0.00 & & 0.75 & 0.16 & 0.00 & & 0.64 & 0.15 & 0.00 & & 0.65 & 0.17 & 0.00 & \\
\hline & & 0.65 & 0.10 & & & 0.43 & 0.02 & & & 0.34 & 0.01 & & & 0.27 & 0.00 & & & 0.24 & 0.00 & & & 0.22 & 0.00 & \\
\hline \multicolumn{25}{|c|}{ Panel B: High-Yield Bond Returns } \\
\hline \multirow[t]{2}{*}{$v p_{t}$} & 0.23 & 0.09 & 0.99 & 0.04 & 0.03 & 0.04 & 0.76 & 0.00 & -0.05 & 0.03 & 0.07 & 0.00 & -0.07 & 0.03 & 0.01 & 0.03 & -0.06 & 0.02 & 0.01 & 0.03 & -0.05 & 0.02 & 0.00 & 0.03 \\
\hline & & 0.13 & 0.95 & & & 0.08 & 0.65 & & & 0.06 & 0.20 & & & 0.03 & 0.01 & & & 0.03 & 0.01 & & & 0.02 & 0.00 & \\
\hline \multirow[t]{2}{*}{$v p_{t}^{g}$} & -0.51 & 0.41 & 0.11 & 0.08 & -0.70 & 0.23 & 0.00 & 0.08 & -0.80 & 0.25 & 0.00 & 0.16 & -0.66 & 0.22 & 0.00 & 0.22 & -0.52 & 0.17 & 0.00 & 0.21 & -0.47 & 0.16 & 0.00 & 0.24 \\
\hline & & 0.34 & 0.05 & & & 0.27 & 0.00 & & & 0.21 & 0.00 & & & 0.15 & 0.00 & & & 0.13 & 0.00 & & & 0.11 & 0.00 & \\
\hline \multirow[t]{2}{*}{$v p_{t}^{b}$} & 1.02 & 0.37 & 0.00 & & 0.80 & 0.28 & 0.00 & & 0.76 & 0.27 & 0.00 & & 0.55 & 0.21 & 0.00 & & 0.43 & 0.17 & 0.01 & & 0.40 & 0.16 & 0.01 & \\
\hline & & 0.35 & 0.00 & & & 0.23 & 0.00 & & & 0.18 & 0.00 & & & 0.14 & 0.00 & & & 0.13 & 0.00 & & & 0.12 & 0.00 & \\
\hline \multicolumn{25}{|c|}{ Panel C: Investment-Grade Bond Returns } \\
\hline \multirow[t]{2}{*}{$v p_{t}$} & -0.10 & 0.03 & 0.00 & 0.02 & -0.08 & 0.03 & 0.00 & 0.04 & -0.04 & 0.01 & 0.00 & 0.02 & -0.05 & 0.02 & 0.00 & 0.05 & -0.04 & 0.01 & 0.00 & 0.05 & -0.03 & 0.01 & 0.00 & 0.05 \\
\hline & & 0.09 & 0.10 & & & 0.06 & 0.07 & & & 0.04 & 0.12 & & & 0.02 & 0.01 & & & 0.02 & 0.01 & & & 0.01 & 0.01 & \\
\hline \multirow[t]{2}{*}{$v p_{t}^{g}$} & -0.46 & 0.18 & 0.01 & 0.05 & -0.44 & 0.12 & 0.00 & 0.12 & -0.35 & 0.13 & 0.00 & 0.13 & -0.28 & 0.13 & 0.02 & 0.17 & -0.23 & 0.11 & 0.02 & 0.17 & -0.21 & 0.09 & 0.01 & 0.20 \\
\hline & & 0.23 & 0.01 & & & 0.18 & 0.00 & & & 0.15 & 0.00 & & & 0.11 & 0.00 & & & 0.09 & 0.00 & & & 0.08 & 0.00 & \\
\hline \multirow[t]{2}{*}{$v p_{t}^{b}$} & 0.28 & 0.18 & 0.06 & & 0.31 & 0.13 & 0.01 & & 0.28 & 0.14 & 0.02 & & 0.20 & 0.13 & 0.06 & & 0.17 & 0.11 & 0.06 & & 0.16 & 0.09 & 0.04 & \\
\hline & & 0.24 & 0.10 & & & 0.16 & 0.01 & & & 0.13 & 0.01 & & & 0.10 & 0.02 & & & 0.09 & 0.02 & & & 0.08 & 0.02 & \\
\hline
\end{tabular}

This table presents predictability regression evidence for equity returns (Panel A), high-yield bond returns (Panel B), and investment-grade bond returns (Panel C) from October 1997 to August 2014. Realized variance measures are computed using 5-minute frequency data for S\&P 500 E-Mini futures prices. The dependent variable is the annualized log excess return over the next $h$ months $(h=1,3,6,12,18,24)$. For each asset, the table shows the coefficient (Coef), the standard errors (SE), and the $p$-values for a univariate predictability regression with the variance premium $v p_{t}$, and a multivariate regression with the good and bad variance premia, $v p_{t}^{g}$ and $v p_{t}^{b}$, as predictor variables. For each coefficient, the first line reports the Newey-West standard error with three more lags than the forecast horizon $h$, and the corresponding $p$-value. The second line reports the standard error and the $p$-value from the bootstrap approach. The $p$-values are calculated for one-sided tests as described in Section 2.4 . 
Table C.5: Predicting Excess Returns with Variance Premium Using Expected Variance

\begin{tabular}{|c|c|c|c|c|c|c|c|c|c|c|c|c|c|c|c|c|c|c|c|c|c|c|c|c|}
\hline & \multicolumn{24}{|c|}{ Forecast Horizon $h$} \\
\hline & \multicolumn{4}{|c|}{1} & \multicolumn{4}{|c|}{3} & \multicolumn{4}{|c|}{6} & \multicolumn{4}{|c|}{12} & \multicolumn{4}{|c|}{18} & \multicolumn{4}{|c|}{24} \\
\hline & Coef & $\mathrm{SE}$ & $p$-val & $\bar{R}^{2}$ & Coef & $\mathrm{SE}$ & $p$-val & $\bar{R}^{2}$ & Coef & $\mathrm{SE}$ & $p$-val & $\bar{R}^{2}$ & Coef & $\mathrm{SE}$ & $p$-val & $\bar{R}^{2}$ & Coef & $\mathrm{SE}$ & $p$-val & $\bar{R}^{2}$ & Coef & $\mathrm{SE}$ & $p$-val & $\bar{R}^{2}$ \\
\hline \multicolumn{25}{|c|}{ Panel A: Equity Returns } \\
\hline \multirow[t]{2}{*}{$v p_{t}$} & 0.42 & 0.15 & 0.00 & 0.08 & 0.25 & 0.04 & 0.00 & 0.07 & 0.20 & 0.03 & 0.00 & 0.08 & 0.06 & 0.03 & 0.01 & 0.01 & 0.03 & 0.03 & 0.11 & 0.00 & 0.03 & 0.02 & 0.06 & 0.00 \\
\hline & & 0.16 & 0.01 & & & 0.13 & 0.04 & & & 0.08 & 0.01 & & & 0.05 & 0.11 & & & 0.04 & 0.20 & & & 0.03 & 0.14 & \\
\hline \multirow[t]{2}{*}{$v p_{t}^{g}$} & -0.57 & 0.63 & 0.18 & 0.10 & -0.45 & 0.46 & 0.16 & 0.10 & -0.48 & 0.21 & 0.01 & 0.14 & -0.48 & 0.17 & 0.00 & 0.08 & -0.48 & 0.14 & 0.00 & 0.09 & -0.46 & 0.15 & 0.00 & 0.11 \\
\hline & & 0.68 & 0.21 & & & 0.52 & 0.20 & & & 0.42 & 0.12 & & & 0.30 & 0.05 & & & 0.25 & 0.03 & & & 0.22 & 0.02 & \\
\hline \multirow[t]{2}{*}{$v p_{t}^{b}$} & 1.35 & 0.61 & 0.01 & & 0.91 & 0.40 & 0.01 & & 0.84 & 0.18 & 0.00 & & 0.58 & 0.16 & 0.00 & & 0.51 & 0.14 & 0.00 & & 0.50 & 0.15 & 0.00 & \\
\hline & & 0.61 & 0.01 & & & 0.42 & 0.01 & & & 0.33 & 0.00 & & & 0.24 & 0.01 & & & 0.21 & 0.01 & & & 0.19 & 0.00 & \\
\hline \multicolumn{25}{|c|}{ Panel B: High-Yield Bond Returns } \\
\hline \multirow[t]{2}{*}{$v p_{t}$} & 0.41 & 0.07 & 1.00 & 0.23 & 0.17 & 0.03 & 1.00 & 0.08 & 0.08 & 0.02 & 1.00 & 0.03 & -0.01 & 0.02 & 0.25 & 0.00 & -0.02 & 0.01 & 0.10 & 0.00 & -0.02 & 0.01 & 0.07 & 0.00 \\
\hline & & 0.08 & 1.00 & & & 0.07 & 0.99 & & & 0.04 & 0.97 & & & 0.03 & 0.34 & & & 0.02 & 0.16 & & & 0.02 & 0.12 & \\
\hline \multirow[t]{2}{*}{$v p_{t}^{g}$} & 0.14 & 0.39 & 0.64 & 0.23 & -0.54 & 0.25 & 0.01 & 0.17 & -0.63 & 0.23 & 0.00 & 0.17 & -0.56 & 0.21 & 0.00 & 0.17 & -0.48 & 0.17 & 0.00 & 0.19 & -0.44 & 0.15 & 0.00 & 0.21 \\
\hline & & 0.35 & 0.67 & & & 0.27 & 0.01 & & & 0.22 & 0.00 & & & 0.16 & 0.00 & & & 0.13 & 0.00 & & & 0.11 & 0.00 & \\
\hline \multirow[t]{2}{*}{$v p_{t}^{b}$} & 0.67 & 0.29 & 0.01 & & 0.85 & 0.20 & 0.00 & & 0.76 & 0.23 & 0.00 & & 0.51 & 0.21 & 0.01 & & 0.42 & 0.17 & 0.01 & & 0.38 & 0.16 & 0.01 & \\
\hline & & 0.31 & 0.01 & & & 0.22 & 0.00 & & & 0.17 & 0.00 & & & 0.13 & 0.00 & & & 0.11 & 0.00 & & & 0.10 & 0.00 & \\
\hline \multicolumn{25}{|c|}{ Panel C: Investment-Grade Bond Returns } \\
\hline \multirow[t]{2}{*}{$v p_{t}$} & 0.13 & 0.05 & 1.00 & 0.06 & -0.03 & 0.01 & 0.02 & 0.00 & 0.00 & 0.01 & 0.53 & 0.00 & -0.03 & 0.01 & 0.00 & 0.03 & -0.02 & 0.01 & 0.00 & 0.02 & -0.02 & 0.01 & 0.00 & 0.03 \\
\hline & & 0.06 & 0.97 & & & 0.05 & 0.27 & & & 0.03 & 0.51 & & & 0.02 & 0.05 & & & 0.01 & 0.05 & & & 0.01 & 0.02 & \\
\hline \multirow[t]{2}{*}{$v p_{t}^{g}$} & -0.24 & 0.17 & 0.08 & 0.09 & -0.44 & 0.12 & 0.00 & 0.10 & -0.29 & 0.13 & 0.01 & 0.10 & -0.27 & 0.12 & 0.02 & 0.15 & -0.22 & 0.10 & 0.02 & 0.15 & -0.21 & 0.09 & 0.01 & 0.19 \\
\hline & & 0.25 & 0.13 & & & 0.20 & 0.01 & & & 0.16 & 0.02 & & & 0.11 & 0.00 & & & 0.10 & 0.01 & & & 0.08 & 0.00 & \\
\hline \multirow[t]{2}{*}{$v p_{t}^{b}$} & 0.48 & 0.17 & 0.00 & & 0.36 & 0.11 & 0.00 & & 0.27 & 0.13 & 0.02 & & 0.20 & 0.12 & 0.05 & & 0.17 & 0.11 & 0.06 & & 0.15 & 0.09 & 0.04 & \\
\hline & & 0.23 & 0.01 & & & 0.16 & 0.01 & & & 0.12 & 0.01 & & & 0.09 & 0.01 & & & 0.08 & 0.01 & & & 0.07 & 0.01 & \\
\hline
\end{tabular}

This table presents predictability regression evidence for equity returns (Panel A), high-yield bond returns (Panel B), and investment-grade bond returns (Panel C) from January 1996 to August 2014. The variance premia are computed using predicted values from the 12-month rolling regressions of the corresponding realized variance measure on lagged good and bad implied and realized variances. The dependent variable is the annualized log excess return over the next $h$ months $(h=1,3,6,12,18,24)$. For each asset, the table shows the coefficient (Coef), the standard errors (SE), and the $p$-values for a univariate predictability regression with the variance premium $v p_{t}$, and a multivariate regression with the good and bad variance premia, $v p_{t}^{g}$ and $v p_{t}^{b}$, as predictor variables. For each coefficient, the first line reports the Newey-West standard error with three more lags than the forecast horizon $h$, and the corresponding $p$-value. The second line reports the standard error and the $p$-value from the bootstrap approach. The $p$-values are calculated for one-sided tests as described in Section 2.4 . 
Table C.6: Predicting Excess Returns with Variance Premium and Implied Skewness

\begin{tabular}{|c|c|c|c|c|c|c|c|c|c|c|c|c|c|c|c|c|c|c|c|c|c|c|c|c|}
\hline & \multicolumn{24}{|c|}{ Forecast Horizon $h$} \\
\hline & \multicolumn{4}{|c|}{1} & \multicolumn{4}{|c|}{3} & \multicolumn{4}{|c|}{6} & \multicolumn{4}{|c|}{12} & \multicolumn{4}{|c|}{18} & \multicolumn{4}{|c|}{24} \\
\hline & Coef & $\mathrm{SE}$ & $p$-val & $\bar{R}^{2}$ & Coef & $\mathrm{SE}$ & $p$-val & $\bar{R}^{2}$ & Coef & $\mathrm{SE}$ & $p$-val & $\bar{R}^{2}$ & Coef & $\mathrm{SE}$ & $p$-val & $\bar{R}^{2}$ & Coef & $\mathrm{SE}$ & $p$-val & $\bar{R}^{2}$ & Coef & $\mathrm{SE}$ & $p$-val & $\bar{R}^{2}$ \\
\hline \multicolumn{25}{|c|}{ Panel A: Equity Returns } \\
\hline \multirow[t]{2}{*}{$v p_{t}^{g}$} & -0.02 & 0.44 & 0.49 & 0.03 & -0.38 & 0.37 & 0.15 & 0.07 & -0.60 & 0.25 & 0.01 & 0.06 & -0.71 & 0.20 & 0.00 & 0.10 & -0.57 & 0.17 & 0.00 & 0.08 & -0.53 & 0.19 & 0.00 & 0.10 \\
\hline & & 0.64 & 0.51 & & & 0.49 & 0.22 & & & 0.39 & 0.06 & & & 0.29 & 0.01 & & & 0.26 & 0.01 & & & 0.23 & 0.01 & \\
\hline \multirow[t]{2}{*}{$v p_{t}^{b}$} & 0.74 & 0.48 & 0.06 & & 0.94 & 0.42 & 0.01 & & 0.87 & 0.28 & 0.00 & & 0.81 & 0.20 & 0.00 & & 0.63 & 0.18 & 0.00 & & 0.59 & 0.21 & 0.00 & \\
\hline & & 0.67 & 0.13 & & & 0.45 & 0.02 & & & 0.36 & 0.01 & & & 0.30 & 0.00 & & & 0.27 & 0.01 & & & 0.25 & 0.01 & \\
\hline \multirow[t]{2}{*}{ skew $_{t}$} & -2.79 & 8.27 & 0.37 & & -5.25 & 7.95 & 0.25 & & -6.68 & 7.09 & 0.17 & & -9.91 & 5.91 & 0.05 & & -5.74 & 6.20 & 0.18 & & -3.24 & 5.50 & 0.28 & \\
\hline & & 8.68 & 0.37 & & & 7.40 & 0.23 & & & 7.25 & 0.17 & & & 6.66 & 0.07 & & & 5.99 & 0.17 & & & 5.50 & 0.28 & \\
\hline \multicolumn{25}{|c|}{ Panel B: High-Yield Bond Returns } \\
\hline \multirow[t]{2}{*}{$v p_{t}^{g}$} & -0.35 & 0.36 & 0.17 & 0.06 & -0.63 & 0.22 & 0.00 & 0.08 & -0.69 & 0.22 & 0.00 & 0.14 & -0.57 & 0.18 & 0.00 & 0.21 & -0.41 & 0.14 & 0.00 & 0.23 & -0.38 & 0.14 & 0.00 & 0.27 \\
\hline & & 0.33 & 0.13 & & & 0.25 & 0.00 & & & 0.20 & 0.00 & & & 0.15 & 0.00 & & & 0.14 & 0.00 & & & 0.12 & 0.00 & \\
\hline \multirow[t]{2}{*}{$v p_{t}^{b}$} & 0.85 & 0.35 & 0.01 & & 0.75 & 0.26 & 0.00 & & 0.67 & 0.26 & 0.00 & & 0.48 & 0.20 & 0.01 & & 0.35 & 0.16 & 0.02 & & 0.33 & 0.16 & 0.02 & \\
\hline & & 0.35 & 0.01 & & & 0.23 & 0.00 & & & 0.19 & 0.00 & & & 0.16 & 0.00 & & & 0.14 & 0.01 & & & 0.13 & 0.01 & \\
\hline skewt $_{t}$ & & 4.46 & 0.55 & & & 3.79 & 0.77 & & & 3.71 & 0.79 & & & 3.42 & 0.77 & & & 3.07 & 0.94 & & & 2.81 & 0.95 & \\
\hline \multicolumn{25}{|c|}{ Panel C: Investment-Grade Bond Returns } \\
\hline \multirow[t]{2}{*}{$v p_{t}^{g}$} & -0.42 & 0.19 & 0.01 & 0.04 & -0.43 & 0.11 & 0.00 & 0.12 & -0.31 & 0.12 & 0.00 & 0.14 & -0.22 & 0.11 & 0.02 & 0.22 & -0.15 & 0.09 & 0.04 & 0.27 & -0.15 & 0.08 & 0.02 & 0.31 \\
\hline & & 0.25 & 0.03 & & & 0.18 & 0.00 & & & 0.15 & 0.01 & & & 0.11 & 0.02 & & & 0.10 & 0.05 & & & 0.09 & 0.04 & \\
\hline \multirow[t]{2}{*}{$v p_{t}^{b}$} & 0.28 & 0.19 & 0.08 & & 0.33 & 0.13 & 0.00 & & 0.26 & 0.13 & 0.03 & & 0.15 & 0.12 & 0.10 & & 0.10 & 0.10 & 0.15 & & 0.12 & 0.09 & 0.09 & \\
\hline & & 0.26 & 0.12 & & & 0.17 & 0.02 & & & 0.13 & 0.02 & & & 0.11 & 0.08 & & & 0.10 & 0.14 & & & 0.09 & 0.10 & \\
\hline \multirow[t]{2}{*}{ skew $_{t}$} & 1.45 & 3.64 & 0.65 & & 0.87 & 2.76 & 0.62 & & 1.75 & 2.14 & 0.79 & & 3.21 & 1.74 & 0.97 & & 4.18 & 1.70 & 0.99 & & 3.49 & 1.44 & 0.99 & \\
\hline & & 3.25 & 0.71 & & & 2.76 & 0.67 & & & 2.71 & 0.78 & & & 2.49 & 0.92 & & & 2.23 & 0.98 & & & 2.05 & 0.96 & \\
\hline
\end{tabular}

This table presents predictability regression evidence for equity returns (Panel A), high-yield bond returns (Panel B), and investment-grade bond returns (Panel C) from January 1996 to August 2014. The dependent variable is the annualized $\log$ excess return over the next $h$ months $(h=1,3,6,12,18,24)$. For each asset, the table shows the coefficient (Coef), the standard errors (SE), and $p$-values for a multivariate regression with the good and bad variance premia, $v p_{t}^{g}$ and $v p_{t}^{b}$, and risk-neutral skewness, $s k e w$, as predictor variables. For each coefficient, the first line reports the Newey-West standard error with three more lags than the forecast horizon $h$, and the corresponding $p$-value. The second line reports the standard error and the $p$-value from the bootstrap approach. The $p$-values are calculated for one-sided tests as described in Section 2.4 . 
Table C.7: Predicting Excess Returns with Variance Premium and Skewness Risk Premium

\begin{tabular}{|c|c|c|c|c|c|c|c|c|c|c|c|c|c|c|c|c|c|c|c|c|c|c|c|c|}
\hline & \multicolumn{24}{|c|}{ Forecast Horizon $h$} \\
\hline & \multicolumn{4}{|c|}{1} & \multicolumn{4}{|c|}{3} & \multicolumn{4}{|c|}{6} & \multicolumn{4}{|c|}{12} & \multicolumn{4}{|c|}{18} & \multicolumn{4}{|c|}{24} \\
\hline & Coef & $\mathrm{SE}$ & $p$-val & $\bar{R}^{2}$ & Coef & $\mathrm{SE}$ & $p$-val & $\bar{R}^{2}$ & Coef & $\mathrm{SE}$ & $p$-val & $\bar{R}^{2}$ & Coef & $\mathrm{SE}$ & $p$-val & $\bar{R}^{2}$ & Coef & $\mathrm{SE}$ & $p$-val & $\bar{R}^{2}$ & Coef & $\mathrm{SE}$ & $p$-val & $\bar{R}^{2}$ \\
\hline \multicolumn{25}{|c|}{ Panel A: Equity Returns } \\
\hline \multirow[t]{2}{*}{$v p_{t}^{g}$} & -0.01 & 0.43 & 0.49 & 0.03 & -0.31 & 0.36 & 0.19 & 0.07 & -0.49 & 0.22 & 0.01 & 0.05 & -0.56 & 0.17 & 0.00 & 0.07 & -0.50 & 0.15 & 0.00 & 0.08 & -0.50 & 0.17 & 0.00 & 0.10 \\
\hline & & 0.62 & 0.50 & & & 0.49 & 0.26 & & & 0.40 & 0.11 & & & 0.30 & 0.03 & & & 0.26 & 0.02 & & & 0.23 & 0.01 & \\
\hline \multirow[t]{2}{*}{$v p_{t}^{b}$} & 0.73 & 0.49 & 0.07 & & 0.88 & 0.42 & 0.02 & & 0.76 & 0.27 & 0.00 & & 0.66 & 0.19 & 0.00 & & 0.56 & 0.17 & 0.00 & & 0.56 & 0.19 & 0.00 & \\
\hline & & 0.65 & 0.13 & & & 0.44 & 0.02 & & & 0.35 & 0.01 & & & 0.29 & 0.01 & & & 0.26 & 0.01 & & & 0.24 & 0.01 & \\
\hline \multirow[t]{2}{*}{$\operatorname{srp}_{t}$} & -2.46 & 1.96 & 0.10 & & -2.08 & 1.71 & 0.11 & & -1.09 & 1.70 & 0.26 & & -1.86 & 1.45 & 0.10 & & -1.69 & 1.15 & 0.07 & & -1.54 & 0.95 & 0.05 & \\
\hline & & 3.00 & 0.21 & & & 2.05 & 0.15 & & & 1.68 & 0.25 & & & 1.48 & 0.10 & & & 1.28 & 0.09 & & & 1.71 & 0.18 & \\
\hline \multicolumn{25}{|c|}{ Panel B: High-Yield Bond Returns } \\
\hline \multirow[t]{2}{*}{$v p_{t}^{g}$} & -0.37 & 0.39 & 0.17 & 0.06 & -0.69 & 0.24 & 0.00 & 0.07 & -0.73 & 0.24 & 0.00 & 0.14 & -0.61 & 0.20 & 0.00 & 0.20 & -0.49 & 0.16 & 0.00 & 0.20 & -0.45 & 0.15 & 0.00 & 0.23 \\
\hline & & 0.33 & 0.11 & & & 0.26 & 0.00 & & & 0.21 & 0.00 & & & 0.16 & 0.00 & & & 0.13 & 0.00 & & & 0.12 & 0.00 & \\
\hline \multirow[t]{2}{*}{$v p_{t}^{b}$} & 0.86 & 0.37 & 0.01 & & 0.80 & 0.30 & 0.00 & & 0.71 & 0.28 & 0.01 & & 0.52 & 0.22 & 0.01 & & 0.42 & 0.18 & 0.01 & & 0.40 & 0.17 & 0.01 & \\
\hline & & 0.34 & 0.01 & & & 0.23 & 0.00 & & & 0.18 & 0.00 & & & 0.15 & 0.00 & & & 0.14 & 0.00 & & & 0.13 & 0.00 & \\
\hline \multirow[t]{3}{*}{$s r p_{t}$} & -0.39 & 1.25 & 0.38 & & -0.16 & 1.29 & 0.45 & & 0.77 & 0.99 & 0.78 & & 0.30 & 0.83 & 0.64 & & 0.39 & 0.74 & 0.70 & & 0.29 & 0.66 & 0.67 & \\
\hline & & 1.57 & 0.43 & & & 1.07 & 0.46 & & & 0.88 & 0.82 & & & 0.77 & 0.66 & & & 0.67 & 0.73 & & & 0.89 & 0.64 & \\
\hline & & 4.46 & 0.55 & & & 3.79 & 0.77 & & & 3.71 & 0.79 & & & 3.42 & 0.77 & & & 3.07 & 0.94 & & & 2.81 & 0.95 & \\
\hline \multicolumn{25}{|c|}{ Panel C: Investment-Grade Bond Returns } \\
\hline \multirow[t]{2}{*}{$v p_{t}^{g}$} & -0.44 & 0.18 & 0.01 & 0.04 & -0.45 & 0.11 & 0.00 & 0.12 & -0.33 & 0.12 & 0.00 & 0.13 & -0.27 & 0.12 & 0.01 & 0.18 & -0.22 & 0.10 & 0.01 & 0.18 & -0.21 & 0.08 & 0.01 & 0.22 \\
\hline & & 0.24 & 0.02 & & & 0.18 & 0.00 & & & 0.15 & 0.01 & & & 0.11 & 0.00 & & & 0.10 & 0.01 & & & 0.09 & 0.01 & \\
\hline \multirow[t]{2}{*}{$v p_{t}^{b}$} & 0.30 & 0.18 & 0.05 & & 0.35 & 0.13 & 0.00 & & 0.28 & 0.14 & 0.02 & & 0.20 & 0.13 & 0.06 & & 0.17 & 0.11 & 0.07 & & 0.17 & 0.09 & 0.04 & \\
\hline & & 0.25 & 0.09 & & & 0.16 & 0.01 & & & 0.13 & 0.01 & & & 0.11 & 0.03 & & & 0.10 & 0.04 & & & 0.09 & 0.03 & \\
\hline \multirow[t]{2}{*}{$\operatorname{srp}_{t}$} & 0.44 & 0.79 & 0.71 & & -0.09 & 0.62 & 0.44 & & 0.56 & 0.51 & 0.86 & & 0.45 & 0.49 & 0.82 & & 0.42 & 0.50 & 0.80 & & 0.25 & 0.44 & 0.72 & \\
\hline & & 1.12 & 0.68 & & & 0.77 & 0.49 & & & 0.63 & 0.84 & & & 0.55 & 0.82 & & & 0.48 & 0.84 & & & 0.64 & 0.68 & \\
\hline
\end{tabular}

This table presents predictability regression evidence for equity returns (Panel A), high-yield bond returns (Panel B), and investment-grade bond returns (Panel C) from January 1996 to August 2014. The dependent variable is the annualized log excess return over the next $h$ months $(h=1,3,6,12,18,24)$. For each asset, the table shows the coefficient (Coef), the standard errors (SE), and $p$-values for a multivariate regression with the good and bad variance premia, $v p_{t}^{g}$ and $v p_{t}^{b}$, and the difference between risk-neutral and realized skewness measures, srp, as predictor variables. For each coefficient, the first line reports the Newey-West standard error with three more lags than the forecast horizon $h$, and the corresponding $p$-value. The second line reports the standard error and the $p$-value from the bootstrap approach. The $p$-values are calculated for one-sided tests as described in Section 2.4. 


\section{References}

Abel, Andrew B, 1999, Risk premia and term premia in general equilibrium, Journal of Monetary Economics 43, 3-33.

Ait-Sahalia, Yacine, Yubo Wang, and Francis Yared, 2001, Do option markets correctly price the probabilities of movement of the underlying asset?, Journal of Econometrics 102, 67-110.

Amaya, Diego, Peter Christoffersen, Kris Jacobs, and Aurelio Vasquez, 2013, Does realized skewness predict the cross-section of equity returns?, Working Paper.

Andersen, Torben, Nicola Fusari, and Viktor Todorov, Forthcoming, The Risk Premia Embedded in Option Panels, Journal of Financial Economics.

Andersen, Torben G, Luca Benzoni, and Jesper Lund, 2002, An empirical investigation of continuous-time equity return models, The Journal of Finance 57, 1239-1284.

Ang, Andrew, Joseph Chen, and Yuhang Xing, 2006, Downside risk, Review of Financial Studies 19, 1191-1239.

Bakshi, Gurdip, Charles Cao, and Zhiwu Chen, 1997, Empirical performance of alternative option pricing models, The Journal of Finance 52, 2003-2049.

Bakshi, Gurdip, and Nikunj Kapadia, 2003, Delta-hedged gains and the negative market volatility risk premium, Review of Financial Studies 16, 527-566.

Bakshi, Gurdip, Nikunj Kapadia, and Dilip Madan, 2003, Stock return characteristics, skew laws, and the differential pricing of individual equity options, Review of Financial Studies 16, 101-143.

Bakshi, Gurdip, and Dilip Madan, 2000, Spanning and derivative-security valuation, Journal of Financial Economics 55, 205-238.

Bali, Turan G, and Hao Zhou, 2014, Risk, uncertainty, and expected returns, Working paper. 
Bansal, Ravi, and Amir Yaron, 2004, Risks for the Long Run: A Potential Resolution of Asset Pricing Puzzles, Journal of Finance 54, 1481-1509.

Barndorff-Nielsen, Ole E, Silja Kinnebrock, and Neil Shephard, 2010, Measuring downside riskrealised semivariance, Working Paper.

Barndorff-Nielsen, Ole E, and Neil Shephard, 2004, Power and bipower variation with stochastic volatility and jumps, Journal of Financial Econometrics 2, 1-37.

Barro, Robert, 2006, Rare Disasters and Asset Markets in the Twentieth Century, Quarterly Journal of Economics 121.

Bates, David S, 2000, Post-'87 crash fears in the S\&P 500 futures option market, Journal of Econometrics 94, 181-238.

Bekaert, Geert, and Eric Engstrom, 2009, Asset return dynamics under bad environment good environment fundamentals, Working Paper.

Bekaert, Geert, Eric Engstrom, and Andrey Ermolov, 2015, Bad environments, good environments: A non-gaussian asymmetric volatility model, Journal of Econometrics 186, 258-275.

Bollerslev, Tim, James Marrone, Lai Xu, and Hao Zhou, 2014, Stock return predictability and variance risk premia: statistical inference and international evidence, Journal of Financial and Quantitative Analysis 49, 633-661.

Bollerslev, Tim, George Tauchen, and Hao Zhou, 2009, Expected stock returns and variance risk premia, Review of Financial Studies 22, 4463-4492.

Bollerslev, Tim, Viktor Todorov, and Lai Xu, Forthcoming, Tail risk premia and return predictability, Journal of Financial Economics.

Breeden, Douglas T, and Robert H Litzenberger, 1978, Prices of State-contingent Claims Implicit in Option Prices, Journal of Business 51, 621-651. 
Broadie, Mark, Mikhail Chernov, and Michael Johannes, 2007, Model specification and risk premia: Evidence from futures options, The Journal of Finance 62, 1453-1490.

Campbell, John Y., and John H. Cochrane, 1999, By force of habit: A consumption-based explanation of aggregate stock market behavior, Journal of Political Economy 107, 205-251.

Campbell, John Y, and Ludger Hentschel, 1992, No news is good news: An asymmetric model of changing volatility in stock returns, Journal of Financial Economics 31, 281-318.

Campbell, John Y, and Robert J Shiller, 1988, The dividend-price ratio and expectations of future dividends and discount factors, Review of Financial Studies 1, 195-228.

Carr, Peter, and Liuren Wu, 2009, Variance risk premiums, Review of Financial Studies 22, 13111341.

Chang, Bo Young, Peter Christoffersen, and Kris Jacobs, 2013, Market skewness risk and the cross section of stock returns, Journal of Financial Economics 107, 46-68.

Cochrane, John H, 2008, The dog that did not bark: A defense of return predictability, Review of Financial Studies 21, 1533-1575.

Colacito, Riccardo, Eric Ghysels, and Jinghan Meng, 2013, Skewness in expected macro fundamentals and the predictability of equity returns: Evidence and theory, Working Paper.

Conrad, Jennifer, Robert F Dittmar, and Eric Ghysels, 2013, Ex ante skewness and expected stock returns, The Journal of Finance 68, 85-124.

Drechsler, Itamar, and Amir Yaron, 2011, What's vol got to do with it, Review of Financial Studies 24, 1-45.

Duffie, Darrell, and Larry G. Epstein, 1992, Stochastic differential utility, Econometrica 60, 353394.

Duffie, Darrell, Jun Pan, and Kenneth Singleton, 2000, Transform analysis and asset pricing for affine jump-diffusions, Econometrica 68, 1343-1376. 
Duffie, Darrell, and Costis Skiadas, 1994, Continuous-time security pricing: A utility gradient approach, Journal of Mathematical Economics 23, 107-131.

Epstein, Larry, and Stan Zin, 1989, Substitution, risk aversion and the temporal behavior of consumption and asset returns: A theoretical framework, Econometrica 57, 937-969.

Eraker, Bjørn, 2004, Do stock prices and volatility jump? Reconciling evidence from spot and option prices, The Journal of Finance 59, 1367-1404.

Eraker, Bjørn, 2008, The volatility premium, Working paper.

Eraker, Bjørn, Michael Johannes, and Nicholas Polson, 2003, The impact of jumps in volatility and returns, The Journal of Finance 58, 1269-1300.

Fama, Eugene F, and Kenneth R French, 1989, Business conditions and expected returns on stocks and bonds, Journal of Financial Economics 25, 23-49.

Feunou, Bruno, Mohammad R Jahan-Parvar, and Cedric Okou, 2014, Downside Variance Risk Premium, Working Paper.

Feunou, Bruno, Mohammad R Jahan-Parvar, and Roméo Tédongap, 2013, Modeling market downside volatility, Review of Finance 17, 443-481.

French, Kenneth R, G William Schwert, and Robert F Stambaugh, 1987, Expected stock returns and volatility, Journal of Financial Economics 19, 3-29.

Glosten, Lawrence R, Ravi Jagannathan, and David E Runkle, 1993, On the relation between the expected value and the volatility of the nominal excess return on stocks, The Journal of Finance 48, 1779-1801.

Guo, Hui, Kent Wang, and Hao Zhou, 2014, Good Jumps, Bad Jumps, and Conditional Equity Premium, Working paper.

Han, Bing, and Yi Zhou, 2012, Variance risk premium and cross-section of stock returns, Working paper. 
Hodrick, Robert J, 1992, Dividend yields and expected stock returns: Alternative procedures for inference and measurement, Review of Financial Studies 5, 357-386.

Huber, Peter J, 1964, Robust estimation of a location parameter, The Annals of Mathematical Statistics 35, 73-101.

Keim, Donald B, and Robert F Stambaugh, 1986, Predicting returns in the stock and bond markets, Journal of Financial Economics 17, 357-390.

Kozhan, Roman, Anthony Neuberger, and Paul Schneider, 2013, The skew risk premium in the equity index market, Review of Financial Studies 26, 2174-2203.

Lettau, Martin, Matteo Maggiori, and Michael Weber, 2014, Conditional risk premia in currency markets and other asset classes, Journal of Financial Economics 114, 197-225.

Li, Junye, and Gabriele Zinna, 2014, The Variance Risk Premium: Components, Term Structures, and Stock Return Predictability, Working Paper.

Liu, Lily Y, Andrew J Patton, and Kevin Sheppard, 2012, Does anything beat 5-minute RV? A comparison of realized measures across multiple asset classes, Working Paper.

Londono, Juan M, and Hao Zhou, 2014, Variance risk premiums and the forward premium puzzle, Working Paper.

Longstaff, Francis A, and Monika Piazzesi, 2004, Corporate earnings and the equity premium, Journal of Financial Economics 74, 401-421.

MacKinnon, James G, 2009, Bootstrap hypothesis testing, Handbook of Computational Econometrics pp. 183-213.

Nowotny, Michael C, 2011, Disaster begets crisis: The role of contagion in financial markets, Working Paper.

Pan, Jun, 2002, The jump-risk premia implicit in options: Evidence from an integrated time-series study, Journal of Financial Economics 63, 3-50. 
Patton, Andrew J, and Kevin Sheppard, 2013, Good volatility, bad volatility: Signed jumps and the persistence of volatility, Working Paper.

Pettenuzzo, Davide, Allan Timmermann, and Rossen Valkanov, 2014, Forecasting stock returns under economic constraints, Journal of Financial Economics 114, 517-553.

Prokopczuk, Marcel, and Chardin Wese Simen, 2014, Variance risk premia in commodity markets, Working Paper.

Santa-Clara, Pedro, and Shu Yan, 2010, Crashes, volatility, and the equity premium: Lessons from S\&P 500 options, The Review of Economics and Statistics 92, 435-451.

Segal, Gill, Ivan Shaliastovich, and Amir Yaron, 2015, Good and bad uncertainty: Macroeconomic and financial market implications, Journal of Financial Economics 117, 369-397.

Seo, Sang Byung, and Jessica A Wachter, 2015, Option prices in a model with stochastic disaster risk, Working Paper.

Singleton, Kenneth J, 2009, Empirical dynamic asset pricing: model specification and econometric assessment. (Princeton University Press).

Tsai, Jerry, and Jessica A Wachter, 2014, Rare booms and disasters in a multi-sector endowment economy, Working Paper.

Weil, Philippe, 1990, Nonexpected utility in macroeconomics, The Quarterly Journal of Economics pp. $29-42$.

Whitelaw, Robert F, 1994, Time variations and covariations in the expectation and volatility of stock market returns, The Journal of Finance 49, 515-541.

Zhou, Hao, 2009, Variance risk premia, asset predictability puzzles, and macroeconomic uncertainty, Working paper. 


\section{Tables and Figures}


Figure 1: Implied Variance
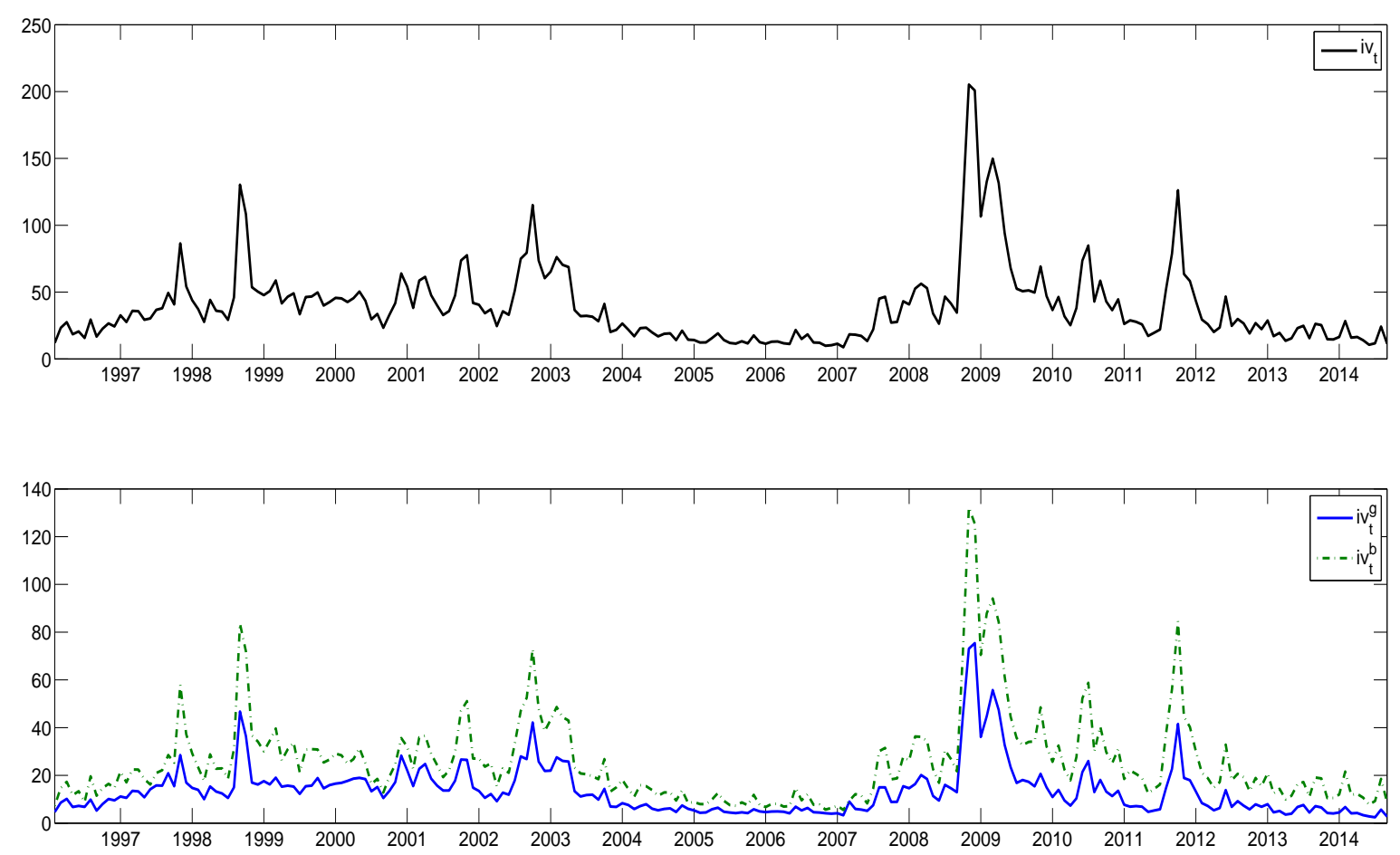

This figure shows the time series of implied variance measures from January 1996 to August 2014. The top panel plots the total implied variance, and the bottom panel depicts good (solid line) and bad (dashed line) implied variances. Measures of implied variance are in units of volatility in percent squared divided by 12 . 
Figure 2: Realized Variance
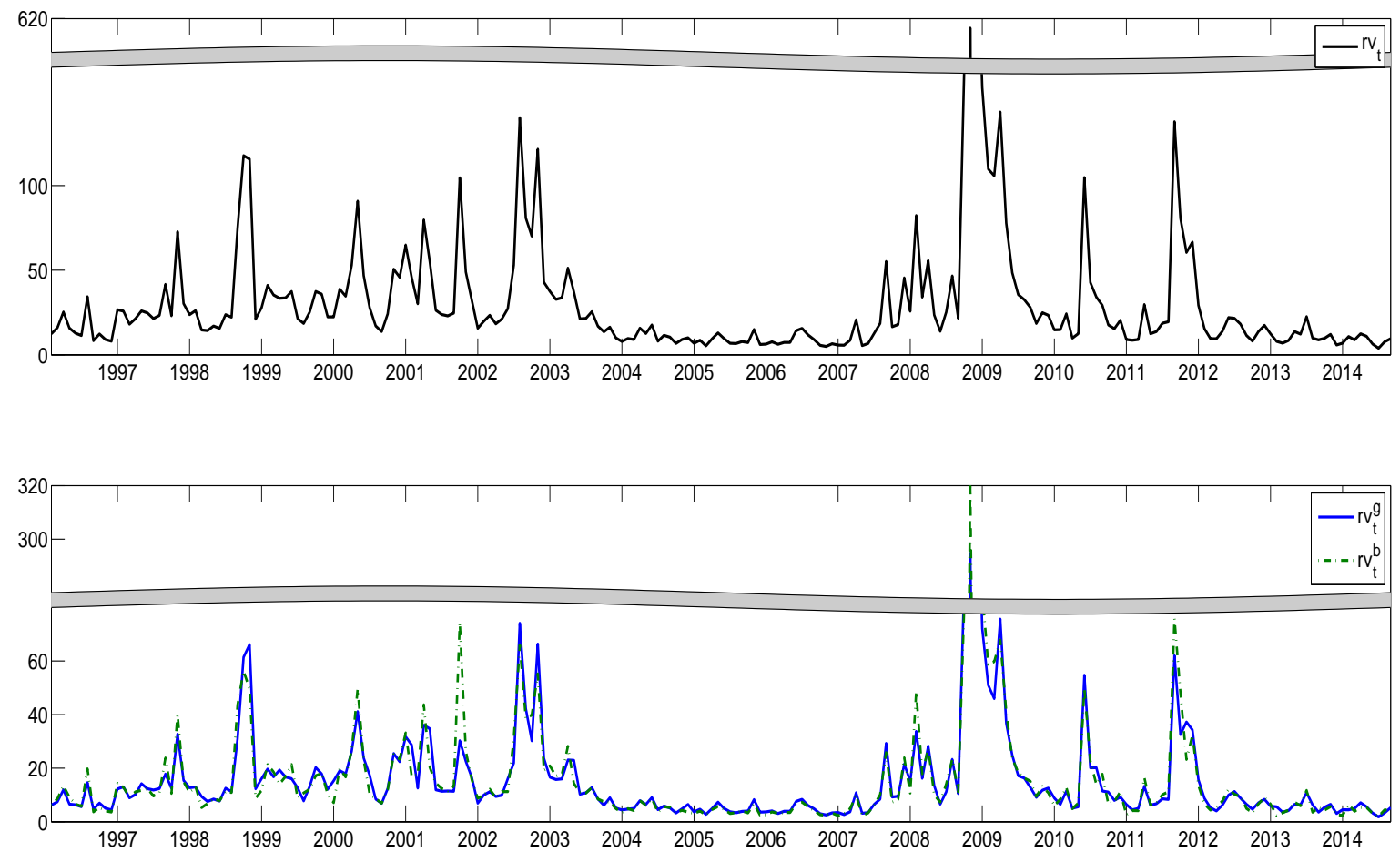

This figure shows the time series of realized variance measures from January 1996 to August 2014. The top panel plots the total realized variance, and the bottom panel depicts good (solid line) and bad (dashed line) realized variances. Measures of realized variance are in units of volatility in percent squared divided by 12 . 
Figure 3: Variance Premium
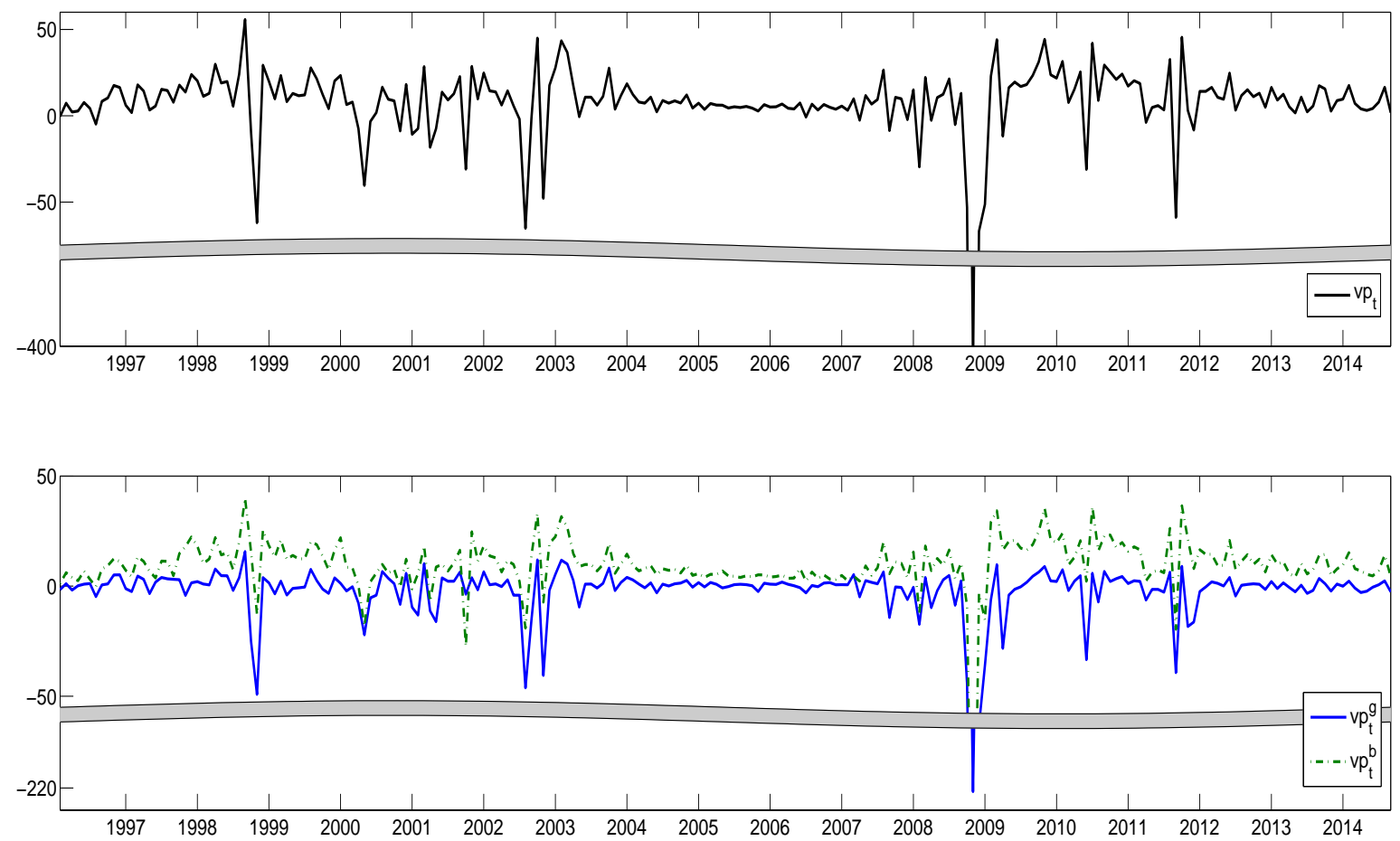

This figure shows the time series of variance premium measures from January 1996 to August 2014. The top panel plots the total variance premium, and the bottom panel depicts good (solid line) and bad (dashed line) variance premia. Measures of variance premium are equal to the difference between the corresponding implied and realized variance measures. 
Figure 4: Predicted 1-Year Excess Returns in the Data

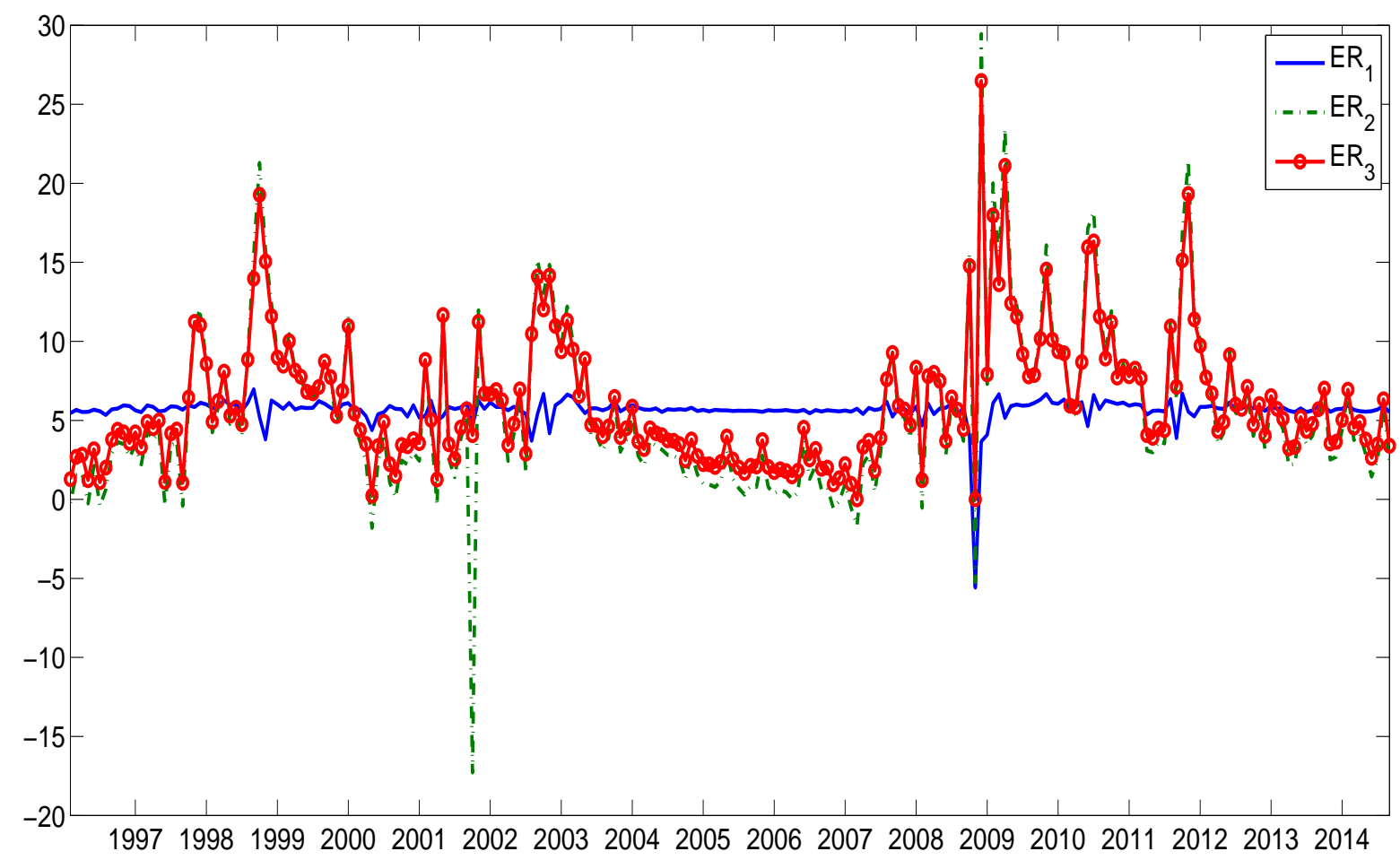

This figure plots the predicted one-year excess aggregate equity returns implied by the predictive regressions. The solid line $\left(E R_{1}\right)$ corresponds to a univariate specification using the total variance premium. The dotted line $\left(E R_{2}\right)$ corresponds to a multivariate specification using the good and bad variance premia jointly. The dashed line $\left(E R_{3}\right)$ corresponds to the multivariate constrained predictability regression using the good and bad variance premia. The values are in annual percentage terms. 
Figure 5: Predicted Excess Returns in the Data and Equity Premium in the Model

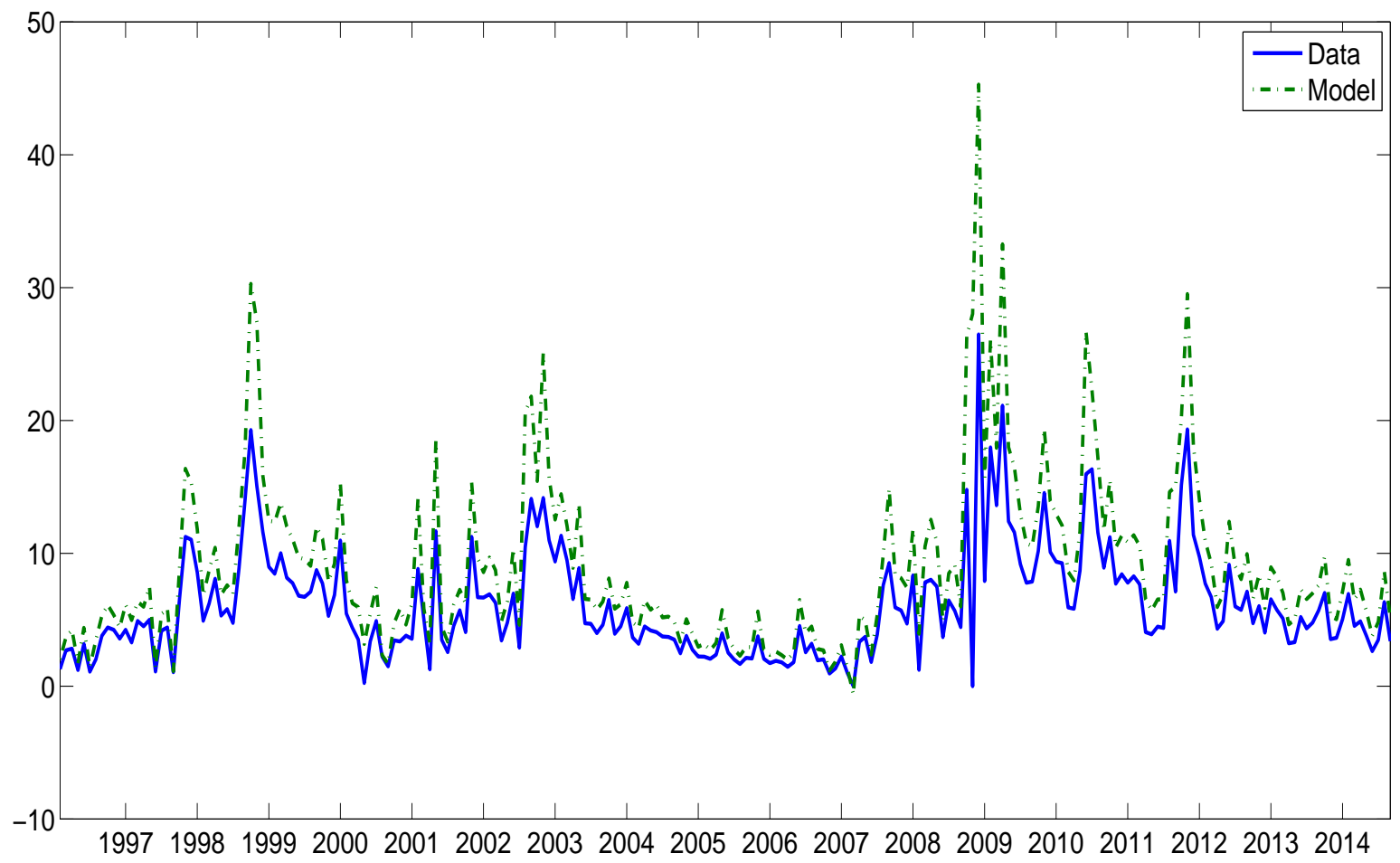

This figure plots the predicted one-year excess aggregate equity returns implied by the constrained regression on the good and bad variance premia (data) and the equity premium implied by the model given the observed good and bad variance premia (model). The values are in annual percentage terms. 
Table 1: Summary Statistics for Variance Variables

\begin{tabular}{lccl}
\hline & Mean & SD & AR(1) \\
\hline \multicolumn{4}{c}{ Panel A: Full Sample } \\
\hline$r v_{t}^{g}$ & 16.19 & 25.08 & 0.62 \\
$i v_{t}^{g}$ & 13.59 & 10.74 & 0.81 \\
$v p_{t}^{g}$ & -2.60 & 17.83 & 0.35 \\
$r v_{t}^{b}$ & 16.39 & 26.64 & 0.57 \\
$i v_{t}^{b}$ & 25.82 & 19.06 & 0.81 \\
$v p_{t}^{b}$ & 9.43 & 16.20 & 0.16 \\
$r v_{t}$ & 32.58 & 51.47 & 0.60 \\
$i v_{t}$ & 39.41 & 29.60 & 0.81 \\
$v p_{t}$ & 6.83 & 32.87 & 0.24 \\
\hline Panel B: Excluding & the Crisis \\
\hline$r v_{t}^{g}$ & 12.80 & 12.12 & 0.57 \\
$i v_{t}^{g}$ & 12.00 & 7.63 & 0.76 \\
$v p_{t}^{g}$ & -0.79 & 8.39 & 0.02 \\
$r v_{t}^{b}$ & 12.76 & 12.86 & 0.54 \\
$i v_{t}^{b}$ & 23.04 & 14.04 & 0.75 \\
$v p_{t}^{b}$ & 10.28 & 8.97 & 0.14 \\
$r v_{t}$ & 25.56 & 24.51 & 0.58 \\
$i v_{t}$ & 35.05 & 21.37 & 0.75 \\
$v p_{t}$ & 9.49 & 15.58 & -0.04 \\
\hline & & &
\end{tabular}

This table shows the summary statistics for realized and implied variance measures, variance premium, and their good and bad components. Panel A presents the results for the benchmark sample from January 1996 to August 2014. Panel B omits the Great Recession period (from December 2007 to June 2009). Measures of implied variance are in units of volatility in percent squared divided by 12 . 
Table 2: Correlation Matrix of Variance Variables

\begin{tabular}{lcccccccc}
\hline & $i v_{t}^{g}$ & $r v_{t}^{g}$ & $v p_{t}^{g}$ & $i v_{t}^{b}$ & $r v_{t}^{b}$ & $v p_{t}^{b}$ & $i v_{t}$ & $r v_{t}$ \\
\hline \multicolumn{1}{c}{ Panel A: Full Sample } \\
\hline$r v_{t}^{g}$ & 0.79 & \multicolumn{1}{c}{${ }^{g}$} & & & & & & \\
$v p_{t}^{g}$ & -0.51 & -0.93 & & & & & & \\
$i v_{t}^{b}$ & 0.97 & 0.78 & -0.52 & & & & & \\
$r v_{t}^{b}$ & 0.80 & 0.98 & -0.90 & 0.80 & & & & \\
$v p_{t}^{b}$ & -0.18 & -0.69 & 0.87 & -0.14 & -0.71 & & & \\
$i v_{t}$ & 0.99 & 0.79 & -0.52 & 0.99 & 0.80 & -0.15 & & \\
$r v_{t}$ & 0.80 & 0.99 & -0.92 & 0.80 & 0.99 & -0.70 & 0.80 & \\
$v p_{t}$ & -0.37 & -0.84 & 0.97 & -0.35 & -0.83 & 0.96 & -0.36 & -0.84 \\
\hline & \multicolumn{1}{c}{ Panel B: Excluding the Crisis } & & \\
\hline$r v_{t}^{g}$ & 0.73 & & & & & & & \\
$v p_{t}^{g}$ & -0.14 & -0.78 & & & & & & \\
$i v_{t}^{b}$ & 0.95 & 0.72 & -0.18 & & & & & \\
$r v_{t}^{b}$ & 0.79 & 0.93 & -0.62 & 0.78 & & & & \\
$v p_{t}^{b}$ & 0.35 & -0.20 & 0.61 & 0.44 & -0.21 & & & \\
$i v_{t}$ & 0.98 & 0.73 & -0.17 & 0.99 & 0.79 & 0.41 & & \\
$r v_{t}$ & 0.77 & 0.98 & -0.71 & 0.77 & 0.98 & -0.21 & 0.78 & \\
$v p_{t}$ & 0.12 & -0.54 & 0.89 & 0.16 & -0.46 & 0.90 & 0.15 & -0.51 \\
\hline & & & & & & & \\
\end{tabular}

This table shows the correlations between the realized and implied variance measures, variance premium, and their good and bad components. Panel A presents the results for the benchmark sample from January 1996 to August 2014. Panel B omits the Great Recession period (from December 2007 to June 2009). Measures of implied variance are in units of volatility in percent squared divided by 12 . 
Table 3: Predicting Aggregate Returns with Variance Premium

\begin{tabular}{|c|c|c|c|c|c|c|c|c|c|c|c|c|c|c|c|c|c|c|c|c|c|c|c|c|}
\hline & \multicolumn{24}{|c|}{ Forecast Horizon $h$} \\
\hline & \multicolumn{4}{|c|}{1} & \multicolumn{4}{|c|}{3} & \multicolumn{4}{|c|}{6} & \multicolumn{4}{|c|}{12} & \multicolumn{4}{|c|}{18} & \multicolumn{4}{|c|}{24} \\
\hline & $\overline{\text { Coef }}$ & $\mathrm{SE}$ & $p$-val & $\bar{R}^{2}$ & Coef & $\mathrm{SE}$ & $p$-val & $\bar{R}^{2}$ & Coef & $\mathrm{SE}$ & $p$-val & $\bar{R}^{2}$ & Coef & SE & $p$-val & $\bar{R}^{2}$ & Coef & $\mathrm{SE}$ & $p$-val & $\bar{R}^{2}$ & Coef & $\mathrm{SE}$ & $p$-val & $\bar{R}^{2}$ \\
\hline \multicolumn{25}{|c|}{ Panel A: Equity Returns } \\
\hline \multirow[t]{2}{*}{$v p_{t}$} & 0.35 & 0.07 & 0.00 & 0.04 & 0.26 & 0.05 & 0.00 & 0.06 & 0.11 & 0.04 & 0.00 & 0.01 & 0.03 & 0.03 & 0.21 & 0.00 & 0.01 & 0.03 & 0.38 & 0.00 & 0.01 & 0.03 & 0.37 & 0.00 \\
\hline & & 0.23 & 0.08 & & & 0.15 & 0.05 & & & 0.10 & 0.14 & & & 0.06 & 0.31 & & & 0.04 & 0.39 & & & 0.04 & 0.38 & \\
\hline \multirow[t]{2}{*}{$v p_{t}^{g}$} & 0.04 & 0.44 & 0.54 & 0.04 & -0.27 & 0.37 & 0.23 & 0.07 & -0.47 & 0.23 & 0.02 & 0.05 & -0.52 & 0.16 & 0.00 & 0.07 & -0.47 & 0.14 & 0.00 & 0.07 & -0.47 & 0.17 & 0.00 & 0.09 \\
\hline & & 0.63 & 0.54 & & & 0.50 & 0.30 & & & 0.40 & 0.12 & & & 0.30 & 0.04 & & & 0.26 & 0.03 & & & 0.23 & 0.02 & \\
\hline \multirow[t]{2}{*}{$v p_{t}^{b}$} & 0.69 & 0.49 & 0.08 & & 0.85 & 0.42 & 0.02 & & 0.75 & 0.27 & 0.00 & & 0.64 & 0.18 & 0.00 & & 0.54 & 0.16 & 0.00 & & 0.54 & 0.19 & 0.00 & \\
\hline & & 0.66 & 0.14 & & & 0.44 & 0.03 & & & 0.35 & 0.02 & & & 0.29 & 0.01 & & & 0.26 & 0.02 & & & 0.24 & 0.01 & \\
\hline \multicolumn{25}{|c|}{ Panel B: High-Yield Bond Returns } \\
\hline \multirow[t]{2}{*}{$v p_{t}$} & 0.22 & 0.09 & 0.99 & 0.04 & 0.02 & 0.03 & 0.74 & 0.00 & -0.05 & 0.03 & 0.03 & 0.00 & -0.07 & 0.02 & 0.00 & 0.04 & -0.06 & 0.02 & 0.00 & 0.04 & -0.05 & 0.02 & 0.00 & 0.04 \\
\hline & & 0.12 & 0.95 & & & 0.08 & 0.64 & & & 0.05 & 0.16 & & & 0.03 & 0.01 & & & 0.02 & 0.00 & & & 0.02 & 0.00 & \\
\hline \multirow[t]{2}{*}{$\overline{v p_{t}^{g}}$} & -0.36 & 0.40 & 0.18 & 0.07 & -0.68 & 0.26 & 0.00 & 0.08 & -0.75 & 0.25 & 0.00 & 0.14 & -0.61 & 0.21 & 0.00 & 0.20 & -0.49 & 0.17 & 0.00 & 0.20 & -0.46 & 0.15 & 0.00 & 0.24 \\
\hline & & 0.33 & 0.11 & & & 0.26 & 0.00 & & & 0.21 & 0.00 & & & 0.16 & 0.00 & & & 0.13 & 0.00 & & & 0.12 & 0.00 & \\
\hline \multirow[t]{2}{*}{$v p_{t}^{b}$} & 0.86 & 0.37 & 0.01 & & 0.80 & 0.30 & 0.00 & & 0.72 & 0.29 & 0.01 & & 0.52 & 0.23 & 0.01 & & 0.42 & 0.18 & 0.01 & & 0.40 & 0.17 & 0.01 & \\
\hline & & 0.34 & 0.00 & & & 0.23 & 0.00 & & & 0.19 & 0.00 & & & 0.15 & 0.00 & & & 0.14 & 0.00 & & & 0.12 & 0.00 & \\
\hline \multicolumn{25}{|c|}{ Panel C: Investment-Grade Bond Returns } \\
\hline \multirow[t]{2}{*}{$v p_{t}$} & -0.09 & 0.03 & 0.00 & 0.02 & -0.07 & 0.02 & 0.00 & 0.04 & -0.04 & 0.01 & 0.00 & 0.02 & -0.05 & 0.01 & 0.00 & 0.06 & -0.04 & 0.01 & 0.00 & 0.06 & -0.03 & 0.01 & 0.00 & 0.06 \\
\hline & & 0.09 & 0.11 & & & 0.06 & 0.07 & & & 0.04 & 0.11 & & & 0.02 & 0.01 & & & 0.02 & 0.01 & & & 0.01 & 0.00 & \\
\hline \multirow[t]{2}{*}{$v p_{t}^{g}$} & -0.45 & 0.18 & 0.01 & 0.05 & -0.45 & 0.11 & 0.00 & 0.12 & -0.34 & 0.13 & 0.00 & 0.13 & -0.28 & 0.12 & 0.01 & 0.18 & -0.23 & 0.10 & 0.01 & 0.18 & -0.22 & 0.09 & 0.01 & 0.22 \\
\hline & & 0.24 & 0.02 & & & 0.19 & 0.00 & & & 0.15 & 0.01 & & & 0.11 & 0.00 & & & 0.10 & 0.01 & & & 0.09 & 0.00 & \\
\hline \multirow[t]{2}{*}{$v p_{t}^{b}$} & 0.30 & 0.18 & 0.05 & & 0.35 & 0.14 & 0.00 & & 0.29 & 0.15 & 0.02 & & 0.21 & 0.13 & 0.06 & & 0.17 & 0.11 & 0.06 & & 0.17 & 0.09 & 0.04 & \\
\hline & & 0.25 & 0.09 & & & 0.16 & 0.01 & & & 0.13 & 0.01 & & & 0.11 & 0.02 & & & 0.10 & 0.03 & & & 0.09 & 0.02 & \\
\hline
\end{tabular}

This table presents predictability regression evidence for equity returns (Panel A), high-yield bond returns (Panel B), and investment-grade bond returns (Panel C) from January 1996 to August 2014. The dependent variable is the annualized log excess return over the next $h$ months $(h=1,3,6,12,18,24)$. For each asset, the table shows the coefficient (Coef), the standard errors (SE), and the $p$-values for a univariate predictability regression with the variance premium $v p_{t}$, and a multivariate regression with the good and bad variance premia, $v p_{t}^{g}$ and $v p_{t}^{b}$, as predictor variables. For each coefficient, the first line reports the Newey-West standard error with three more lags than the forecast horizon $h$, and the corresponding $p$-value. The second line reports the standard error and the $p$-value from the bootstrap approach. The $p$-values are calculated for one-sided tests as described in Section 2.4. 
Table 4: Predictability in the Cross-Section of Portfolios

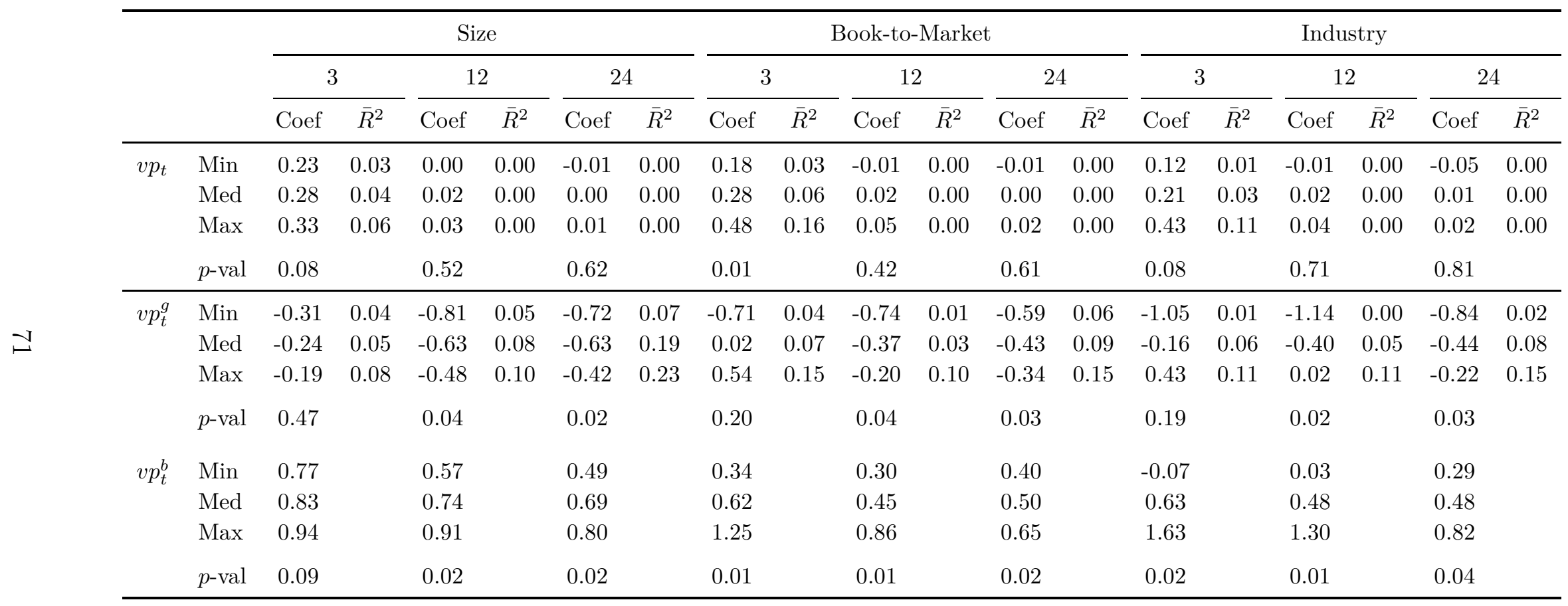

This table presents predictability regression evidence for a cross-section of equity returns from January 1996 to August 2014. The dependent variable is the annualized $\log$ excess return over the next $h$ months $(h=1,3,6,12,18,24)$. The table shows the minimum, median, and maximum values of the coefficient (Coef) and the joint $p$-values for a univariate predictability regression with the variance premium $v p_{t}$, and a multivariate regression with the good and bad variance premia, $v p_{t}^{g}$ and $v p_{t}^{b}$, as predictor variables among ten size, book-to-market, and industry portfolios. The joint $p$-values are computed as described in Appendix A.2. 
Table 5: Predicting Excess Returns with Variance Premium Excluding the Great Recession

\begin{tabular}{|c|c|c|c|c|c|c|c|c|c|c|c|c|c|c|c|c|c|c|c|c|c|c|c|c|}
\hline & \multicolumn{24}{|c|}{ Forecast Horizon $h$} \\
\hline & \multicolumn{4}{|c|}{1} & \multicolumn{4}{|c|}{3} & \multicolumn{4}{|c|}{6} & \multicolumn{4}{|c|}{12} & \multicolumn{4}{|c|}{18} & \multicolumn{4}{|c|}{24} \\
\hline & Coef & $\mathrm{SE}$ & $p$-val & $\bar{R}^{2}$ & Coef & $\mathrm{SE}$ & $p$-val & $\bar{R}^{2}$ & Coef & $\mathrm{SE}$ & $p$-va & $\bar{R}^{2}$ & Coef & $\mathrm{SE}$ & $p$-val & $\bar{R}^{2}$ & Coef & $\mathrm{SE}$ & $p$-val & $\bar{R}^{2}$ & Coef & $\mathrm{SE}$ & $p$-val & $\bar{R}^{2}$ \\
\hline \multicolumn{25}{|c|}{ Panel A: Equity Returns } \\
\hline \multirow[t]{2}{*}{$v p_{t}$} & 0.39 & 0.29 & 0.09 & 0.01 & 0.28 & 0.14 & 0.02 & 0.02 & 0.20 & 0.10 & 0.02 & 0.02 & 0.14 & 0.07 & 0.03 & 0.01 & 0.13 & 0.08 & 0.06 & 0.01 & 0.12 & 0.07 & 0.04 & 0.01 \\
\hline & & 0.31 & 0.11 & & & 0.16 & 0.04 & & & 0.11 & 0.04 & & & 0.08 & 0.04 & & & 0.06 & 0.01 & & & 0.06 & 0.02 & \\
\hline \multirow[t]{2}{*}{$v p_{t}^{g}$} & -0.01 & 0.65 & 0.49 & 0.01 & -0.50 & 0.43 & 0.13 & 0.05 & -0.33 & 0.27 & 0.11 & 0.05 & -0.37 & 0.14 & 0.00 & 0.06 & -0.34 & 0.17 & 0.02 & 0.06 & -0.33 & 0.19 & 0.04 & 0.07 \\
\hline & & 0.70 & 0.49 & & & 0.51 & 0.15 & & & 0.39 & 0.18 & & & 0.28 & 0.08 & & & 0.24 & 0.07 & & & 0.21 & 0.05 & \\
\hline \multirow[t]{2}{*}{$v p_{t}^{b}$} & 0.76 & 0.45 & 0.05 & & 1.00 & 0.36 & 0.00 & & 0.69 & 0.27 & 0.01 & & 0.61 & 0.19 & 0.00 & & 0.57 & 0.19 & 0.00 & & 0.53 & 0.23 & 0.01 & \\
\hline & & 0.64 & 0.11 & & & 0.47 & 0.01 & & & 0.39 & 0.03 & & & 0.33 & 0.03 & & & 0.29 & 0.02 & & & 0.26 & 0.02 & \\
\hline \multicolumn{25}{|c|}{ Panel B: High-Yield Bond Returns } \\
\hline \multirow[t]{2}{*}{$v p_{t}$} & -0.03 & 0.16 & 0.42 & 0.00 & 0.07 & 0.07 & 0.83 & 0.00 & 0.02 & 0.07 & 0.61 & 0.00 & 0.01 & 0.05 & 0.54 & 0.00 & 0.02 & 0.05 & 0.67 & 0.00 & 0.02 & 0.04 & 0.67 & 0.00 \\
\hline & & 0.15 & 0.42 & & & 0.08 & 0.83 & & & 0.05 & 0.64 & & & 0.04 & 0.56 & & & 0.03 & 0.78 & & & 0.03 & 0.73 & \\
\hline \multirow[t]{2}{*}{$v p_{t}^{g}$} & -0.44 & 0.28 & 0.06 & 0.01 & -0.44 & 0.14 & 0.00 & 0.06 & -0.40 & 0.17 & 0.01 & 0.07 & -0.31 & 0.18 & 0.04 & 0.06 & -0.24 & 0.17 & 0.08 & 0.04 & -0.26 & 0.16 & 0.05 & 0.07 \\
\hline & & 0.33 & 0.08 & & & 0.24 & 0.02 & & & 0.19 & 0.01 & & & 0.14 & 0.01 & & & 0.12 & 0.02 & & & 0.10 & 0.00 & \\
\hline \multirow[t]{2}{*}{$v p_{t}^{b}$} & 0.34 & 0.25 & 0.09 & & 0.54 & 0.21 & 0.01 & & 0.40 & 0.19 & 0.02 & & 0.30 & 0.18 & 0.05 & & 0.26 & 0.17 & 0.06 & & 0.28 & 0.18 & 0.07 & \\
\hline & & 0.31 & 0.12 & & & 0.23 & 0.01 & & & 0.18 & 0.01 & & & 0.16 & 0.03 & & & 0.14 & 0.03 & & & 0.13 & 0.01 & \\
\hline \multicolumn{25}{|c|}{ Panel C: Investment-Grade Bond Returns } \\
\hline \multirow[t]{2}{*}{$v p_{t}$} & -0.06 & 0.07 & 0.22 & 0.00 & -0.02 & 0.03 & 0.32 & 0.00 & -0.03 & 0.03 & 0.18 & 0.00 & 0.00 & 0.02 & 0.49 & -0.01 & 0.00 & 0.02 & 0.45 & -0.01 & 0.01 & 0.02 & 0.63 & 0.00 \\
\hline & & 0.11 & 0.33 & & & 0.06 & 0.40 & & & 0.04 & 0.27 & & & 0.03 & 0.49 & & & 0.02 & 0.44 & & & 0.02 & 0.63 & \\
\hline \multirow[t]{2}{*}{$v p_{t}^{g}$} & -0.32 & 0.20 & 0.05 & 0.01 & -0.31 & 0.11 & 0.00 & 0.05 & -0.20 & 0.13 & 0.06 & 0.04 & -0.11 & 0.12 & 0.18 & 0.02 & -0.09 & 0.10 & 0.18 & 0.02 & -0.12 & 0.09 & 0.09 & 0.05 \\
\hline & & 0.25 & 0.09 & & & 0.18 & 0.03 & & & 0.14 & 0.06 & & & 0.10 & 0.13 & & & 0.09 & 0.13 & & & 0.08 & 0.06 & \\
\hline \multirow[t]{2}{*}{$v p_{t}^{b}$} & 0.18 & 0.19 & 0.16 & & 0.25 & 0.12 & 0.02 & & 0.14 & 0.11 & 0.11 & & 0.10 & 0.12 & 0.21 & & 0.08 & 0.11 & 0.23 & & 0.12 & 0.10 & 0.12 & \\
\hline & & 0.23 & 0.19 & & & 0.17 & 0.05 & & & 0.14 & 0.15 & & & 0.12 & 0.19 & & & 0.11 & 0.22 & & & 0.10 & 0.10 & \\
\hline
\end{tabular}

This table presents predictability regression evidence for equity returns (Panel A), high-yield bond returns (Panel B), and investment-grade bond returns (Panel C) from January 1996 to August 2014, omitting the Great Recession (from December 2007 to June 2009). The dependent variable is the annualized log excess return over the next $h$ months $(h=1,3,6,12,18,24)$. For each asset, the table shows the coefficient (Coef), the standard errors (SE), and the $p$-values for a univariate predictability regression with the variance premium $v p_{t}$, and a multivariate regression with the good and bad variance premia, $v p_{t}^{g}$ and $v p_{t}^{b}$, as predictor variables. For each coefficient, the first line reports the Newey-West standard error with three more lags than the forecast horizon $h$, and the corresponding $p$-value. The second line reports the standard error and the $p$-value from the bootstrap approach. The $p$-values are calculated for one-sided tests as described in Section 2.4 . 
Table 6: Predicting Excess Returns with Variance Premium in a Longer Sample

\begin{tabular}{|c|c|c|c|c|c|c|c|c|c|c|c|c|c|c|c|c|c|c|c|c|c|c|c|c|}
\hline & \multicolumn{24}{|c|}{ Forecast Horizon $h$} \\
\hline & \multicolumn{4}{|c|}{1} & \multicolumn{4}{|c|}{3} & \multicolumn{4}{|c|}{6} & \multicolumn{4}{|c|}{12} & \multicolumn{4}{|c|}{18} & \multicolumn{4}{|c|}{24} \\
\hline & Coef & $\mathrm{SE}$ & $p$-val & $\bar{R}^{2}$ & Coef & $\mathrm{SE}$ & $p$-val & $\bar{R}^{2}$ & Coef & $\mathrm{SE}$ & $p$-val & $\bar{R}^{2}$ & Coef & $\mathrm{SE}$ & $p$-val & $\bar{R}^{2}$ & Coef & $\mathrm{SE}$ & $p$-val & $\bar{R}^{2}$ & Coef & $\mathrm{SE}$ & $p$-val & $\bar{R}^{2}$ \\
\hline \multicolumn{25}{|c|}{ Panel A: Equity Returns } \\
\hline \multirow[t]{2}{*}{$v p_{t}$} & 0.42 & 0.29 & 0.07 & 0.01 & 0.34 & 0.15 & 0.01 & 0.03 & 0.24 & 0.10 & 0.01 & 0.03 & 0.15 & 0.08 & 0.03 & 0.02 & 0.13 & 0.09 & 0.07 & 0.02 & 0.11 & 0.07 & 0.07 & 0.01 \\
\hline & & 0.33 & 0.10 & & & 0.17 & 0.02 & & & 0.12 & 0.02 & & & 0.09 & 0.04 & & & 0.07 & 0.03 & & & 0.06 & 0.04 & \\
\hline$v p_{t}^{g}$ & & 0.76 & 0.40 & & & 0.53 & 0.07 & & & 0.39 & 0.07 & & & 0.27 & 0.03 & & & 0.22 & 0.05 & & & 0.19 & 0.09 & \\
\hline \multirow[t]{2}{*}{$v p_{t}^{b}$} & 0.98 & 0.49 & 0.02 & & 1.36 & 0.40 & 0.00 & & 0.98 & 0.31 & 0.00 & & 0.73 & 0.23 & 0.00 & & 0.59 & 0.21 & 0.00 & & 0.44 & 0.21 & 0.02 & \\
\hline & & 0.70 & 0.07 & & & 0.52 & 0.00 & & & 0.40 & 0.00 & & & 0.33 & 0.01 & & & 0.30 & 0.02 & & & 0.26 & 0.04 & \\
\hline \multirow[t]{2}{*}{$v p_{t}$} & -0.04 & 0.16 & 0.41 & 0.00 & 0.12 & 0.09 & 0.92 & 0.01 & 0.06 & 0.08 & 0.76 & 0.00 & 0.03 & 0.06 & 0.68 & 0.00 & 0.03 & 0.06 & 0.72 & 0.00 & 0.02 & 0.04 & 0.68 & 0.00 \\
\hline & & 0.16 & 0.42 & & & 0.08 & 0.93 & & & 0.06 & 0.85 & & & 0.04 & 0.76 & & & 0.03 & 0.85 & & & 0.03 & 0.75 & \\
\hline$v p_{t}^{g}$ & & 0.37 & 0.02 & & & 0.26 & 0.00 & & & 0.19 & 0.00 & & & 0.13 & 0.00 & & & 0.11 & 0.00 & & & 0.09 & 0.00 & \\
\hline \multirow[t]{2}{*}{$v p_{t}^{b}$} & 0.63 & 0.38 & 0.05 & & 0.95 & 0.36 & 0.00 & & 0.72 & 0.31 & 0.01 & & 0.48 & 0.23 & 0.02 & & 0.36 & 0.19 & 0.03 & & 0.29 & 0.17 & 0.05 & \\
\hline & & 0.35 & 0.03 & & & 0.26 & 0.00 & & & 0.20 & 0.00 & & & 0.16 & 0.00 & & & 0.14 & 0.01 & & & 0.13 & 0.01 & \\
\hline \multicolumn{25}{|c|}{ Panel C: Investment-Grade Bond Returns } \\
\hline \multirow[t]{2}{*}{$v p_{t}$} & -0.06 & 0.08 & 0.22 & 0.00 & 0.00 & 0.04 & 0.49 & -0.01 & -0.01 & 0.04 & 0.38 & 0.00 & 0.01 & 0.03 & 0.60 & 0.00 & 0.00 & 0.02 & 0.50 & -0.01 & 0.01 & 0.02 & 0.62 & -0.01 \\
\hline & & 0.11 & 0.31 & & & 0.06 & 0.49 & & & 0.04 & 0.39 & & & 0.03 & 0.60 & & & 0.02 & 0.49 & & & 0.02 & 0.62 & \\
\hline \multirow[t]{2}{*}{$v p_{t}^{g}$} & -0.36 & 0.21 & 0.04 & 0.01 & -0.40 & 0.15 & 0.00 & 0.09 & -0.30 & 0.17 & 0.04 & 0.09 & -0.16 & 0.13 & 0.11 & 0.06 & -0.12 & 0.12 & 0.14 & 0.04 & -0.11 & 0.09 & 0.11 & 0.05 \\
\hline & & 0.26 & 0.07 & & & 0.18 & 0.01 & & & 0.13 & 0.01 & & & 0.09 & 0.03 & & & 0.08 & 0.05 & & & 0.06 & 0.05 & \\
\hline \multirow[t]{2}{*}{$v p_{t}^{b}$} & 0.22 & 0.21 & 0.14 & & 0.37 & 0.17 & 0.01 & & 0.26 & 0.18 & 0.07 & & 0.17 & 0.16 & 0.14 & & 0.12 & 0.13 & 0.19 & & 0.11 & 0.11 & 0.15 & \\
\hline & & 0.24 & 0.16 & & & 0.18 & 0.01 & & & 0.14 & 0.02 & & & 0.11 & 0.07 & & & 0.10 & 0.12 & & & 0.09 & 0.10 & \\
\hline
\end{tabular}

This table presents predictability regression evidence for equity returns (Panel A), high-yield bond returns (Panel B), and investment-grade bond returns (Panel C) from January 1988 to August 2014. The dependent variable is the annualized log excess return over the next $h$ months $(h=1,3,6,12,18,24)$. For each asset, the table shows the coefficient (Coef), the standard errors (SE), and the $p$-values for a univariate predictability regression with the variance premium $v p_{t}$, and a multivariate regression with the good and bad variance premia, $v p_{t}^{g}$ and $v p_{t}^{b}$, as predictor variables. For each coefficient, the first line reports the Newey-West standard error with three more lags than the forecast horizon $h$, and the corresponding $p$-value. The second line reports the standard error and the $p$-value from the bootstrap approach. The $p$-values are calculated for one-sided tests as described in Section 2.4. 
Table 7: Predicting Excess Returns with Variance Premium with Constrained Regression

\begin{tabular}{|c|c|c|c|c|c|c|c|c|c|c|c|c|c|c|c|c|c|c|c|c|c|c|c|c|}
\hline & \multicolumn{24}{|c|}{ Forecast Horizon $h$} \\
\hline & \multicolumn{4}{|c|}{1} & \multicolumn{4}{|c|}{3} & \multicolumn{4}{|c|}{6} & \multicolumn{4}{|c|}{12} & \multicolumn{4}{|c|}{18} & \multicolumn{4}{|c|}{24} \\
\hline & Coef & $\mathrm{SE}$ & $p$-val & $\bar{R}^{2}$ & Coef & $\mathrm{SE}$ & $p$-val & $\bar{R}^{2}$ & Coef & $\mathrm{SE}$ & $p$-val & $\bar{R}^{2}$ & Coef & $\mathrm{SE}$ & $p$-val & $\bar{R}^{2}$ & Coef & SE & $p$-val & $\bar{R}^{2}$ & Coef & $\mathrm{SE}$ & $p$-val & $\bar{R}^{2}$ \\
\hline \multicolumn{25}{|c|}{ Panel A: Equity Returns } \\
\hline \multirow[t]{2}{*}{$v p_{t}$} & 0.02 & 0.24 & 0.47 & 0.00 & 0.02 & 0.17 & 0.46 & 0.00 & 0.01 & 0.05 & 0.39 & 0.00 & 0.01 & 0.03 & 0.30 & 0.00 & 0.01 & 0.03 & 0.40 & 0.00 & 0.01 & 0.03 & 0.37 & 0.00 \\
\hline & & 0.08 & 0.18 & & & 0.07 & 0.17 & & & 0.05 & 0.18 & & & 0.04 & 0.17 & & & 0.03 & 0.28 & & & 0.02 & 0.26 & \\
\hline \multirow[t]{2}{*}{$v p_{t}^{g}$} & -0.37 & 0.67 & 0.29 & 0.00 & -0.53 & 0.54 & 0.17 & 0.03 & -0.50 & 0.24 & 0.02 & 0.05 & -0.44 & 0.18 & 0.01 & 0.06 & -0.41 & 0.16 & 0.01 & 0.06 & -0.39 & 0.19 & 0.02 & 0.09 \\
\hline & & 0.34 & 0.33 & & & 0.30 & 0.14 & & & 0.26 & 0.11 & & & 0.21 & 0.07 & & & 0.19 & 0.06 & & & 0.17 & 0.04 & \\
\hline \multirow[t]{2}{*}{$v p_{t}^{b}$} & 0.45 & 0.46 & 0.16 & & 0.63 & 0.38 & 0.05 & & 0.59 & 0.28 & 0.02 & & 0.52 & 0.21 & 0.01 & & 0.48 & 0.19 & 0.00 & & 0.46 & 0.22 & 0.02 & \\
\hline & & 0.33 & 0.17 & & & 0.28 & 0.05 & & & 0.24 & 0.03 & & & 0.21 & 0.03 & & & 0.20 & 0.03 & & & 0.19 & 0.02 & \\
\hline \multicolumn{25}{|c|}{ Panel B: High-Yield Bond Returns } \\
\hline \multirow[t]{2}{*}{$v p_{t}$} & 0.01 & 0.22 & 0.52 & 0.00 & 0.01 & 0.03 & 0.66 & 0.00 & -0.05 & 0.03 & 0.04 & 0.00 & -0.08 & 0.02 & 0.00 & 0.04 & -0.06 & 0.02 & 0.00 & 0.04 & -0.05 & 0.02 & 0.00 & 0.04 \\
\hline & & 0.05 & 0.87 & & & 0.04 & 0.86 & & & 0.03 & 0.16 & & & 0.02 & 0.00 & & & 0.02 & 0.00 & & & 0.01 & 0.00 & \\
\hline \multirow[t]{2}{*}{$v p_{t}^{g}$} & -0.46 & 0.49 & 0.17 & 0.03 & -0.48 & 0.28 & 0.04 & 0.07 & -0.52 & 0.30 & 0.04 & 0.13 & -0.48 & 0.25 & 0.03 & 0.19 & -0.44 & 0.18 & 0.01 & 0.21 & -0.42 & 0.17 & 0.01 & 0.25 \\
\hline & & 0.20 & 0.05 & & & 0.16 & 0.02 & & & 0.14 & 0.00 & & & 0.11 & 0.00 & & & 0.10 & 0.00 & & & 0.09 & 0.00 & \\
\hline \multirow[t]{2}{*}{$v p_{t}^{b}$} & 0.55 & 0.41 & 0.09 & & 0.56 & 0.33 & 0.04 & & 0.48 & 0.33 & 0.07 & & 0.38 & 0.27 & 0.08 & & 0.36 & 0.20 & 0.04 & & 0.36 & 0.19 & 0.03 & \\
\hline & & 0.20 & 0.01 & & & 0.16 & 0.00 & & & 0.14 & 0.00 & & & 0.12 & 0.00 & & & 0.11 & 0.00 & & & 0.10 & 0.00 & \\
\hline \multicolumn{25}{|c|}{ Panel C: Investment-Grade Bond Returns } \\
\hline \multirow[t]{2}{*}{$v p_{t}$} & -0.08 & 0.03 & 0.01 & 0.02 & -0.07 & 0.02 & 0.00 & 0.04 & -0.04 & 0.01 & 0.00 & 0.03 & -0.05 & 0.01 & 0.00 & 0.06 & -0.04 & 0.01 & 0.00 & 0.06 & -0.03 & 0.01 & 0.00 & 0.06 \\
\hline & & 0.03 & 0.06 & & & 0.03 & 0.03 & & & 0.02 & 0.09 & & & 0.01 & 0.01 & & & 0.01 & 0.01 & & & 0.01 & 0.00 & \\
\hline \multirow[t]{2}{*}{$v p_{t}^{g}$} & -0.39 & 0.17 & 0.01 & 0.05 & -0.37 & 0.12 & 0.00 & 0.12 & -0.33 & 0.14 & 0.01 & 0.13 & -0.30 & 0.13 & 0.01 & 0.19 & -0.25 & 0.10 & 0.01 & 0.20 & -0.24 & 0.09 & 0.00 & 0.24 \\
\hline & & 0.13 & 0.02 & & & 0.11 & 0.01 & & & 0.10 & 0.01 & & & 0.08 & 0.00 & & & 0.07 & 0.00 & & & 0.06 & 0.00 & \\
\hline \multirow[t]{2}{*}{$v p_{t}^{b}$} & 0.24 & 0.17 & 0.08 & & 0.27 & 0.15 & 0.03 & & 0.28 & 0.16 & 0.04 & & 0.23 & 0.14 & 0.04 & & 0.20 & 0.12 & 0.05 & & 0.20 & 0.09 & 0.02 & \\
\hline & & 0.13 & 0.08 & & & 0.11 & 0.03 & & & 0.09 & 0.01 & & & 0.08 & 0.01 & & & 0.08 & 0.02 & & & 0.07 & 0.01 & \\
\hline
\end{tabular}

This table presents predictability regression evidence for equity returns (Panel A), high-yield bond returns (Panel B), and investment-grade bond returns (Panel C) from January 1996 to August 2014 using the constrained regression approach described in Section 2.5. The dependent variable is the annualized log excess return over the next $h$ months $(h=1,3,6,12,18,24)$. For each asset, the table shows the coefficient (Coef), the standard errors (SE), and the $p$-values for a univariate predictability regression with the variance premium $v p_{t}$, and a multivariate regression with the good and bad variance premia, $v p_{t}^{g}$ and $v p_{t}^{b}$, as predictor variables. For each coefficient, the first line reports the Newey-West standard error with three more lags than the forecast horizon $h$, and the corresponding $p$-value. The second line reports the standard error and the $p$-value from the bootstrap approach. The $p$-values are calculated for one-sided tests as described in Section 2.4 . 
Table 8: Calibration

\begin{tabular}{|c|c|}
\hline \multicolumn{2}{|c|}{ Parameter Values } \\
\hline$\gamma$ & 10 \\
\hline$\beta$ & 0.00001 \\
\hline$\mu$ & 0.0016 \\
\hline$k_{i, c}$ & 0.05 \\
\hline$\mu_{i, c}$ & 0.0015 \\
\hline$\kappa_{i}$ & 0.36 \\
\hline$k_{i, \lambda}$ & 0.1 \\
\hline$\mu_{i, \lambda}$ & 0.12 \\
\hline$\sigma_{i, \lambda}$ & 1.07 \\
\hline$\mu_{d}$ & 0.0016 \\
\hline$\phi$ & 5 \\
\hline \multicolumn{2}{|c|}{ Statistics for $\lambda_{i}$} \\
\hline $\mathbb{E}\left[\lambda_{i}\right]$ & 0.58 \\
\hline$\sigma\left(\lambda_{i}\right)$ & 1.26 \\
\hline $\operatorname{AR}(1)$ & 0.81 \\
\hline
\end{tabular}

This table shows the parameter values for the benchmark calibration of the model. The parameter values are expressed at a monthly frequency. The calibration parameters for good and bad jumps, $i=g, b$, are identical. The bottom panel shows the mean, volatility, and an AR(1) coefficient for the good and bad jump intensities implied by the model calibration. 
Table 9: Macroeconomic and Equity Market Moments in the Data and Model

\begin{tabular}{lcccccccc}
\hline & $\mathbb{E}[\Delta c]$ & $\sigma(\Delta c)$ & $\mathbb{E}[\Delta d]$ & $\sigma(\Delta d)$ & $\mathbb{E}\left[r-r^{f}\right]$ & $\sigma(r)$ & $\mathbb{E}\left[r^{f}\right]$ & $\sigma\left(r^{f}\right)$ \\
\hline Data & 1.74 & 1.58 & 3.86 & 9.83 & 5.62 & 19.74 & 0.24 & 1.92 \\
& $(0.55)$ & $(0.33)$ & $(2.13)$ & $(1.39)$ & $(4.39)$ & $(3.05)$ & $(0.71)$ & $(0.21)$ \\
$50 \%$ & 1.93 & 2.38 & 1.97 & 11.97 & 5.33 & 16.06 & 1.35 & 2.08 \\
$5 \%$ & 0.34 & 0.97 & -5.98 & 4.85 & -1.35 & 7.49 & -0.19 & 0.95 \\
$95 \%$ & 3.46 & 5.05 & 9.61 & 25.26 & 12.14 & 31.20 & 2.35 & 4.62 \\
Population & 1.91 & 2.99 & 1.88 & 14.98 & 5.36 & 18.87 & 1.25 & 2.65 \\
\hline
\end{tabular}

This table shows the moments of the consumption, dividend, equity return, and risk-free rate in the data and in the model. Data moments correspond to annual observations from 1996 to 2014. Standard errors are Newey-West adjusted with three lags. Model output is computed from a long simulation of the model (population), and using 10,000 samples with length of 18 years each. The model is simulated at a monthly frequency and time-aggregated to an annual frequency. The values are in percentage terms. 
Table 10: Variance Moments in the Data and Model

\begin{tabular}{lccccccccc}
\hline & $\mathbb{E}\left[r v_{g}\right]$ & $\mathbb{E}\left[i v_{g}\right]$ & $\mathbb{E}\left[v p_{g}\right]$ & $\mathbb{E}\left[r v_{b}\right]$ & $\mathbb{E}\left[i v_{b}\right]$ & $\mathbb{E}\left[v p_{b}\right]$ & $\mathbb{E}[r v]$ & $\mathbb{E}[i v]$ & $\mathbb{E}[v p]$ \\
\hline Data & 16.19 & 13.60 & -2.60 & 16.39 & 25.82 & 9.43 & 32.58 & 39.41 & 6.83 \\
& $(3.27)$ & $(1.83)$ & $(1.67)$ & $(3.45)$ & $(3.22)$ & $(1.37)$ & $(6.71)$ & $(5.00)$ & $(2.70)$ \\
$50 \%$ & 14.85 & 12.11 & -2.60 & 15.90 & 23.01 & 7.12 & 30.98 & 35.21 & 4.41 \\
$5 \%$ & 8.77 & 7.09 & -5.45 & 8.12 & 11.55 & 3,44 & 17.85 & 19.41 & -0.07 \\
$95 \%$ & 25.32 & 20.75 & -1.25 & 32.47 & 47.60 & 15.04 & 56.02 & 67.56 & 12.53 \\
Population & 15.67 & 12.80 & -2.87 & 17.49 & 25.37 & 7.89 & 33.15 & 38.17 & 5.02 \\
\hline \multirow{2}{*}{ Data } & $\sigma\left(r v_{g}\right)$ & $\sigma\left(i v_{g}\right)$ & $\sigma\left(v p_{g}\right)$ & $\sigma\left(r v_{b}\right)$ & $\sigma\left(i v_{b}\right)$ & $\sigma\left(v p_{b}\right)$ & $\sigma(r v)$ & $\sigma(i v)$ & $\sigma(v p)$ \\
\hline \multirow{2}{*}{$50 \%$} & 25.08 & 10.74 & 17.83 & 26.64 & 19.06 & 16.20 & 51.47 & 29.60 & 32.87 \\
$5 \%$ & $(8.80)$ & $(2.30)$ & $(6.57)$ & $(9.34)$ & $(3.82)$ & $(5.38)$ & $(18.20)$ & $(6.15)$ & $(12.16)$ \\
95\% & 21.27 & 17.46 & 5.09 & 29.22 & 43.13 & 13.92 & 47.19 & 58.21 & 15.38 \\
Population & 24.22 & 20.16 & 6.26 & 36.33 & 53.61 & 17.30 & 56.48 & 71.54 & 18.41 \\
\hline
\end{tabular}

This table shows the moments of the realized and implied variance measures and the variance premia, and their good and bad components in the data and in the model. Data moments correspond to monthly observations from 1996 to 2014. Standard errors are Newey-West adjusted with ten lags. Model output is computed from a long simulation of the model (population), and using 10,000 samples with length of 18 years each. The model is simulated at a monthly frequency and time-aggregated to an annual frequency. Measures of variance are in units of volatility in percent squared divided by 12 . 
Table 11: Predictability Regressions in the Model

\begin{tabular}{|c|c|c|c|c|c|c|c|}
\hline & & \multicolumn{6}{|c|}{ Forecast Horizon $h$} \\
\hline & & 1 & 3 & 6 & 12 & 18 & 24 \\
\hline \multicolumn{8}{|c|}{ Panel A: Univariate Predictability } \\
\hline \multirow[t]{4}{*}{$v p$} & $50 \%$ & 0.38 & 0.32 & 0.25 & 0.16 & 0.12 & 0.10 \\
\hline & $5 \%$ & -0.49 & -0.45 & -0.38 & -0.28 & -0.22 & -0.18 \\
\hline & $95 \%$ & 1.35 & 0.98 & 0.68 & 0.42 & 0.32 & 0.27 \\
\hline & Population & 0.17 & 0.14 & 0.10 & 0.06 & 0.05 & 0.04 \\
\hline \multirow[t]{4}{*}{$R^{2}$} & $50 \%$ & 0.01 & 0.03 & 0.04 & 0.04 & 0.04 & 0.04 \\
\hline & $5 \%$ & 0.00 & 0.00 & 0.00 & 0.00 & 0.00 & 0.00 \\
\hline & $95 \%$ & 0.10 & 0.21 & 0.28 & 0.29 & 0.29 & 0.28 \\
\hline & Population & 0.00 & 0.00 & 0.01 & 0.00 & 0.00 & 0.00 \\
\hline \multicolumn{8}{|c|}{ Panel B: Multivariate Predictability } \\
\hline \multirow[t]{4}{*}{$v p^{g}$} & $50 \%$ & -0.39 & -0.27 & -0.16 & -0.07 & -0.04 & -0.01 \\
\hline & $5 \%$ & -2.74 & -2.20 & -1.70 & -1.14 & -0.86 & -0.69 \\
\hline & $95 \%$ & 1.93 & 1.51 & 1.17 & 0.81 & 0.66 & 0.58 \\
\hline & Population & -0.72 & -0.59 & -0.46 & -0.29 & -0.21 & -0.16 \\
\hline \multirow[t]{4}{*}{$v p^{b}$} & $50 \%$ & 0.62 & 0.50 & 0.37 & 0.23 & 0.16 & 0.12 \\
\hline & $5 \%$ & -0.29 & -0.26 & -0.23 & -0.17 & -0.14 & -0.12 \\
\hline & $95 \%$ & 1.79 & 1.24 & 0.83 & 0.51 & 0.39 & 0.33 \\
\hline & Population & 0.29 & 0.23 & 0.18 & 0.11 & 0.08 & 0.06 \\
\hline \multirow[t]{4}{*}{$R^{2}$} & $50 \%$ & 0.04 & 0.08 & 0.10 & 0.09 & 0.08 & 0.08 \\
\hline & $5 \%$ & 0.00 & 0.01 & 0.01 & 0.01 & 0.01 & 0.01 \\
\hline & $95 \%$ & 0.14 & 0.28 & 0.34 & 0.36 & 0.34 & 0.33 \\
\hline & Population & 0.01 & 0.02 & 0.03 & 0.02 & 0.02 & 0.02 \\
\hline
\end{tabular}

This table shows the model-implied slope coefficients and the $R^{2} \mathrm{~s}$ in the regressions of future excess equity returns at horizons from 1 month to 2 years on the total variance premium (Panel A) and the good and bad variance premia (Panel B). Model output is computed from a long simulation of the model (population), and using 10,000 samples with length of 18 years each. The model is simulated at a monthly frequency and time-aggregated to an annual horizon. 